\title{
Cellulose Nanoparticles Extracted from Sugarcane Bagasse and Their Use in Biodegradable Recipients for Improving Physical Properties and Water Barrier of the Latter
}

\author{
Antônio Jedson Caldeira Brant*, Natália Naime, Ademar Benévolo Lugão, Patrícia Ponce \\ Instituto de Pesquisas Energéticas e Nucleares/IPEN, São Paulo, Brazil \\ Email: *thonybrant@gmail.com
}

How to cite this paper: Brant, A.J.C., Naime, N., Lugão, A.B. and Ponce, P. (2020) Cellulose Nanoparticles Extracted from Sugarcane Bagasse and Their Use in Biodegradable Recipients for Improving Physical Properties and Water Barrier of the Latter. Materials Sciences and Applications, 11, 81-133.

https://doi.org/10.4236/msa.2020.111007

Received: October 2, 2019

Accepted: January 16, 2020

Published: January 19, 2020

Copyright $\odot 2020$ by author(s) and Scientific Research Publishing Inc. This work is licensed under the Creative Commons Attribution International License (CC BY 4.0).

http://creativecommons.org/licenses/by/4.0/

\begin{abstract}
The present work firstly aimed to obtain cellulose from sugarcane bagasse by using alkaline methods in pulping/delignifying and, at bleaching stages, using sodium chlorite, glacial acetic acid, and hydrogen peroxide, associated to $\mathrm{NaOH} / \mathrm{KOH}$. The process was carried out at temperatures varying from $55^{\circ} \mathrm{C}$ to $110^{\circ} \mathrm{C}$, under magnetic stirring in various steps lasting from $2 \mathrm{~h}$ to $12 \mathrm{~h}$. The yields of the two cellulose extracted, SCB24-Na-I and SCB24-Na-II, were $37 \%$ and $41 \%$, respectively, from samples of ca. $15 \mathrm{~g}$ of the bagasse. Secondly, it is to extract nanoparticles from the obtained celluloses via acid hydrolysis (with $77 \% \mathrm{H}_{2} \mathrm{SO}_{4}$ ) to lately be tested as reinforcement in biodegradable packagings. Both celluloses and their respective nanoparticles were characterized by several techniques, among them ATR-FTIR, DSC-TGA, XRD, SEM, and TEM. Despite that the yields of cellulose nanoparticles have been low, the preliminary studies of their use in biodegradable films coated on biodegradable pots were promising.
\end{abstract}

\section{Keywords}

Sugarcane Bagasse, Cellulose from Alkaline Extraction, Acid Hydrolysis of Cellulose, Celullose Nanoparticles, Film-Forming Suspensions, Biodegradable Packaging

\section{Introduction}

Sugarcane (Saccharum officinarum L.) was introduced in America by Spanish 
and Portuguese settlers. There are reports that Christopher Columbus, on his second trip to America in 1493, introduced the plant in the Caribbean island Hispaniola (now Haiti and the Dominican Republic). In Brazil, its entrance was soon after the discovery and occupation by the Portuguese of this continental country in 1500, and it was brought by Martinho Afonso de Souza in 1531 [1]. Nowadays, it is cultivated in all Brazilian states.

According to Sales and Lima (2010) [2], Brazil produces about $60 \%$ of the ethyl alcohol (ethanol) consumed worldwide and is the world's largest sugar producer. Sugarcane bagasse-Saccharum officinarum L., the most cultivated species in Brazil-is an abundant waste in the sugar-alcohol industry as the result of the broth extraction after crushing sugarcane in the mills. Hence, it is the largest agro-industrial residue in Brazil, mainly used as fuel for cogeneration of electric energy along with its burning [3] [4] and forage for cattle feeding [5] [6]. It is estimated that 1 tonne of sugarcane generates about $280 \mathrm{~kg}$ of bagasse after total milling [7]. Other important applications of sugarcane bagasse: manufacture of composts via composting [8] [9] [10]; biodegradable tubes and vases for use in plant cultivation in green-houses, e.g. Bio \& Green Embalagens Biodegradáveis [11]; agglomerated panels are used in civil construction and in the furniture industry [12].

Agro-industrial residues, for example, straw and sugarcane bagasse, rice husk, coconut shell fiber and others have been studied for the manufacture of cellulose pulp and cellulosic derivatives for the most diverse applications [13] [14] [15] [16] [17].

Sugarcane bagasse and other types of vegetal biomass are fibrous compounds consisting of cellulose, hemicellulose, lignin (Figure 1), adapted from $\mathrm{Xu}$ et al. (2014) [18], and small amounts of extractive and mineral salts [19] [20]. In the case of sugarcane bagasse specifically, according to Mulinari et al. (2009) [21], it contains $46.0 \%$ of cellulose, $24.5 \%$ of hemicellulose, $19.95 \%$ of lignin, $3.5 \%$ of fat and waxes, $2.4 \%$ of ashes, $2.0 \%$ of silica and $1.7 \%$ of other elements.

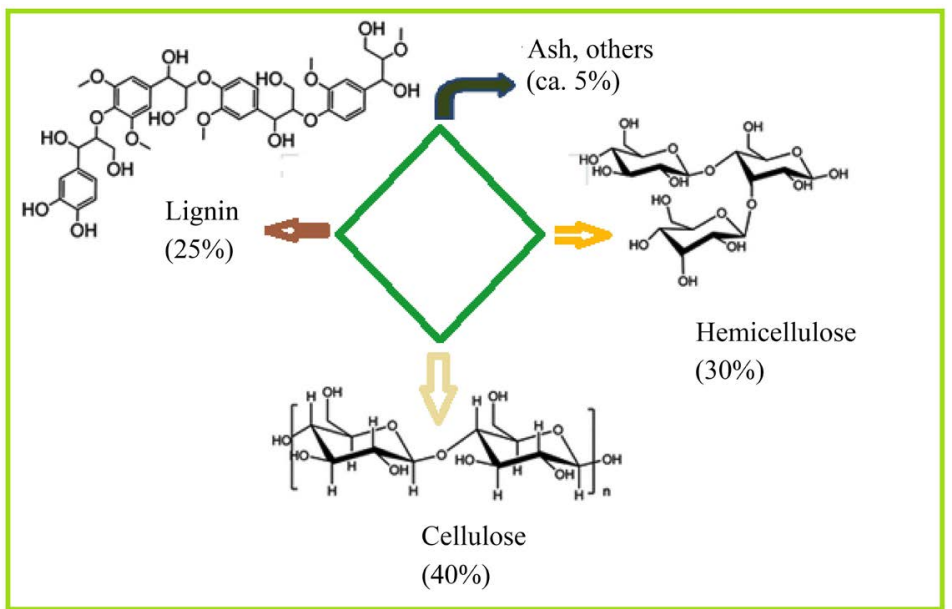

Figure 1. Proportion of hemicellulose (30\% - 35\%), cellulose (40\% - 45\%) and lignin $(25 \%-30 \%)$ as lignocellulosic components (adapted from Xu et al. (2014)). 
Cellulose is a linear homopolysaccharide composed of anhydroglucose units linked by $\beta$-1,4-glycosidic bonds [22]. In its extraction from lignocellulosic materials encompassing woods (several kinds) and the agro-industrial wastes cited above, diverse approaches have been utilized: steam explosion, alkaline pretreatments, acid pretreatments, organosolv pretreatments, ozonolysis, and others [23] [24] [25].

It is possible to obtain two classes of nanocellulose from cellulose, such as nanofibrils and cellulose nanocrystals; the latter ones also have been reported in the literature as nanowhiskers, nanocellulose, crystallites or cellulose crystals.

The most commonly used methodology for the production of cellulose nanocrystals (NCCs) is the acid hydrolysis, in which the amorphous domains of cellulose are destroyed, preserving its crystalline part. The morphology, dimensions and properties of the NCCs are strongly dependent on the cellulose source as well as on the reaction conditions, such as time, temperature, concentration and type of acid [26] [27]. In order to obtain nanoparticles of cellulose (NPCs) in this work, hydrolysis was carried out using sulfuric acid (SA) in accordance with the methodology adapted from Michael Ioelovich (2012) [28], where dialysis bags after centrifugation steps were not used. Hydrolysis with sulfuric acid leaves the surface with negative charges, which facilitates the dispersion of cellulose nanocrystals in the aqueous system [29].

The use of film-forming solutions/suspensions of NPCs in biodegradable composites has been widely studied as a promising way of improving the mechanical and barrier characteristics of these materials.

The aim of this work was to extract cellulose from sugarcane bagasse (SCB) by using alkaline pretreatments in pulping and bleaching, aided by some more eco-friendly chemicals, and, subsequently, to isolate nanoparticles from the extracted cellulose. These would be characterized and evaluated as a material of reinforcement in packagings, especially in those of biodegradable nature, and in other applications involving nanotechnology.

\section{Methods and Esperimental}

\subsection{Materials}

\subsubsection{Main Raw Material}

Sugarcane bagasse (acquired with 50\% - 60\% moisture content from Usina Santa Rosa-Estação Vicente Palma, 21,500, Km 5, Boituva-SP, Brazil). Before use, it is submitted to drying in the sun for several hours (at least $8 \mathrm{~h}$ ) until it reaches ca. $30 \%$ moisture. Then, it is again ground in a semi-industrial mill equipped with a knife system. After grinding, it was collected and packed in plastic bags with ca. $15 \%$ moisture and particles/fibers below $2 \mathrm{~cm}$ long.

\subsubsection{Chemicals}

Glacial acetic acid/GAA $\left(\mathrm{CH}_{3} \mathrm{COOH}\right)$ from Neon Comercial Ltda.; sulfuric acid (98\% $\left.\mathrm{H}_{2} \mathrm{SO}_{4}\right)$, potassium hydroxide $(\mathrm{KOH})$, sodium hydroxide $(\mathrm{NaOH})$, hydro- 
gen peroxide $\left(\mathrm{H}_{2} \mathrm{O}_{2}\right)$, ethanol $\left(\mathrm{CH}_{3} \mathrm{CH}_{2} \mathrm{OH}\right)$, and toluene $\left(\mathrm{PhCH}_{3}\right)$ from LabSynth; anthraquinone $\left(\mathrm{C}_{14} \mathrm{H}_{8} \mathrm{O}_{2}\right)$, sodium chlorite $\left(\mathrm{NaClO}_{2}\right)$, and potassium bicarbonate $\left(\mathrm{KHCO}_{3}\right)$ from Sigma-Aldrich.

\subsection{Experimental}

\subsubsection{Part A: Methods for Characterizing Sugarcane Bagasses, Extracting Celluloses Therefrom and Characterizing the Latter}

\section{1) Biomass Moisture Content}

Samples of 1 to $3 \mathrm{~g}$ in triplicate of sugarcane bagasse (SCB) were weighed on an electronic analytical balance Mettler-Toledo with $10^{-4}$ precision, using aluminium foil molds as tare weights, and dried on a hot air circulating oven at $105^{\circ} \mathrm{C}$ $\pm 5^{\circ} \mathrm{C}$ for at least $3 \mathrm{~h}$. Then, the dry samples were kept in a desiccator for subsequent weighing at room temperature and humidity $\left(23^{\circ} \mathrm{C} \pm 2^{\circ} \mathrm{C}\right.$ and $\left.68 \% \pm 2 \%\right)$. The percentage moisture content was calculated from the variation of the weight of the wet sample, according to Equation (1).

$$
\% H=\frac{m_{i}-m_{f}}{m_{i}} \times 100
$$

where $\% H$ is the percent water content in the biomass, $m_{i}$ and $m_{f}$ are the initial and final weights of the moist and dry biomass, respectively. The final results were taken as the arithmetic mean of the moisture contents of the samples tested and including the standard deviations.

\section{2) Biomass Ash Content}

Ca. $2 \mathrm{~g} / \mathrm{sample}$ of SCB in duplicate was weighed in porcelain crucibles (tare weights) on the same electronic analytical balance cited in "Biomass moisture content". After weighing the biomass samples, their burning was processed in a muffle furnace-Fanem electric oven of $220 \mathrm{~V}$, Mod. 412 , up to $1200^{\circ} \mathrm{C}$, Brazil-at $600^{\circ} \mathrm{C}$ for $2 \mathrm{~h}$. After removed cautiously from the muffle, with appropriated nippers, the samples were transferred to a dissicator, where they were kept for acclimating and subsequent weighing at room temperature and humidity conditions $\left(23^{\circ} \mathrm{C} \pm 2{ }^{\circ} \mathrm{C}\right.$ and $\left.68 \% \pm 2 \%\right)$. Ash content was calculated according to Equation (2).

$$
\% A=\frac{m_{i}-m_{f}}{m_{i}} \times 100
$$

where $\% A$ is the percent ash content, $m_{i}$ and $m_{f}$ are weights of SCB and of its incineration residue, respectively. The final results were taken as the arithmetic mean of the ash contents of the samples tested and including the standard deviations.

\section{3) Dewaxing of Sugarcane Bagasse (SCB48)}

A Soxhlet extractor set was utilized in this experiment, mounted in a fume hood. Ca. $2 \mathrm{~g}$ of SCB48/experiment was packed into a cellulose thimble (Soxfit from Labynth, Diadema-SP, Brazil) and placed in the appropriated compartment of the set; the reflux balloon was filled with $300 \mathrm{~mL}$ of a toluene-ethanol solution $(2: 1, \mathrm{v} / \mathrm{v}$, respectively), and the system was heated and 
maintained for 6 to $8 \mathrm{~h}$ at $70^{\circ} \mathrm{C}-75^{\circ} \mathrm{C}$. After extraction, the assembly of bagasse and cellulose thimble was dried on a hot air circulating oven at $70^{\circ} \mathrm{C}$ for $4 \mathrm{~h}$. Next, it was kept in a desiccator for acclimating; afterwards, weighed in an electronic analytical balance with $10^{-4}$ g precision for evaluation of its eventual loss of waxes and other organic compounds present in the lignocellulosic material.

\section{4) Sieving, Washing and Drying of Sugarcane Bagasse (SCB) \\ Sieving}

Ca. 40 to $50 \mathrm{~g}$ of the crushed bagasse described in " Main raw material” was weighed (on a balance with $10^{-2}$ precision) and placed on the first granulometric metallic sieve of a set of 4 sieves stacked in the increasing mesh order from up to down: 16, 24, 48, and 80 mesh (from Bertel Indústria Metalúrgica Ltda., Caieiras-SP, Brazil). Afterwards, the bagasse was sieved manually. After an intense screening, the bagasse residue in each sieve was weighed, and its percentage distribution of particle/fibre sizes was estimated.

\section{Washing and Drying of the Bagasses Selected Granulometrically}

The bagasses with granulometries (in mesh) chosen subjectively for the subsequent tests were coded as SCB48 and SCB24, that is, those retained on 48- and 24 -mesh sieves, respectively. Washing was made using tap water at $55^{\circ} \mathrm{C}$ for 5 times on average, with the aid of the metal sieve of 80 mesh until the filtrate became transparent and practically colorless. The washing purpose was to remove saccharides/polysaccharides and other water-soluble components. The bagasses were then drained into the sieve itself; thereafter, they were transferred to teflon-coated aluminium trays for drying in a circulating hot air oven at $105^{\circ} \mathrm{C} \pm$ $5^{\circ} \mathrm{C}$ for at least $12 \mathrm{~h}$.

\section{5) Sugarcane Bagasse Pulping/Delignifying and Bleaching \\ A Simplified Formulation}

Ca. $2.00 \mathrm{~g}$ of dewaxed bagasse was placed in a 250 - $300 \mathrm{~mL}$ Erlenmeyer flask. Next, addition of $0.0015 \mathrm{~g}$ of anthraquinone dissolved in $20 \mathrm{~mL}$ of absolute ethanol, $100 \mathrm{~mL}$ of $20 \% \mathrm{NaOH}$ aqueous solution $(\mathrm{m} / \mathrm{v})$. The Erlenmeyer flask containing the whole mixture was placed on an electric heating steel plate with temperature regulation, kept under magnetic agitation and temperature regulated to $90^{\circ} \mathrm{C}-100^{\circ} \mathrm{C}$. The Erlenmeyer flask mouth was tightly sealed with a PVC transparent film, followed by an aluminum foil reinforcement. The mixture was cooked for $24 \mathrm{~h}$. Afterwards, the material was cooled at room temperature and filtered-with the aid of a vacuum pump-in a previously weighed appropriate Whatman filter and using a Büchner funnel coupled to a $600 \mathrm{~mL}$ Kitasato. The filtrate was collected in the Kitasato. The washing of the residue was done with distilled water for several times until the filtrate reached the neutral $\mathrm{pH}$ or slightly below the neutral one (between 6 and 7, measurements by $\mathrm{pH}$ strips, Macherey-Nagel brand). The residue with the paper filter was placed on glass Petri dishes for drying in a circulating hot air oven at $70^{\circ} \mathrm{C}$ for at least $2 \mathrm{~h}$. After acclimating at $23^{\circ} \mathrm{C}$ and $65 \%$ humidity, it was weighed to quantify the yield of 
lignocellulosic material from this first stage.

Partial adaptations of the processes of delignifying and delignifying/bleaching were based on the works of Rocha, Sivério and their coworkers, and are summed up as described in Scheme 1 and Scheme 2, respectively.

Celluloses Extracted from Sugarcane Bagasse (SCB24) in an Optimized Process

SCB24 without having been previously submitted to Sohxlet extraction was used as starting bagasse. Approx. $50 \mathrm{~g}$ of the bagasse were immersed in tap water in a kettle, which was heated on an electric plate until the boiling of the system. After $10 \mathrm{~min}$ of boiling, the bagasse was cooled at room temperature and manually pressed in a 80 mesh metal sieve, washed with tap water for four consecutive times, always manually pressed after each washing operation to remove excess water. Then, the lignocellulosic mass was dried in a hot air circulating oven at $70^{\circ} \mathrm{C}$ during $12 \mathrm{~h}$.

A Partial Adaptation of Sugarcane Bagasse Delignification Based on the Work of Rocha et al. (2014) [30].

\section{DELIGNIFYING}

1. Formulation

To a $500 \mathrm{~mL}$ glass beaker containing $200 \mathrm{~mL}$ of aqueous solution of $0.8 \% \mathrm{NaOH}(\mathrm{m} / \mathrm{v})$ addition of $8.0 \mathrm{~g}$ of dry bagasse (SCB48) with ca. $7 \%$ moisture

2. Suspension formation<smiles></smiles>

3. Procedures

- The beaker is sealed with a PVC transparent film, and suspension is kept under magnetic stirring at ca. $100^{\circ} \mathrm{C}$ for $6 \mathrm{~h}$ on a heating steel plate.

$\downarrow$

Suspension filtration.

$\downarrow$

Heating and stirring at $90-100^{\circ} \mathrm{C}$ for $6 \mathrm{~h}$.

$\downarrow$

Cooling the system to room temperature/ filtrations/washings with distilled water until residue / filtrate reaching $\mathrm{pH}$ ca. 7.

Drying of the delignified biomass in an air-circulating oven at $70^{\circ} \mathrm{C}$ for $48 \mathrm{~h}$.

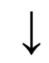

Solid residue formation.

Scheme 1. Sugarcane bagasse (SCB48) delignification [30]. 
A Partial Adaptation of Sugarcane Bagasse Delignification and Bleaching Based on the Work of Silvério et al. (2013) [31].

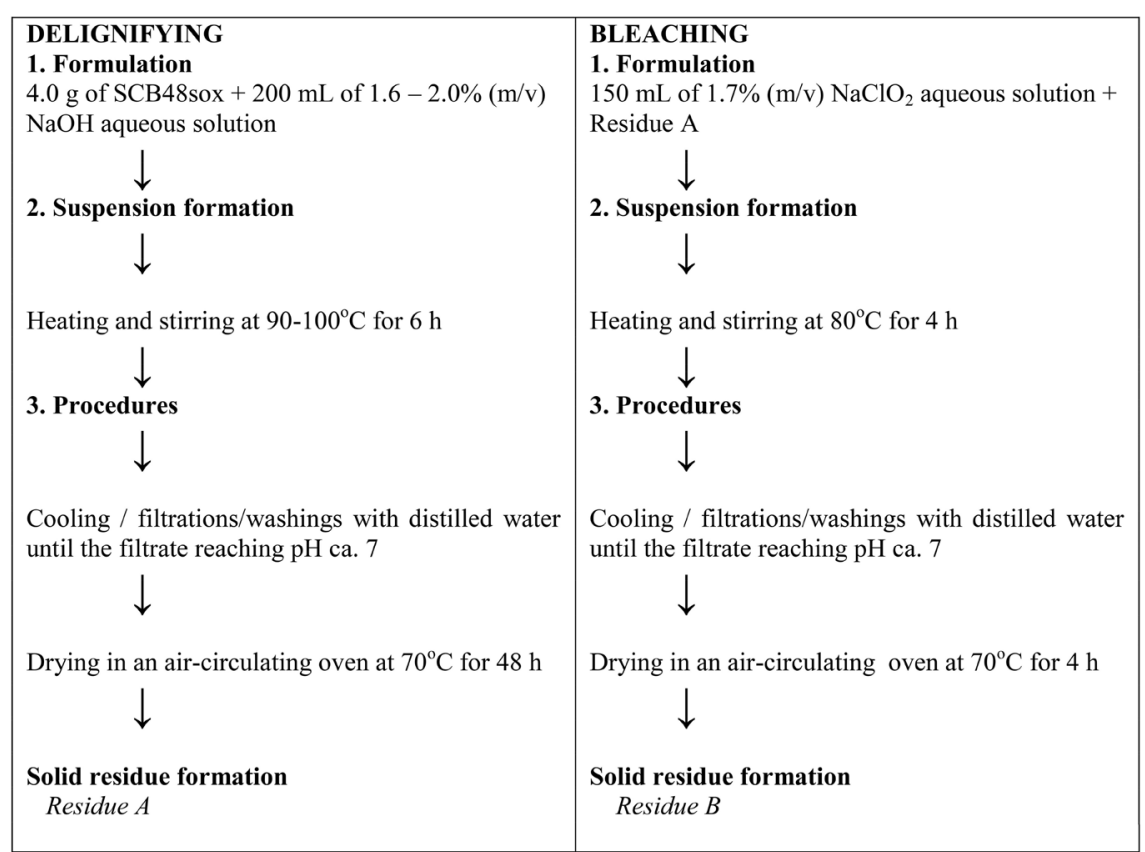

Scheme 2. Sugarcane bagasse (SCB48) delignification and bleaching [31].

Two portions of $15 \mathrm{~g}$ were removed from the dry biomass for the pulping and bleaching experiments. Their pulping/delignification was carried out using for each sample: $300 \mathrm{~mL}$ of $5 \% \mathrm{NaOH}(\mathrm{m} / \mathrm{v}), 50 \mathrm{~mL}$ of absolute ethanol, $<0.002 \mathrm{~g}$ of anthraquinone in a $600 \mathrm{~mL}$ glass beaker or erlenmeyer provided of magnetic stirrer. The suspensions were covered with PVC plastic films and aluminium foils, then placed on hot steel plates, where they were kept under stirring at $90^{\circ} \mathrm{C}$ $-100^{\circ} \mathrm{C}$ for $6 \mathrm{~h}$. Thereafter, they were cooled at room temperature, submitted to vacuum filtrations, whose residues were washed with distilled water several times, fallowed by filtration after each washing until the filtrate reached a $\mathrm{pH}$ ca. 7.

Next, each residue from pulping/delignification was treated with a mixture of $150 \mathrm{~mL}$ of aqueous sodium chlorite at $1.7 \%(\mathrm{~m} / \mathrm{v})$ and $150 \mathrm{~mL}$ of aqueous $\mathrm{NaOH}-\mathrm{GAA}$ (from a solution of $27 \mathrm{~g}$ of $\mathrm{NaOH}+75 \mathrm{~mL}$ of glacial acetic acid diluted to $1 \mathrm{~L}$ with distilled water, $\mathrm{pH}$ ca. 5). Both systems were cooked at $90^{\circ} \mathrm{C}$ $100^{\circ} \mathrm{C}$ for $4 \mathrm{~h}$ under stirring. Then, they underwent filtrations and washings similarly as described above until reached a $\mathrm{pH}$ ca. 7 .

By continuing the bleaching, each cellulose went through new bleaching at $55^{\circ} \mathrm{C}-60^{\circ} \mathrm{C}$ for 2 hours under magnetic agitation, where $300 \mathrm{~mL}$ of an aqueous solution containing $250 \mathrm{~mL}$ of water, $6 \mathrm{~g}$ of $\mathrm{NaOH}$ or $\mathrm{KOH}$ and $50 \mathrm{~mL}$ of $\mathrm{H}_{2} \mathrm{O}_{2}$ at $29 \%-30 \%$. After the bleaching, several vacuum filtrations, followed by washings with distilled water, were performed on the cellulosic residues until the filtrate reached a $\mathrm{pH}$ ca. 7 . Next, final drying of the last residues at $70^{\circ} \mathrm{C}$ for $24 \mathrm{~h}$.

6) Elemental Analysis: \%C, $H, \mathrm{~N}$ 
For the tests, use of a few milligrams (2 - $5 \mathrm{mg}$ ) of each sample encompassing sugarcane bagasse and celluloses extracted from this. Instrument: Elemental Analyzer-CHN-Perkin Elmer 2400 series II (USP/CCA).

7) Attenuated Total Reflection Fourier Infrared Spectroscopy (ATR-FTIR)

Instrument: Perkin Elmer Spectrum version 10.03.09 and Perkin Elmer-Frontier, at University of São Paulo/Center of Chemistry Analysis (USP/CCA).

\section{8) Thermal Analysis (TA) and Differential Scanning Calorimetry (DSC) Differential Scanning Calorimetry (DSC)}

Use of a few milligrams (1 - $10 \mathrm{mg})$ of each sample in the tests: DSC Q10-TA Instruments: the equipment operates in the range from $-80^{\circ} \mathrm{C}$ to $400^{\circ} \mathrm{C}$, using sample in hermetically sealed alumina crucibles, without or with atmospheric gases. 1 to $3 \mathrm{mg}$ of sample was utilized per test at a heating rate of $10^{\circ} \mathrm{C} \cdot \mathrm{min}^{-1}$ under a $\mathrm{N}_{2}$ atmosphere with $50 \mathrm{~mL} \cdot \mathrm{min}^{-1}$ flow. Tests carried out at USP/CCA.

\section{Thermogravimetric Analysis (TGA)}

Use of 1 - $10 \mathrm{mg}$ of sample per test on Hi-resTM, model TGA 2950 of TA Instruments operating in the temperature range of $25^{\circ} \mathrm{C}$ to $900^{\circ} \mathrm{C}$ under $\mathrm{N}_{2}$ atmosphere with flow rate of $50 \mathrm{~mL} \cdot \mathrm{min}^{-1}$, heating ratio of $20^{\circ} \mathrm{C} \cdot \mathrm{min}^{-1}$. Tests carried out at USP/CCA.

\section{9) X-Ray Diffractometry (XRD)}

A Rigaku Miniflex-30 KV/15MA equipment with a Bragg-Brentano type $2 \theta / \theta$ goniometer was used for the powder-shaped samples (sugarcane bagasse and celluloses thereof). The diffractograms were obtained from the values run between $2^{\circ}$ and $140^{\circ} / 2 \theta$ ( 2 theta), using a stationary copper tube as a source of $\mathrm{X}$-rays ( $\alpha \alpha 1.2 ; \lambda=1.5418 \AA$; approx. $8.0 \mathrm{keV}$ ). The test conditions of the samples were as follows: for the bagasse (SCB) sample: scanning mode: continuous; scanning speed: $2^{\circ} / \mathrm{min}$; step: $0.02^{\circ}$; scanning axis: $2 \theta / \theta$, sweep range: $3^{\circ}$ to $90^{\circ}$. For the cellulose samples, the same conditions were applied to the SCB, except for the scanning speed: $1^{\circ} / \mathrm{min}$; sweep range, $5^{\circ}$ to $60^{\circ}$. The tests were carried at USP/CCA. For calculating the crystallinity index (CI) of the samples, Equation (3) was employed, based on Segal et al. (1959) method [32]:

$$
\mathrm{CI}=\left(\frac{I_{002}-I_{a m}}{I_{002}}\right) \times 100
$$

where $I_{002}$ or totaI $I$ represents the maximum intensity at $2 \theta=23^{\circ}$, crystalline region of cellulose, and $I_{\mathrm{am}}$ at $2 \theta=18^{\circ}$, amorphous region of cellulose.

\section{0) Scanning Electron Microscopy (SEM)}

The samples of bagasse (SCB) and celluloses thereof were tested without a previous metallic sputtering (gold, palladium, others) on a SEM Jeol Neoscope JCM 5000 instrument with a conventional tungsten filament cannon, fixed acceleration voltages of 15,10 , and $5 \mathrm{kV}$, a maximum magnification of $\times 40,000$, and observation at high and low vacuum $(30 \mathrm{~Pa})$.

Note: Origin 8 program was used in the processing of the results obtained 
(spectrometry, thermoanalytical, and others in general) to generate the histograms and graphs presented. The photos referring to the experiments performed in the laboratory were taken by the camera of a Samsung mobile phone.

\subsubsection{Part B: Methods for Obtaining Cellulose Nanoparticles, Their Characterization and Application as Coating on Biodegradable Recipients}

Two types of cellulose were used (Figure 2), both extracted from sugarcane bagasse from the same power plant, but differing in treatment-with and without $\mathrm{KOH}$ aqueous solution of the cellulose filtration residue, after the second bleaching. $\mathrm{CBC} 1$ was denominated the sugarcane bagasse cellulose with $\mathrm{KOH}$-treated residue, originally named as $\mathrm{SCB} 24-\mathrm{Na}-\mathrm{I}$, and $\mathrm{CBC} 2$, the sugarcane bagasse cellulose without $\mathrm{KOH}$-treated residue, originally named as SCB24-Na-II.

\section{Production of Nanoparticles of Cellulose (NPCs)}

In order to obtain the cellulose nanoparticles (NPCs), hydrolysis was carried out using sulfuric acid (SA) in accordance with the methodology adapted from Michael Ioelovich (2012) [28]. To prepare the NPCs the following treatment conditions were used for the acid hydrolysis: SA concentration at about $77 \%$ $(\mathrm{m} / \mathrm{v})$; ratio of acid volume/cellulose mass $=9$; temperature between $45^{\circ} \mathrm{C}$ and $55^{\circ} \mathrm{C}$; and $60 \mathrm{~min}$ time of reaction. The hydrolysis procedures were quenched by adding ice-cold distilled water into each reaction mixture. The cellulose sediments of the formed suspensions were separated from the liquid phase by various centrifugations (rotational speed of $6500 \mathrm{rpm}$ for $25 \mathrm{~min}$ in a Quimis tube centrifuge) and subsequent washes with distilled water and addition of $5 \%$ potassium carbonate aqueous solution $(\mathrm{m} / \mathrm{v})$ separately until the suspensions reached the neutrality $(\mathrm{pH} \approx 7.0)$. The $\mathrm{pH}$ measurements were checked by means of $\mathrm{pH}$ tapes at each washing/centrifugation of the suspensions. Their dry powders (the expected NPCs) were obtained by lyophilization in a vertical lyophilizer containing 6 glass bottles from Solab Equipamentos de Laboratório Ltda., thus allowing to calculate the yield $(\mathrm{R})$ of the different suspensions, that is, $\mathrm{R}=\left(m_{\text {powder after liophilization }} \times 100\right) / m_{\text {initial of cellulose }}$.

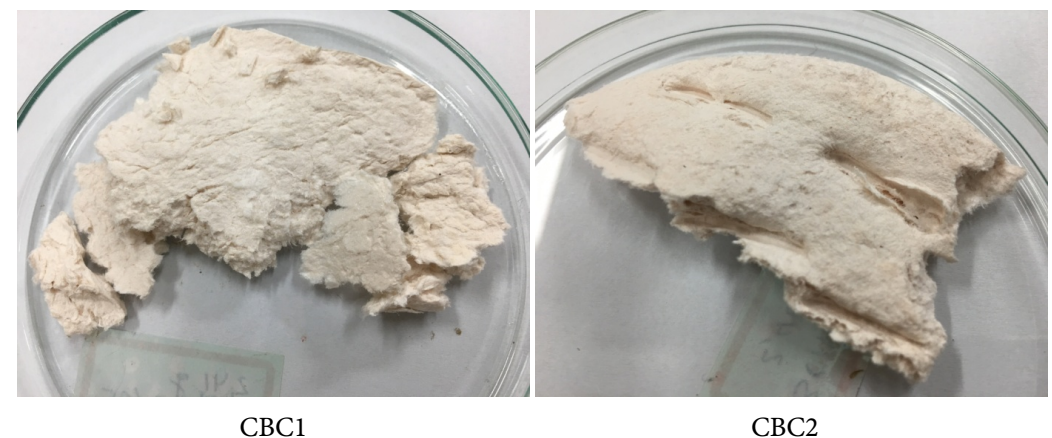

Figure 2. Visual aspect of the two types of sugarcane bagasse cellulose: $\mathrm{CBC} 1$ (with $\mathrm{KOH}$-treated residue, originally named as SCB24-Na-I) and $\mathrm{CBC} 2$ (without $\mathrm{KOH}$-treated residue, originally named as SCB-Na-II), used separately to obtain their nanoparticles. $\mathrm{CBC}=$ sugarcane bagasse cellulose. 
The water dispersions of the nanoparticles were evaporated in a vacuum system at $80^{\circ} \mathrm{C}$ for $24 \mathrm{~h}$, then washed with distilled water and finally homogenized in a MaxiClean-1400 sonicator at $40 \mathrm{kHz}$ for $30 \mathrm{~min}$, resulting in different suspensions of nanocellulose. For the production of NPCs, preliminarily only $2.0 \mathrm{~g}$ of each CBC was used, due to the small amounts obtained in the extraction process; the remainders of the samples were used to obtain their NPCs to be incorporated in biodegradable recipients (plants pots made of sugarcane bagasse) separately. To do this, both celluloses were cut into small pieces (as much as possible) with the help of a pair of scissors, before starting the reactions, as shown in Figure 3.

The hydrolysis for each CBC was performed under the same treatment conditions: SA (acid sulfuric acid) concentration at about $77 \%(\mathrm{~m} / \mathrm{v})$; ratio of acid volume/cellulose mass $=9$; temperatures between $45^{\circ} \mathrm{C}$ and $55^{\circ} \mathrm{C}$; reaction time of $60 \mathrm{~min}$, resulting, therefore, in two different suspensions: SCBC1 and SCBC2, shown in Figure 3.

The two suspensions obtained had the same visual characteristics between themselves, being apparently homogeneous and of dark color (black) soon after the hydrolysis ceased (Figure 4(a)), and heterogeneous after 24 hours, with sedimented cellulose particles and light yellow supernatants (Figure 4(b)).

After neutralization by washes with distilled water and $\mathrm{KHCO}_{3}$ aqueous solution until $\mathrm{pH} \approx 7.0-18$ washes and centrifugations for SCBC1 and 24 washes and centrifugations for SCBC2-parts of the obtained suspensions were sent to transmission electron microscopy (TEM), and the remaining ones lyophilized for subsequent calculation of yield and scanning electron microscopy (SEM) analysis.

1) Transmission Electron Microscopy (TEM) of Cellulose Nanoparticles'

\section{Suspensions}

Both samples (SCBC1 and SCBC2) suspended in distilled water were analyzed by transmission electron microscopy (TEM) at the Materials Science and Technology Center of IPEN, using an electronic microscope, JEOL brand and JEM-2100 model. A small portion of both samples (in suspension) were analyzed by energy dispersive spectroscopy (EDS) at 5, 20 and $50 \mathrm{~nm}$ scales.

\section{2) Yields (R) of Cellulose Nanoparticles' Suspensions}

The yields $(\mathrm{R})$ of the different cellulose nanoparticles' suspensions were calculated by the Equation (4):

$\mathrm{R}=\left(m_{\text {powder after liophilization }} \times 100\right) / m_{\text {initial of cellulose }}$ where $m$ is the mass in $\mathrm{g}$ on dry basis.

3) Scanning Electron Microscopy (SEM) of Cellulose Nanoparticles' Suspensions

Both lyophilized samples (SCBC1 and SCBC2), dry, were analyzed by SEM at the Lasers and Applications Center of IPEN, using the Tabletop SEM equipment of the HITACHI brand and model TM3000. Small portions of both samples were analyzed by the program's "Analy" (AL) system, with increases of 500 and 1000 times. 


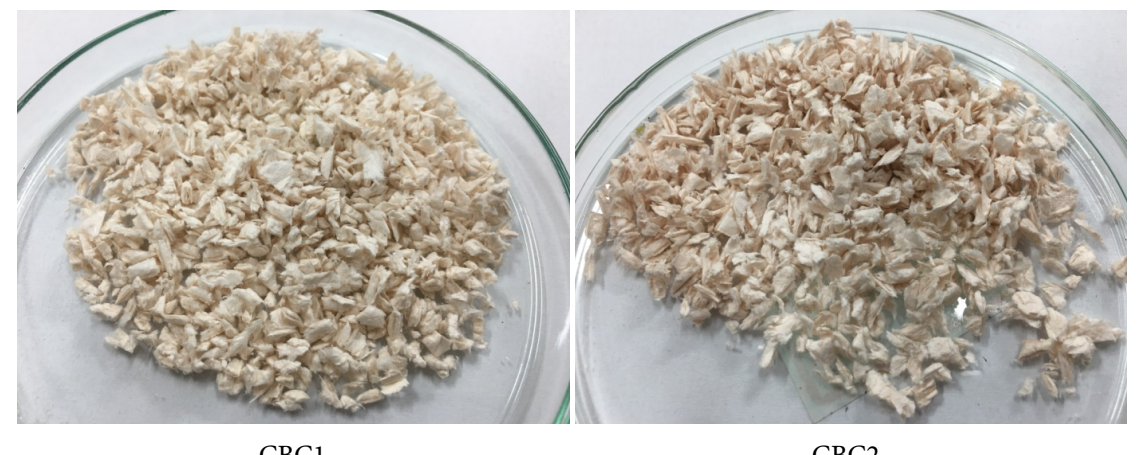

$\mathrm{CBC} 1$

$\mathrm{CBC} 2$

Figure 3. $\mathrm{CBC} 1$ (with $\mathrm{KOH}$-treated residue) and $\mathrm{CBC} 2$ (without $\mathrm{KOH}$-treated residue) cut into small pieces prior to their hydrolysis. $\mathrm{CBC}=$ sugarcane bagasse cellulose.
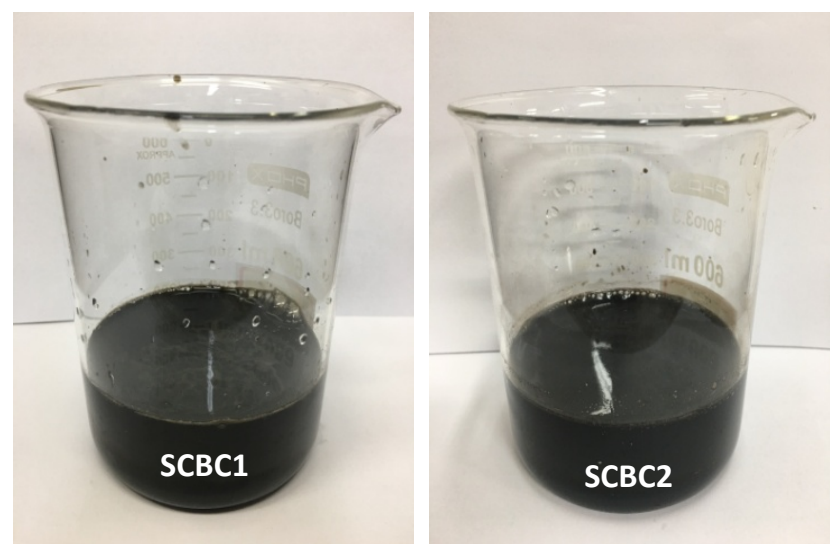

(a)
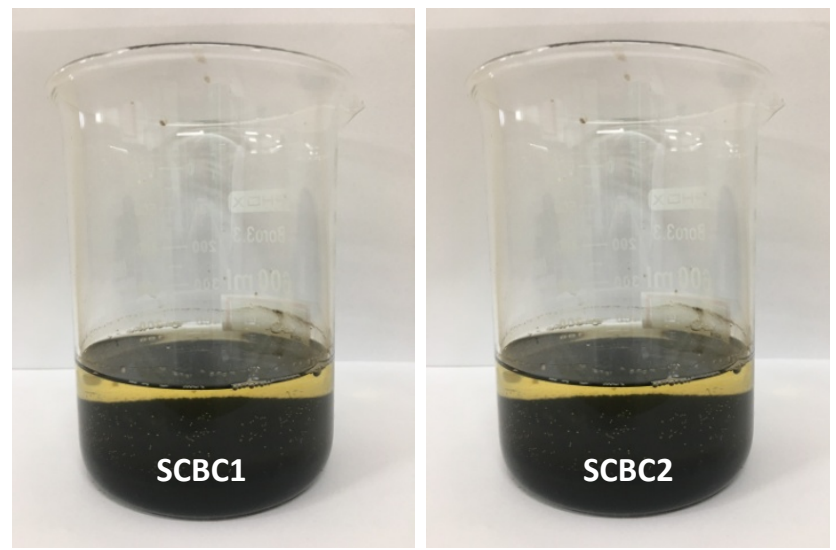

(b)

Figure 4. Suspensions obtained after hydrolysis of sugarcane bagasse celluloses type 1: SCBC1; and type 2: SCBC2, (a) upon cessation of such reactions and (b) 24 hours later with the pelleted particles (precipitate $\times$ supernatant). SCBC $=$ suspension after hydrolysis of sugarcane bagasse cellulose. From the use of $2.0 \mathrm{~g}$ of each type of SCBC.

\section{4) Brush Application of Cellulose Nanoparticles from Sugarcane Bagasse} on Biodegradable Recipients

The production of new nanoparticles of the $\mathrm{CBC} 1$ and $\mathrm{CBC} 2$ celluloses to be brushed on biodegradable recipients occurred in the same way described pre- 
viously (subitem 3.2.1 of this work), but using a larger amount of cellulose: $7.0 \mathrm{~g}$ of each sample, separately. The two suspensions resulting from the acid hydrolyses of $\mathrm{CBC} 1$ and $\mathrm{CBC} 2$, named by $\mathrm{SCBC} 1 \mathrm{~A}$ and $\mathrm{SCBC} 2 \mathrm{~A}$, are shown in Figure 5.

After the hydrolysis ceased (Figure 5(a)), the two suspensions obtained had the same visual characteristics compared each other, being apparently homogeneous and of dark (black) coloration, but after 24 hours (Figure 5(b)), the two suspensions showed some differences between each other, although not all of the cellulose particles sedimented on the bottom of the beakers, a fact that was further evidenced, in much smaller proportions, when NPCs were produced from hydrolyses of $2.0 \mathrm{~g}$ of each CBC (as shown in the SCBCs of Figure 6). The SCBC1A suspension presented a light yellow supernatant with few suspended particles, whereas in the supernatant of the SCBC2A suspension its color appeared to be a little clearer, showing more suspended particles with larger sizes than those of SCBC1A supernatant. These details of the supernatants of both suspensions can be verified in Figure 6.

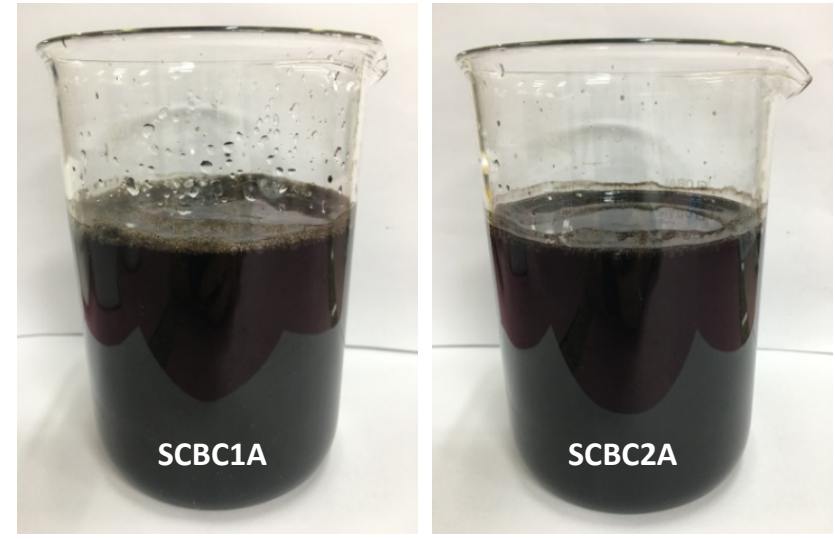

(a)

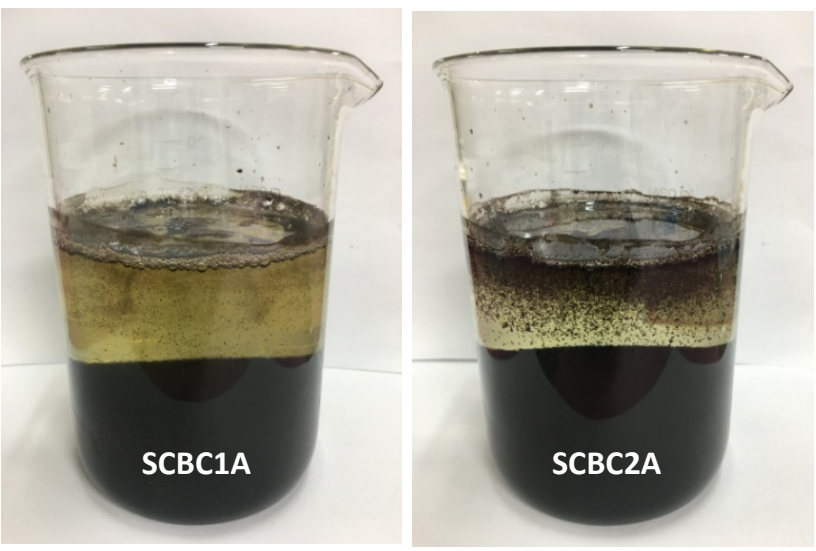

(b)

Figure 5. Suspensions obtained after hydrolysis of bagasse celluloses type 1: SCBC1A; and type 2: SCBC2A, (a) upon cessation of such reactions and (b) 24 hours later with the pelleted particles (precipitate $\times$ supernatant). $\mathrm{SCBC}=$ suspension after hydrolysis of sugarcane bagasse cellulose. From the use of $7.0 \mathrm{~g}$ of each type of CBC. 


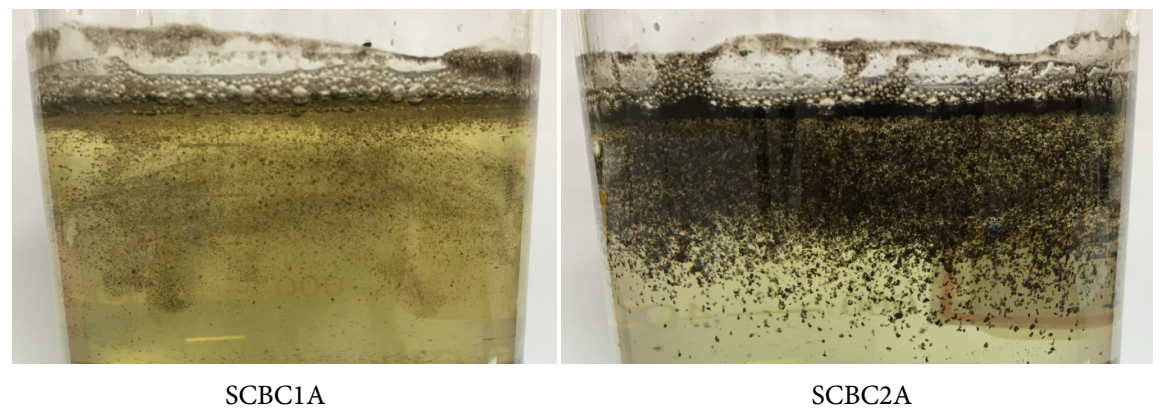

Figure 6. Details of the suspension supernatants obtained after 24 hours of celluloses hydrolysis from the sugarcane bagasse type 1: SCBC1A; and type 2: SCBC2A, with some suspended particles. SCBC $=$ suspension after hydrolysis of sugarcane bagasse cellulose.

The SCBC1A and SCBC2A suspensions, once lyophilized and with a pH close to neutrality-after 47 and 80 washes with distilled water, respectively-had their NPCs (from sugarcane bagasse celluloses) separately brushed onto biodegradable recipient inner walls and bottoms according to the casting technique. This consisted in the preparation of film-forming suspensions separately, dissolving cassava starch, previously mixed in the different NPCs $(1.0 \mathrm{~g}$ of each CBC powder, $5 \mathrm{~g}$ of starch, and addition of $1 \mathrm{~g}$ of glycerin as a plasticizing agent) in $100 \mathrm{~g}$ of distilled water. The suspensions were then heated to the gelatinizing temperature of the starch $\left(80^{\circ} \mathrm{C}\right)$ under constant magnetic stirring for the first 15 minutes, and subsequent manual shaking for another 5 minutes. Thus, two gels were obtained, which we named as "F-CBC1" containing NPCs formed from $\mathrm{CBC} 1$ ( $\mathrm{KOH}$-treated cellulose) and "F-CBC2" containing NPCs formed from $\mathrm{CBC} 2$ (KOH-untreated cellulose). For comparison effect of both substances, a standard film-forming suspension was also made; it means, without NPCs, using equal amounts of starch, glycerin and water, denoted only by "F". Figure 7 shows the three produced gels.

The three film-forming suspensions obtained, all in exactly 20 minutes under constant stirring and heating on electric steel plates, apparently presented the same viscosity, and were characterized as "gels". From Figure 7, it can be seen that the addition of the $\mathrm{CBC} 1$ and $\mathrm{CBC} 2$ NPCs to the mixtures to form their film-forming suspensions resulted in dark gels, unlike that with no NPC ("F" suspension), as expected due to the purplish color of NPCs produced.

Parts of these three film-forming suspensions (gels) produced were brushed as a thin layer on the inside of 30 biodegradable recipients -10 recipients brushed with each gel-and the remainder distributed in a total of 36 polystyrene Petri dishes with internal diameter of $5.8 \mathrm{~cm}$. Initially, $4.0 \mathrm{~g}$ of each gel was weighed into 6 Petri dishes and subsequently $3.0 \mathrm{~g}$ of each gel into 6 additional Petri dishes (in order to fill the entire dish/plate) with the intention of forming the thinnest films as possible to resemble those who would eventually form inside the biodegradable recipients. All Petri dishes and recipients containing the different film-forming suspensions were placed in a drying oven at $60^{\circ} \mathrm{C} \pm 2{ }^{\circ} \mathrm{C}$, with air circulation, for 4 hours. Figure 8 shows the 30 internally coated recipients 


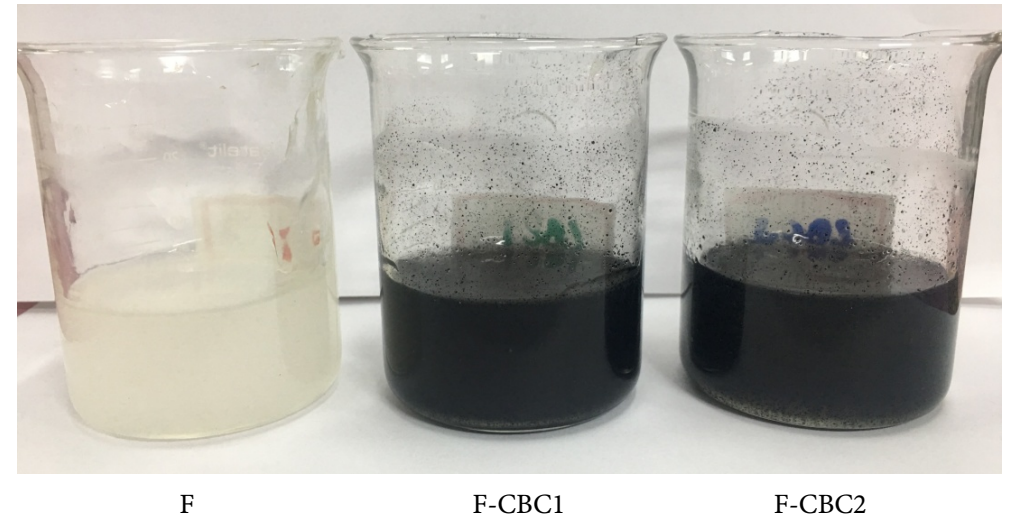

Figure 7. Film-forming suspensions (gels) produced and applied according to the casting technique. Gels: F = gel without NPCs; F-CBC1 = gel with $\mathrm{CBC} 1$ NPCs; F-CBC2 = gel with CBC2 NPCs.

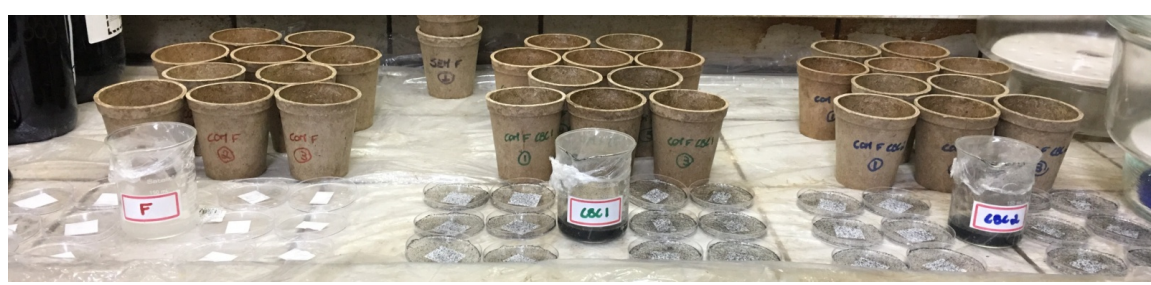

Figure 8. Recipients internally coated by a thin layer of the different film-forming suspensions (gels) and the different films formed inside the Petri dishes, after drying in the oven. RECIPIENTS/FILMS: F = film without NPCs; F-CBC1 = film with CBC1 NPCs; F-CBC2 = film with CBC2 NPCs. Additional note: the recipients were molded at Bio \& Green Produtos Biodegradáveis Ltda., ex-company linked to IPEN projects.

with the different dried gels (10 recipients for each type of gel), and the dried film-forming suspensions in the 36 Petri dishes (12 dishes/plates for each type of gel, 6 of these dishes/plates having $3.0 \mathrm{~g}$ of gel and the other 6 with $4.0 \mathrm{~g}$ of gel).

The different formed films were kept in the fume hood of the Polymers Laboratory of the CQMA/IPEN, at room temperature and relative humidity (respectively, $20^{\circ} \mathrm{C}$ to $25^{\circ} \mathrm{C}$ and $76 \%$ to $88 \%$ ) for 48 hours until they absorbed a little moisture, purposely, to facilitate their detachments from their respective Petri dishes. This procedure was done because, as soon as the dishes were removed from the oven, the obtained films showed to be a little brittle, and their removals probably would be very difficult.

5) Water Absorption by Biodegradable Recipients with and without Sugarcane Bagasse NPCs

It is worth noting that, for the accomplishment of this experiment, the recipients (pots for growing seedlings) without holes in their bottoms were used to hinder the water drain. Five recipients (without hole) for each type of applied inner coating (F, F-CBC1 and F-CBC2) were weighed, and $200 \mathrm{~mL}$ of water were added therein for 60 seconds at room temperature. After this period, the water was discarded and its excess removed until no more drops of water dripped from inside the recipients, which were weighed again. Finally, the mean values of 
water absorption were calculated for each type of recipient. The same procedure was done for recipients without coating (SEM F) for comparison purposes.

6) Moisture Absorption by Biodegradable Recipients with and without Sugarcane Bagasse NPCs

The moisture content of recipients without coating and those coated with and without NPCs, kept in the fume hood of the CQMA/IPEN Polymers Laboratory, throughout the days, without controlled temperature and humidity, was calculated as a percentage of the initial mass of the packing. The weighing of the recipients was done with a digital balance, at time zero (when they were removed from the drying oven of their respective films) and then every seven days. For each type of coating (with and without NPCs), five recipients were used, calculating the moisture content averages. The same procedure was done for recipients without coating (SEM F) for comparison purposes. It is worth remembering that this assay was done for only 14 days due to the short time remaining for submission this report (Fundep deadline).

7) Crotalaria Plantation in Biodegradable Recipients with and without Sugarcane Bagasse NPCs

The internally coated recipients with film-formig suspensions (gels) with and without sugarcane bagasse NPCs and those without coating (for comparison purposes) were used for planting crotalaria (Crotalaria juncea), in order to verify the influence of these recipients on the plant development and their physical integrity during the nursery phase-it means, during the germination and growth of the seedlings to further be transplanted into the field without removing them from the recipients-since they are biodegradable and compostable. It is noteworthy that, unfortunately, it will not be possible to show the transplantation phase in this report due to the limited time for submission of this work. For the same reason, the results of the plants' development and the recipients' integrity in the crotalaria planting will be presented only during the first fourteen days of seedling.

For planting, five recipients of each type of studied coating in this project were used (with and without the sugarcane bagasse NPCs), as well as the same amount used for those without coating. All recipients were filled to the brim with peat "Tropstrato Florestal", from Vida Verde Indústria e Comércio de Insumos Orgânicos Ltda., as shown in Figure 9, and in each of them four crotalaria seeds (Figure 9) were buried superficially.

Among the many seed options available to plant and taking into account the short time remaining for submission this report (deadline), we chose for Crotalaria juncea because, through experiments carried out before this SIBRATECNANO project, our researchers' team verified that the crotalaria germination and the plant development occur very quickly and efficiently in greenhouse, and such seeds (Figure 10) were easily available at the CQMA/IPEN Polymers Laboratory. 


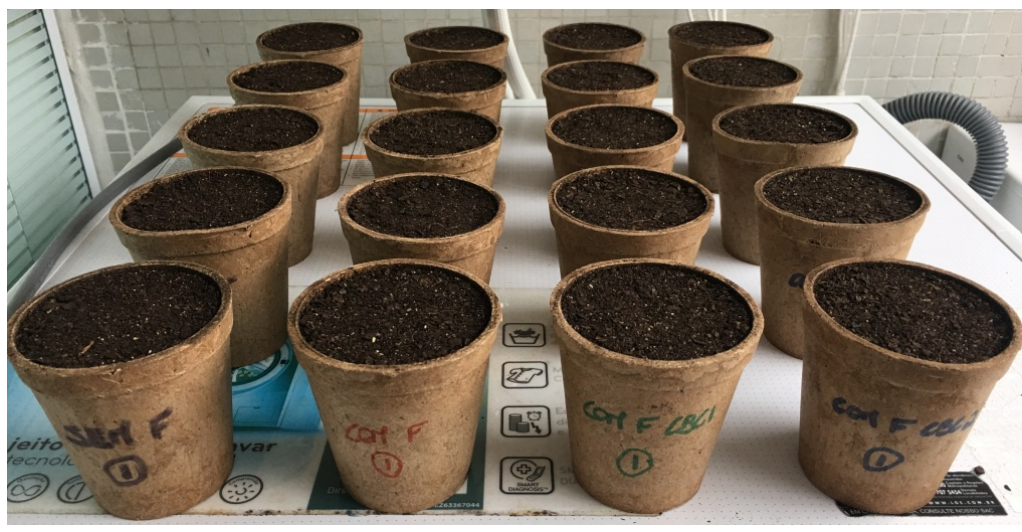

Figure 9. Recipients filled with peat "Tropstrato Florestal", used for the plantation. RECIPIENTS: SEM F = without film; F = film without NPCs; F-CBC1 = film with CBC1 NPCs; F-CBC2 = film with CBC2 NPCs.

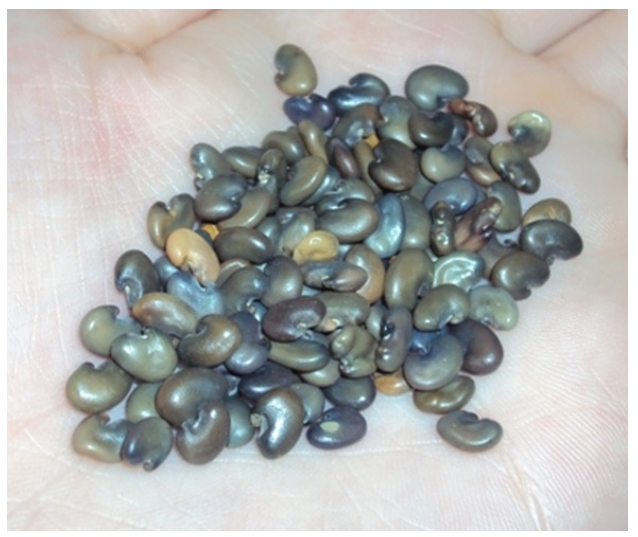

Figure 10. Crotalaria (Crotalaria juncea) seeds.

\section{8) Plants' Development in Recipients with and without Sugarcane Bagasse} NPCs

Measurements of 1) the plants' height, 2) the stalks' diameter and 3) the number of leaves (NF) were performed weekly from day 7 of planting, closing such analyzes (for this report) no longer 14th day of sowing, according to the reason already explained previously. The averages for each of these measurements and in each type of recipient used in this test were estimated before transplanting the seedlings into the field. It is worth mentioning that it was decided to make the first stalk diameter measures just 15 days after the beginning of plantation, because before that, the seedlings stalks were still very fragile.

9) Integrity of the Recipients with and without Sugarcane Bagasse NPCs along the Plant Development

Because they are made of biodegradable materials from renewable natural sources (sugarcane bagasse and cassava starch), the recipients are very sensitive to moisture and water (from irrigation), thus causing deformations on their edges, walls and bottoms. Such events lead them to softening, cracking, and they subsequently rupture as time goes by. Hence, the objectives of studying the incorporation of sugarcane bagasse NPCs $(\mathrm{CBC} 1$ and $\mathrm{CBC} 2)$ into these recipients 
were to verify possible improvements in their mechanical/physical and water barrier properties.

The integrity of the uncoated recipients and those coated by the different film-forming suspensions (with and without the sugarcane bagasse NPCs) were analyzed weekly, from the day of sowing (zero time) until the 14th day of planting, and the reason for the short test period was previously explained in this report. The study was based on the softening and/or cracking 1) of the edges, 2) walls (body), and 3) bottoms of the recipients, being numerically evaluated from 3 to 0 , where the recipients numbered: $3=$ good (integers, without any modification); 2 = softened and/or cracked; 1 = very softened and/or very cracked; and 0 $=$ broken $/$ dismantled.

\section{Results and Discussion}

\subsection{Part A: Sugarcane Bagasse and Celluloses Therefrom}

\subsubsection{Biomass Moisture Content}

Sugarcane bagasse, originally received from the supplier with moisture ca. 50\%, after dried in the sun for $8 \mathrm{~h}$ at ca. $30^{\circ} \mathrm{C}$, showed $27.22 \% \pm 0.78 \%$ moisture from samples tested in triplicate. After dried, ground by the miller equipped with a knife system, its moisture dropped to $15.54 \pm 0.03$ from another triplicate of samples evaluated, fact already explained in "Main raw material".

\subsubsection{Original Biomass Ash Content}

The results of ash content were: $2.42 \% \pm 0.81 \%$ for SCB and $1.02 \% \pm 0.03 \%$ for WP. In the case of sugarcane bagasse, Pandey et al. (2000) [33] cite their chemical composition with $2.4 \%$ ash content, and other authors found values close or well above, for example, 5.4\% [34].

Figure 11 shows ashes of incinerated sugarcane bagasse (SCB) and wood powder (WP) from a furniture industry (as reference).

The ash colors of the wood powder and sugarcane bagasse were quite different each other: darkgrey and reddish-grey, respectively (Figure 11). It probably is due to formation of different metal oxides throughout incineration of the materials, and those were not identified. Here it is worth mentioning that their coloration may depend on lots of factors, such as, soil nature and contaminants, fertilizers in the plant cultivation, metals absorbed by the plant in the metabolism, the crop season, and the storage conditions of the lignocellulosic residues in sugar/alcohol industries. For example, the bagasse we have used in production of biodegradable tubes and vases (for agriculture), and trays (for food packaging) at Bio \& Green comes with various color shades: from yellowish to light brown.

Note: On following of the tests, the wood powder (WP), originated from a furniture factory, contained crosslinked resins as numerous formica particles of difficult removal from the wood (maybe some species of pinus or eucalyptus). Owing to that, one gave up to continue its tests for comparison with those on sugarcane bagasse, except for the XRD test. 


\subsubsection{Sieving of Sugarcane Bagasse (SCB)}

The histogram (Figure 12) was generated from 3 sievings of $50.0 \mathrm{~g}$ of the SCB described in "Main raw material", previously washed and dried. It is explicative per se. In terms of the residue amounts of the sifted bagasse, one can infer from the histogram the average results obtained after sieving of $50.0 \mathrm{~g}$, starting on the 16 mesh sieve: $28.3 \mathrm{~g}$ (56.5\%) on the 16 mesh sieve; $12.5 \mathrm{~g}$ (25\%) on the 24 mesh sieve; 8.2 (16.4\%) on the 48 mesh sieve; approx. $1 \%$ on the 80 mesh sieve.

This type of sieving process, done manually and prone to reasonable losses in manipulation (for instance, as wood dusts in the air), probably is less accurate than that done by using an electrical system with an appropriate vibrator, whose time and intensity of the vibrations can be programmed. One must still consider the irregularity of the material in terms of fiber/particle sizes, making difficult to obtain high amounts of low-sized fibers/particles from a unique batch. In the choice of lignocellulosic materials for subsequent tests, SCB48 (sieving residue on the 48 mesh sieve) was subjectively chosen. Throughout the experiments, SCB24 (residue on the 24 mesh sieve) also was tested in some characterization items and had a performance practically equal to that of SCB48.

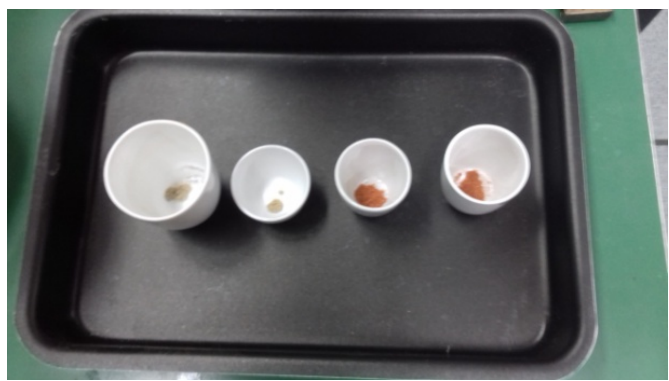

Figure 11. Ashes obtained from samples of WP (the first two on the left) and SCB (the last two on the right) after incineration in a muffle at $600^{\circ} \mathrm{C}$ for $2 \mathrm{~h}$.

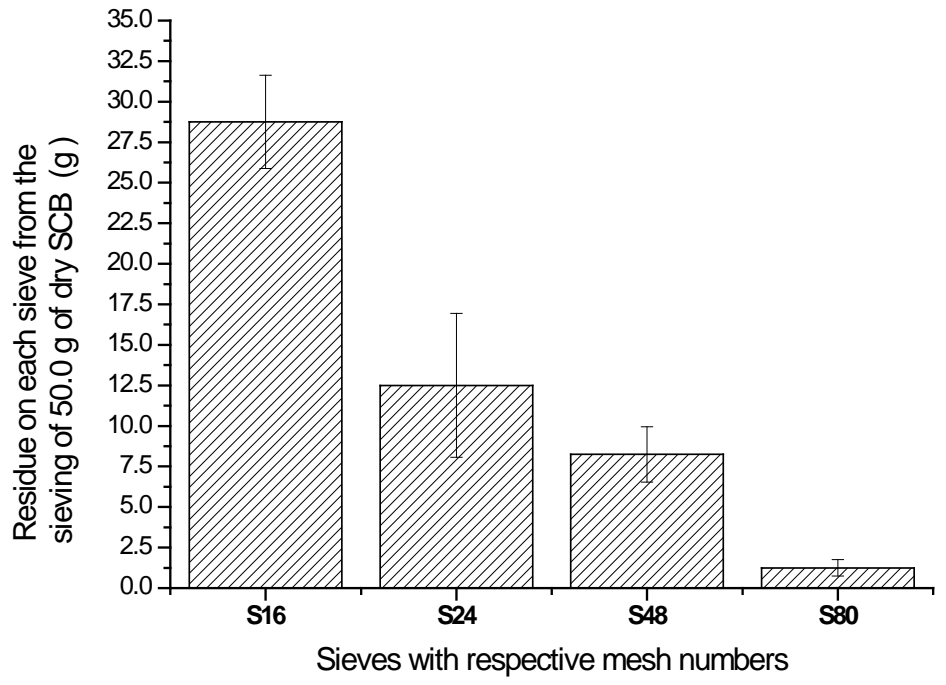

Figure 12. Amounts of SCB residues (final mass in g) on sieves from 4 distinguished manual sievings using a set of 4 granulometric sieves arranged in an ascending order of mesh from up to down: 16, 24, 48, and 80 . 


\subsubsection{Dewaxing of Sugarcane Bagasse (SCB48) by Soxhlet Extraction}

Table 1 shows the results from Soxhlet extractions emphasizing percentual losses of organic compounds present in the SCB48 (waxes, dyes, etc.) soluble in the toluene/ethanol solution at the stablished conditions.

The average result of the Soxhlet extractions from SCB48 was $5.58 \%$ of extractables (Table 1, minus signal indicating loss). The extractable percentages quite vary in the literature, for example: $0.8 \%$ in toluene-ethanol $(2 / 1, \mathrm{v} / \mathrm{v})$, according to Sun et al., (2004) [35]; 2.79\% in ethanol 95\%, according to Neves (2014) [36]; 4.10\%, cyclohexane-ethanol 5\% - 95\%, respectively, according to Canilha et al. (2007) [37]; cyclohexane-ethanol (1/1, v/v) for $48 \mathrm{~h}$ and then with water for $24 \mathrm{~h}$, according to Hoareau et al. (2006) [38]. One must take in account that the yield differences of extractables come from the variety of solvents, processing duration times, and different temperatures utilized in this test, whose parameters depend on the researcher choice without following rigid patterns.

\subsubsection{Phase 1: Preliminary Pulping/Delignification and Bleaching of Sugarcane Bagasse (SCB48)}

Several preliminary experiments were performed adapting methodologies based on the literature to make the alkaline pulping of sugarcane bagasse. Aqueous solutions of sodium hydroxide $(\mathrm{NaOH})$ were used together with other reagents at different concentrations, reaction times at diverse temperatures and different biomass amounts.

Table 2 records several experiments aimed at the alkaline extraction of cellulose pulp from sugarcane bagasse (SCB) from September of 2017 to May of 2018, emphasizing the $\mathrm{NaOH}$ concentrations, yields and colors of the celluloses obtained. The last three preliminary cellulose pulp yields of sugarcane bagasse, seen from top to bottom in Table 2 (33.92\%, 33.17\%, and 33.70\%, respectively), are in conformity with results cited by Rowell et al. (1997) [39], which is $32 \%$ $44 \%$, although the literature mostly reports values of $40 \%-43 \%$ in general. Concerning the first two results on top (52.89\% and 53.94\%), maybe their respective samples still have high percentages of hemicellulose and lignin. It should be point out that the raw celluloses obtained by alkaline pathway in this work were results from experiments partially adapted from the literature [19] [30] [31] [40] [41] [42] [43] [44], especially in relation to $\mathrm{NaOH}$ concentrations. There is not an entirely safe and reproducible protocol for this type of research, where the main raw material is an agro-waste biomass. Many are the variables involved, which would demand a very long time and countless experiments in the laboratory to optimize parameters (physical and chemical pretreatments of biomass, diversity of reagents and concentrations thereof in the processes, controls of temperature and times for the reactions, stirring times, solid/liquid ratio in each cycle of the experiment, etc.). The authors do not always clearly inform the total cycles of treatment to which the biomass was subjected, not citing, for example, some impasses in obtaining the final product, especially in the bleaching stage. 
Table 1. Extractables as \% losses from Soxhlet extraction of sugarcane bagasse (SCB48) using a (2/1, v/v) toluene-ethanol solution at $70^{\circ} \mathrm{C}$ for $6 \mathrm{~h}$.

\begin{tabular}{cccccccc}
\hline \multicolumn{7}{c}{ BEx: Before Soxhlet extraction AEx: After Soxhlet extraction } \\
\hline Tubcel (g) & Tubcel + SCB (g) & SCB48 (g) & Tubcel + SCB (g) & Loss (g) & Loss (\%) & Mean loss (\%) & SD (\%) \\
\hline 3.4008 & 5.3940 & 1.9932 & 5.0799 & -0.3141 & -5.82 & -5.58 & \pm 0.34 \\
3.2524 & 5.2416 & 1.9892 & 4.9413 & -0.3003 & -5.73 & & \\
3.3730 & 5.4800 & 2.1070 & 5.1934 & -0.2866 & -5.19 & & \\
\hline
\end{tabular}

Tubcel = cellulose thimble; SD = standard deviation; Loss: difference between AEx and BEx involving (Tubcel + SCB48).

Table 2. Attempts of cellulose extraction from sugarcane bagasse by using aqueous alkaline solutions at different temperatures, reaction times, and reagent concentrations.

\begin{tabular}{|c|c|c|c|c|c|c|c|c|}
\hline & & & Delignific & tion (A)/Prebleaching (B) & $\begin{array}{l}\text { Processing } \\
\text { conds. }\end{array}$ & Partial yield & $\begin{array}{l}\text { Total } \\
\text { yield }\end{array}$ & $\begin{array}{l}\text { Raw cellulose } \\
\text { color }\end{array}$ \\
\hline Date & Sample & $\begin{array}{l}\text { Initial } \\
\text { mass }(\mathrm{g})\end{array}$ & $\begin{array}{l}\text { Final } \\
\text { mass }(\mathrm{g})\end{array}$ & $\begin{array}{l}\text { Aqueous } \\
\text { solutions utilized }\end{array}$ & $\mathrm{S} / \mathrm{L} /{ }^{\circ} \mathrm{C} / \mathrm{h}$ & $(\%)$ & $\begin{array}{l}\text { rounded } \\
(\%)\end{array}$ & \\
\hline $\begin{array}{l}\text { Sep 18, } \\
2017\end{array}$ & SCB $48^{*}$ & 8.046 & 4.2556 & $5 \% \mathrm{NaOH}(\mathrm{A})$ & $1: 40 / 90-100 / 12$ & 52.89 & 52.89 & greyish-white \\
\hline $\begin{array}{l}\text { Dec 12, } \\
2017\end{array}$ & SCB $48^{\star *}$ & 2.0500 & 1.3829 & $20 \% \mathrm{NaOH} / 0.75 \% \mathrm{AQ}(\mathrm{A})$ & $1: 50 / 90-100 / 6$ & 67.46 & 53.94 & earthy yellow \\
\hline $\begin{array}{l}\text { Jan16, } \\
2018\end{array}$ & SCB48 & 1.3829 & 1.1058 & $\begin{array}{l}1.35 \% \mathrm{NaOH} / 3.94 \% \\
\mathrm{GAA} / 1.7 \% \mathrm{NaClO}_{2}(\mathrm{~B})\end{array}$ & $1: 50 / 90-100 / 4$ & 79.96 & & \\
\hline $\begin{array}{l}\text { Jan } 9 \\
2018\end{array}$ & SCB $48 \operatorname{sox}^{* *}$ & 4.0261 & 1.7226 & $20 \% \mathrm{NaOH}(\mathrm{A})$ & $1: 50 / 90-100 / 6$ & 42.78 & 33.92 & earthy yellow \\
\hline $\begin{array}{l}\text { Feb 6, } \\
2018\end{array}$ & SCB48sox & 1.7226 & 1.3655 & $4.5 \% \mathrm{GAA} / 4.28 \% \mathrm{NaClO}_{2}$ (B) & $1: 50 /$ ca. $80 / 12$ & 79.27 & & \\
\hline $\begin{array}{l}\text { Mar 19, } \\
2018\end{array}$ & SCB $48 \operatorname{sox}^{* *}$ & 4.0873 & 3.1747 & $1.6 \% \mathrm{NaOH}(\mathrm{A})$ & $1: 50 / 90-100 / 6$ & 77.67 & 33.27 & slight pink \\
\hline $\begin{array}{l}\text { Apr 2, } \\
2018\end{array}$ & SCB48sox & 3.1747 & 1.3599 & $\begin{array}{l}1.16 \% \mathrm{NaOH} / 3.38 \% \\
\text { GAA/0.43\% } \mathrm{NaClO}_{2}(\mathrm{~B})\end{array}$ & $1: 50 /$ ca. $80 / 4$ & 42.83 & & \\
\hline \multirow[t]{2}{*}{$\begin{array}{l}\text { Apr 14, } \\
2018\end{array}$} & $\mathrm{SCB} 24^{* * * * *}$ & 15.0000 & 6.2513 & $4 \% \mathrm{NaOH}(\mathrm{A})$ & $1: 40 / 90-100 / 6$ & 41.67 & 33.7 & greyish-rose \\
\hline & SCB24 & 6.2513 & 6.0997 & $\begin{array}{l}1.35 \% \mathrm{NaOH} / 3.94 \% \\
\mathrm{GAA} / 1.7 \% \mathrm{NaClO}_{2}(\mathrm{~B})\end{array}$ & $1: 40 / \mathrm{ca} .80 / 3$ & 97.57 & & \\
\hline $\begin{array}{l}\text { May 8, } \\
2018\end{array}$ & SCB24 & 6.0997 & 5.6207 & $5 \% \mathrm{KOH}(\mathrm{B})$ & $1: 40 / 90-100 / 3$ & 92.14 & & \\
\hline \multirow[t]{2}{*}{$\begin{array}{l}\text { May 15, } \\
2018\end{array}$} & SCB24 & 5.6207 & 5.1200 & $2.5 \% \mathrm{NaOH} / 11.6 \% \mathrm{H}_{2} \mathrm{O}_{2}(\mathrm{~B})$ & 1:40/ca. 55/2 & 89.93 & & \\
\hline & SCB24 & 5.1200 & 5.0546 & $2.5 \% \mathrm{KOH}(\mathrm{B})$ & $1: 40 / 90-100 / 2$ & 98.72 & & \\
\hline
\end{tabular}

NOTES: ${ }^{*}=$ sequences of steps (from 1 to $5^{\star}$ from the initial biomass); GAA = glacial acetic acid; AQ = anthraquinone; sox $=$ Soxhlet-extracted sugarcane bagasse; $\%(\mathrm{~m} / \mathrm{v})$ concentrations of aqueous solutions; $\mathrm{S} / \mathrm{L}(\mathrm{m} / \mathrm{v})=$ ratio between solid (dry biomass) and liquid (distilled water or solutions therefrom); conds. = conditions of S/L, temperature in oC, and time duration of the process in h; cel. = cellulose; SCB48 and SCB24 = sugarcane bagasse from 48 and 24-mesh sievings, respectively.

The exemplification in Figure 13 refers to the first of the last three experiments mentioned in Table 2, showing a bleaching stage of the raw cellulose. For a partial discussion in Table 2 and Figure 13, let us comment, for example, the preliminary pulping/delignification, where there were two steps $\left.{ }^{(*}\right)$, on Jan. 9, 2018 and Feb. 6, 218) of chemical treatment of ca. $4 \mathrm{~g}$ of the bagasse SCB48, 


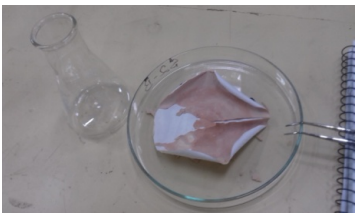

(a)

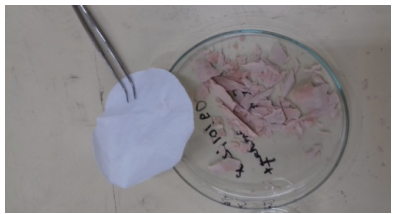

(b)

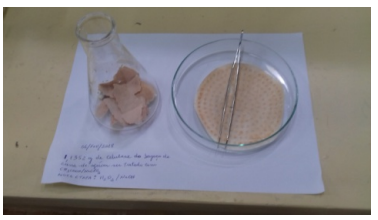

(c)

Figure 13. (a) Sample photo of ca. $1.72 \mathrm{~g}$ of SCB48-Na delignified with aqueous $\mathrm{NaOH}$ solution, adhered to the paper filter; (b) Sequential photo of the dry sample detached from the filter paper and placed on a Petri dish; (c) Sequential photo of ca. $1.36 \mathrm{~g}$ of dry sample, fragmented and placed in an Erlenmeyer flask (left) for a possible new bleaching with an aqueous solution of sodium chlorite- $\mathrm{NaOH}$-glacial acetic acid. The paper filter impregnated with SCB48-Na residue rests on a Petri dish (right).

previously submitted to a Soxhlet extraction (SCB48sox). In the first step, pulping/delignification with an aqueous $20 \%(\mathrm{~m} / \mathrm{v}) \mathrm{NaOH}$ solution at $90^{\circ} \mathrm{C}-100^{\circ} \mathrm{C}$ for $6 \mathrm{~h}$. Its yield was $1.72 \mathrm{~g}$ of earthy yellow SCB48sox (33.92\% in raw cellulose obtained from the original sample). In the second step, a bleaching of SCB48sox with an aqueous solution of $\mathrm{GAA}-\mathrm{NaClO}_{2}$ at ca. $80^{\circ} \mathrm{C}$ for $12 \mathrm{~h}$ afforded $1.36 \mathrm{~g}$ of earthy yellow color SCB48sox, probably owing to still small parcels of lignin remaining in the sample. This resulting sample was named as SCB48-Na for simplicity, whose photo is exhibited in Figure 13.

In continuation, after the first bleaching of SCB48-Na sample, its color practically did not change, in other words, it remained earthy yellow like the original one only delignified. Yield: $1.36 \mathrm{~g}$ of SCB48-Na after an expressive mass loss: $20.93 \%$ based on the $1.72 \mathrm{~g}$ sample. Thus, the total cellulose yield, relative to the original sample of ca. $4 \mathrm{~g}$ of bagasse, was ca. $34 \%$. Therefore, this event discouraged us to attempt a second bleaching of the sample. For more detailed understanding of the two stages, Table 2 displays the pulping/delignification and bleaching data of five experiments with SCB samples.

In these preliminary studies, one noted that the use of Soxhlet-purified bagasse did not increase the bleaching level of the raw cellulose obtained. For a work aiming to obtain expressive amounts of cellulose for tests in semi-industrial or industrial scale, such a process practically would become unviable by cost, besides being hazardous to the environment.

\subsubsection{A Partial Adaptation of Sugarcane Bagasse Delignification Based on the Work of Rocha et al. (2014) [31]}

Along the pulping/delignification process, distilled water was added to the suspension: $50 \mathrm{~mL}, 50 \mathrm{~mL}, 100 \mathrm{~mL}$, and $50 \mathrm{ml}$ after $1 \mathrm{~h}, 2 \mathrm{~h}, 4 \mathrm{~h}$, and $6 \mathrm{~h}$, respectively, in order to compensate water losses by evaporation. The result was a dry lignocellulosic residue with dark brown color, that was discarded. For this reason, the $\mathrm{NaOH}$ concentration was increased from $0.8 \%$ to $5 \%(\mathrm{~m} / \mathrm{v})$, aiming at obtaining a lighter color of the raw cellulose. Thus, a new experiment was run with $5 \% \mathrm{NaOH}$, using ca. $8 \mathrm{~g}$ of SCB48 at the same conditions applied to the first pulping/delignification. The raw cellulose obtained showed a grayish-white color with ca. $53 \%$ yield (Table 2 ). 


\subsubsection{A Partial Adaptation the Sugarcane Bagasse Delignification and Bleaching Based on the Work of Silvério et al., (2013) [31]}

The delignification afforded a dry lignocellulosic biomass (Residue A) with a light brown color. The former, in turn, generated a second residue with a roselike color (Residue B) after bleaching according to Scheme 2. Their respective yields were ca. $77.67 \%$ (partial delignying) and ca. 33.27\% (total after bleaching) (Table 2).

\subsubsection{Phase Two: Celluloses Extracted from Sugarcane Bagasse (SCB24) in an Optimized Process}

At this stage, celluloses were extracted from sugarcane bagasse following the scripts presented in Table 3 and Table 4.

Table 3. Extraction of celluloses after Pulping/Delignifying of Sugarcane Bagasse (SCB), followed by bleaching with blends of aqueous solution of soldium chlorite and aqueous solution of sodium hydroxide and glacial acetic acid. (a) Delignifying of BCA24 with $\mathrm{NaOH}$ aqueous solution ( $15 \mathrm{~g}$ of $\mathrm{NaOH}$ dissolved in distilled water up to $300 \mathrm{~mL}$, i.e. $5 \%, \mathrm{~m} / \mathrm{v}$ ). (b) Bleaching with $\mathrm{NaC}$ $\mathrm{lO}_{2}-\mathrm{NaOH}-\mathrm{CH}_{3} \mathrm{COOH}$ aqueous solution.

(a)

\begin{tabular}{|c|c|c|c|c|c|c|c|}
\hline $\begin{array}{l}\text { Original sample: } \\
\text { SCB24 }\end{array}$ & $\mathrm{AQ} /$ Ethanol $(\mathrm{g} / \mathrm{mL})$ & $\begin{array}{c}5 \% \mathrm{NaOH} \text { aq.sol. } \\
(\mathrm{mL})\end{array}$ & $\begin{array}{c}\text { Temperature } \\
\left({ }^{\circ} \mathrm{C}\right)\end{array}$ & $\begin{array}{c}\text { Time } \\
\text { (h) }\end{array}$ & $\begin{array}{c}\text { Stirring } \\
(\mathrm{rpm})\end{array}$ & $\begin{array}{c}\text { Suspension } \\
\text { initial } \mathrm{pH}\end{array}$ & $\begin{array}{l}\text { Final } \mathrm{pH} \text { of residue/filtrate after } \\
\text { filtrations/washings with dist. } \mathrm{H}_{2} \mathrm{O}\end{array}$ \\
\hline $\begin{array}{c}\text { SCB24 as } \\
\text { SCB24-Na-I } \\
(15.00 \mathrm{~g})\end{array}$ & $0.0024 / 50$ & 300 & $90^{\circ} \mathrm{C}-100^{\circ} \mathrm{C}$ & 6 & 30 & ca. 13 & ca. 7 \\
\hline $\begin{array}{c}\text { SCB24 as } \\
\text { SCB24-Na-II } \\
(15.00 \mathrm{~g})\end{array}$ & $0.0153 / 50$ & 300 & $90^{\circ} \mathrm{C}-100^{\circ} \mathrm{C}$ & 6 & 30 & ca. 13 & ca. 7 \\
\hline
\end{tabular}

$\mathrm{SCB}=$ sugarcane bagasse; $\mathrm{AQ}=$ anthraquinone; aq. sol. = aqueous solution; dist. = distilled; rpm = rotations per minute.

(b)

\begin{tabular}{|c|c|c|c|c|c|c|c|}
\hline $\begin{array}{l}\text { Sample }\left(\mathrm{R}_{1}\right)-\mathrm{R}_{\mathrm{i}} \\
\text { first bleaching }\end{array}$ & $\begin{array}{l}\text { Aq. sol. of } 1.7 \% \\
\mathrm{NaClO}_{2}(\mathrm{~m} / \mathrm{v}) \\
(\mathrm{mL})\end{array}$ & $\begin{array}{c}\text { Aq. sol. of } \\
\text { NaOH-GAA } \\
\text { (buffer at pH ca. } \\
\text { 5) (mL) }\end{array}$ & $\begin{array}{c}\text { Temperature } \\
\left({ }^{\circ} \mathrm{C}\right)\end{array}$ & $\begin{array}{l}\text { Time } \\
\text { (h) }\end{array}$ & $\begin{array}{l}\text { Stirring } \\
\text { (rpm) }\end{array}$ & $\begin{array}{l}\text { Suspension } \\
\text { intial } \mathrm{pH}\end{array}$ & $\begin{array}{c}\text { Residue/filtrate after } \\
\text { filtrations/washings with } \\
\text { dist. water }\end{array}$ \\
\hline SCB24Na-I & 150 & 150 & $90-100$ & 4 & 30 & ca. 5 & ca. 7 \\
\hline SCB24Na-II & 150 & 150 & $90-100$ & 4 & 30 & ca. 5 & ca. 7 \\
\hline SCB24Na-I* & 140 & 140 & $90-100$ & 4 & 30 & ca. 5 & ca. 7 \\
\hline SCB24Na-II & 150 & 150 & $90-100$ & 4 & 30 & ca. 5 & ca. 7 \\
\hline \multicolumn{8}{|l|}{$\begin{array}{l}\text { Sample }\left(\mathrm{R}_{3}\right)-\mathrm{R}_{\mathrm{i}} \\
\text { third bleaching }\end{array}$} \\
\hline SCB24Na-II & 125 & 125 & $90-100$ & 4 & 30 & ca. 5 & ca. 7 \\
\hline \multicolumn{8}{|l|}{$\begin{array}{l}\text { Sample }\left(\mathrm{R}_{4}\right)-\mathrm{R}_{\mathrm{i}} \\
\text { fourth bleaching }\end{array}$} \\
\hline SCB24Na-I & 125 & 125 & $90-100$ & 4 & 30 & ca. 5 & ca. 7 \\
\hline SCB24Na-II & 125 & 125 & $90-100$ & 4 & 30 & ca. 5 & ca. 7 \\
\hline
\end{tabular}

*Immediately after the second bleaching, cellulose SCB24-Na-I $\left(\mathrm{R}_{2}\right)$ still had a slightly pink coloration and was bleached with a 5\% KOH aqueous solution $(\mathrm{m} / \mathrm{v})$ for $2 \mathrm{~h}$ at $90^{\circ} \mathrm{C}-100^{\circ} \mathrm{C}$. Afterwards, $\mathrm{R}_{2}$ was filtered and washed several times with distilled water until reaching $\mathrm{pH}$ ca. 7 . SCB $=$ sugarcane bagasse; $\mathrm{GAA}=$ glacial acetic acid; Aq. sol. = aqueous solution; dist. = distilled; $r p m=$ rotations per minute; $\mathrm{Ri}=$ sequential residue $\mathrm{i}$, $\mathrm{i}$ varying form $\mathrm{i}$ to $\mathrm{n}$ (in this case, i from 1 to 4$)$. 
Table 4. Extraction of celluloses after a Novel Bleaching of Sugarcane Bagasse (SCB24) with aqueous solution of sodium hydroxide and hydrogen peroxide. (a) Bleaching with solution of $\mathrm{NaOH}-\mathrm{H}_{2} \mathrm{O}_{2}\left(250 \mathrm{~mL}\right.$ of dist. $\mathrm{H}_{2} \mathrm{O}+6 \mathrm{~g}$ of $\mathrm{NaOH}+50 \mathrm{~mL}$ of $\mathrm{H}_{2} \mathrm{O}_{2}$ at $29 \%-$ $30 \%$ ); (b) Yields of the samples after drying at $70^{\circ} \mathrm{C}$ for $24 \mathrm{~h}$, based on the initial crude bagasse before pulping/delignifying ( $15.00 \mathrm{~g}$ per sample).

(a)

\begin{tabular}{ccccccc}
\hline $\begin{array}{c}\text { Sample } \\
(\mathrm{R} 4 \text { from B1) }\end{array}$ & $\begin{array}{c}\text { Aq. sol. } \\
\mathrm{NaOH}-\mathrm{H}_{2} \mathrm{O}_{2} \\
\text { in the first } \\
\text { bleaching }(\mathrm{mL})\end{array}$ & $\begin{array}{c}\text { Temperature } \\
\left({ }^{\circ} \mathrm{C}\right)\end{array}$ & $\begin{array}{c}\text { Time } \\
(\mathrm{h})\end{array}$ & $\begin{array}{c}\text { Stirring } \\
(\mathrm{rpm})\end{array}$ & $\begin{array}{c}\text { Suspension } \\
\text { initial } \mathrm{pH}\end{array}$ & $\begin{array}{c}\mathrm{pH} \text { of residues/ } \\
\text { filtrates after } \\
\text { filtrations/washings } \\
\text { with dist. water }\end{array}$ \\
\hline SCB24-Na-I & 300 & $55^{\circ} \mathrm{C}-60^{\circ} \mathrm{C}$ & 2 & 30 & ca. 12 & ca. 7 \\
\hline SCB24-Na-II & 300 & $55^{\circ} \mathrm{C}-60^{\circ} \mathrm{C}$ & 2 & 30 & ca. 12 & ca. 7 \\
\hline
\end{tabular}

Note: The second to fourth bleaching occurred at same conditions applied to the first one.

(b)

\begin{tabular}{ccc}
\hline & $(\mathrm{g})$ & $(\%)$ \\
\hline SCB24-Na-I & 5.5590 & 37.06 \\
SCB24-Na-II & 6.1965 & 41.31 \\
\hline
\end{tabular}

Aq. sol. $=$ aqueous solution; $\mathrm{rpm}=$ rotations per minute; dist. $=$ distilled.

As starting bagasse, SCB24 was used without having been previously submitted to Sohxlet extraction. Approx. $50 \mathrm{~g}$ of this bagasse was immersed in tap water inside a kettle, which was heated to boiling of the system on an electrical heating steel plate. After $10 \mathrm{~min}$ boiling, the bagasse was cooled at room temperature and manually pressed in a 80 mesh metal sieve, washed with tap water for four consecutive times, always pressed after each washing operation to remove water excess. Then, the lignocellulosic mass was dried in a hot air circulating oven at $70^{\circ} \mathrm{C}$ for $12 \mathrm{~h}$. After cooled to room temperature, two portions of $15 \mathrm{~g}$ from the dry mass were removed for the pulping and bleaching experiments. Table 3 and Table 4 summarize the data and results of delignification/pulping and bleaching processes.

Delignification/pulping was carried out using aqueous $\mathrm{NaOH}$-anthraquinone solution (Table 3(a)). Four bleachings were done at this stage (Table 3(b)), using for that blends of two aqueous solutions, $125-150 \mathrm{~mL}$ of sodium chlorite at $1.7 \%(\mathrm{~m} / \mathrm{v})$ and $125-150 \mathrm{~mL}$ of $\mathrm{NaOH}-\mathrm{GAA}$ at $90^{\circ} \mathrm{C}-100^{\circ} \mathrm{C}$ for $4 \mathrm{~h}$ per sample each time, followed by several vacuum filtrations, washings with distilled water, $\mathrm{pH}$ adjustments. Then, four new bleachings were performed with $300 \mathrm{~mL}$ of aqueous solution containing $\mathrm{NaOH}$ and $\mathrm{H}_{2} \mathrm{O}_{2}$ at $55^{\circ} \mathrm{C}-60^{\circ} \mathrm{C}$ for $2 \mathrm{~h}$ per sample each time (Table 4(a)). After each new bleaching, several vacuum filtrations, followed by washings with distilled water, were effected on the cellulosic residues until the filtrate reached a $\mathrm{pH}$ ca. 7. Next, final drying of the last residues in a hot air circulating oven at $70^{\circ} \mathrm{C}$ for $24 \mathrm{~h}$.

Both celluloses extracted from the SCB24 showed white staining (Figure 14) but slightly more pronounced for SCB24-Na-I. The cellulose sugarcane bagasse yield was $37.06 \%$ for SCB24-Na-I and $41.31 \%$ for SCB24-Na-II (Table 4). They were considered promising for preliminary extraction of nanocelluloses therefrom. 


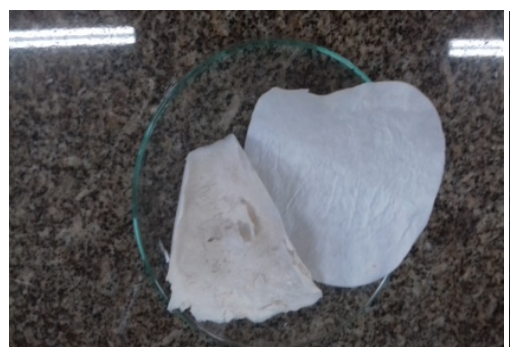

(a)

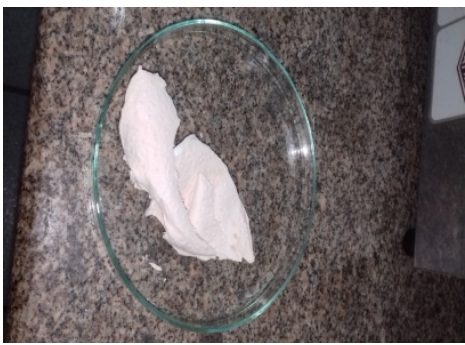

(b)

Figure 14. (a) Cellulose SCB24-Na-I, bent on the left of the paper filter; (b) Cellulose SCB24-Na-II.

\subsubsection{Elemental Analysis: (C $\mathrm{H} \mathrm{N}$ )}

The average percents of carbon, hydrogen and nitrogen of SCB48 were very close to those reported in the literature, for example, $45.3 \%, 6.8 \%$, and $0.5 \%$, respectively, according to Paula et al. (2011) [45]; 44.05\%, 6.00\%, and $0.13 \%$, respectively, according to Ferreira et al. (2015) [46]. The cellulose SCB48-Na (cited in Table 2), presented values of $\% \mathrm{C}, \mathrm{H}$ and $\mathrm{N}$ (Table 5), in general, very close to those of cellulose published in the literature [47] [48]. Regarding the celluloses extracted from sugarcane bagasse-SCB24-Na-I and BCA-Na-II-CHN tests were not performed.

\subsubsection{Attenuated Total Reflection Fourier Infrared Spectroscopy (ATR-FTIR)}

Table 6 sums up absorption ranges, functional groups and attributions of the three main lignocellulosic components of sugarcane bagasse (SCB48 and SCB24). It also can help us deal with the interpretation of ATR-FTIR spectra of the raw celluloses (SCB48-Na, SCB24-Na-I, SCB24Na-II) obtained.

Figure 15 shows the ATR-FTIR spectra of SCB48 and that of the raw cellulose extracted from this after treatments of the bagasse with an aqueous solution of sodium hydroxide containing a minimal parcel of anthraquinone for the delignification cycle, followed by a bleaching cycle with blends of aqueous solutions comprising one of sodium chlorite and another of sodium hydroxide together with glacial acetic acid.

The main absorbance peaks for characterizing the two materials are: 3546 $\mathrm{cm}^{-1}$, O-H stretching vibration of hydroxyls present in lignin and cellulose, absorbed water on the sample; $2904 \mathrm{~cm}^{-1}$, C-H stretching vibration of $\mathrm{CH}_{2}$ and $\mathrm{CH}_{3}$ of alkyl, aliphatic and aromatic groups; aprox. $1730 \mathrm{~cm}^{-1}$, stretching vibration of carbonyls $(\mathrm{C}=\mathrm{O})$ of ketones, carboxylic acids and acetyl groups present in the hemicellulose-it disappears in the SCB48- $\mathrm{Na}$ spectrum, an indicative of hemicellulose removal from the bagasse SCB $48 ; 1640 \mathrm{~cm}^{-1}$, O-H bending vibration of water absorbed by the sample; $1605 \mathrm{~cm}^{-1}$, skeletal stretching vibration of $\mathrm{C}=\mathrm{C}$ of aromatic rings, confirming lignin in the bagasse, and it is could not be totally observed in the SCB48-Na-another indicative of almost whole removal of lignin from SCB48; 1507 and $1372 \mathrm{~cm}^{-1}$, O-H stretching vibration of phenolic hydroxyls in lignin; $1239 \mathrm{~cm}^{-1}$, O-H stretching vibrations of hydroxyls of phenols 
Table 5. Data of elemental analysis of sugarcane bagasse and celluloses extracted therefrom.

\begin{tabular}{ccccc}
\hline Sample & $\mathrm{C}(\%)$ & $H(\%)$ & $\mathrm{N}(\%)$ & $\mathrm{O}(\%)^{*}$ \\
\hline SCB48 & $44.60 \pm 0.03$ & $6.01 \pm 0.05$ & $0.37 \pm 0.01$ & 49.02 \\
SCB48-Na & $41.30 \pm 0.11$ & $6.56 \pm 0.15$ & $0.12 \pm 0.02$ & 52.02 \\
SCB24-Na-I & ND & ND & ND & ND \\
SCB24-Na-II & ND & ND & ND & ND
\end{tabular}

*Average percent of oxygen calculated basing on the sum of the percentages of C, $\mathrm{H}$ and N. ND: not done.

Table 6. Typical attributions in lignocellulosic materials by DRIFT spectroscopy.

\begin{tabular}{|c|c|c|}
\hline Absorption ranges $\left(\mathrm{cm}^{-1}\right)$ & Functional groups & Attributions \\
\hline $3200-3640$ & $\begin{array}{l}\text { Hydroxyls }(\mathrm{OH}) \text { of alcohols, } \\
\text { phenols and carboxylic acids }\end{array}$ & Lignin and cellulose \\
\hline $2840-3000$ & $\begin{array}{l}\mathrm{CH}_{2} \text { and } \mathrm{CH}_{3} \text { of alkyl, aliphatic } \\
\text { and aromatic groups }\end{array}$ & Extractables and cellulose \\
\hline $1540-1870$ & $\begin{array}{l}\text { Carbonyls }(\mathrm{C}=\mathrm{O}) \text { of ketones, } \\
\text { carboxylic acids and acetyl groups }\end{array}$ & Hemicellulose \\
\hline $1516-1610$ & $(\mathrm{C}=\mathrm{C})$ of aromatic rings & Lignin \\
\hline $1330-1420$ & Phenol hydroxyls $(\mathrm{OH})$ & Lignin and carbohydrates \\
\hline $1200-1400$ & $\begin{array}{l}\text { Hydroxyls of phenols and (C-O-C) } \\
\text { in aryl alkyl ether }\end{array}$ & Hemicellulose and lignin \\
\hline $1085-1150$ & $(\mathrm{C}-\mathrm{O}-\mathrm{C})$ in pyronose ring & Cellulose \\
\hline $675-900$ & $\begin{array}{l}(\mathrm{C}-\mathrm{H}) \text { in lignin aromatic } \\
\text { rings }\end{array}$ & Lignin \\
\hline
\end{tabular}

DRIFT: Diffuse reflectance infrared Fourier transform. Translated and adapted by A. J.C. Brant from de Assumpção et al. (2016) [49].

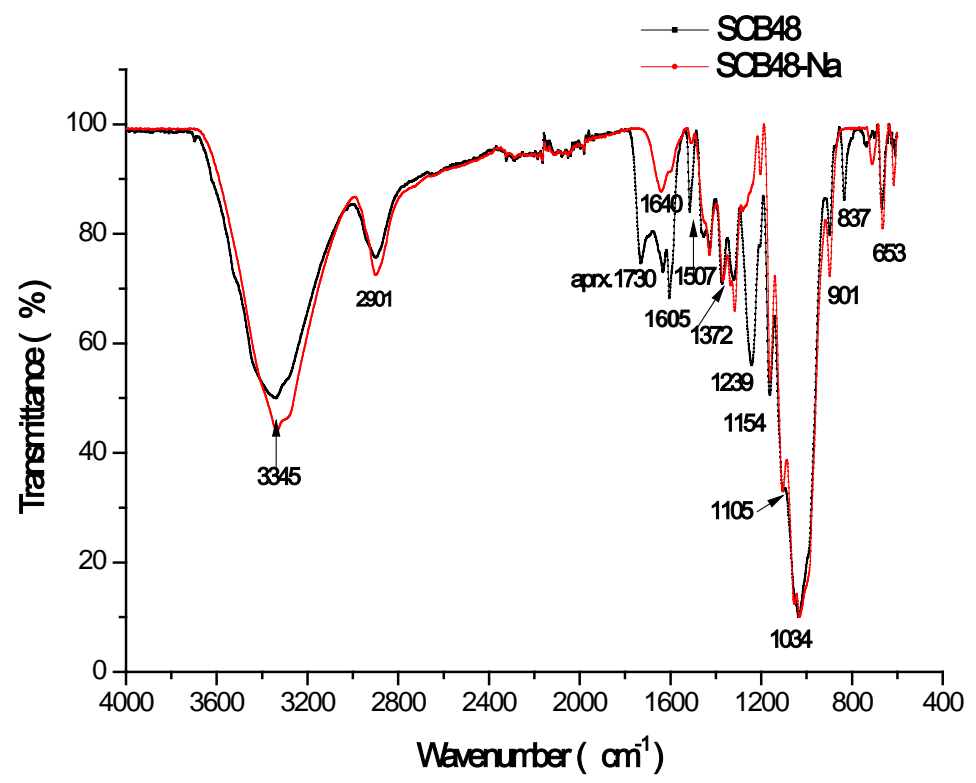

Figure 15. ATR-FTIR spectra of in natura sugarcane bagasse (SCB48) and the raw cellulose (SCB48-Na) extracted from this. 
and C-O-C in aryl alkyl ether in lignin and hemicellulose, weakly observed vibration signal for SCB-Na-again indicating at least removal of the hemicellulose from the bagasse; $1034 \mathrm{~cm}^{-1}$, C-O-C skeletal vibration of pyranose ring, associated with $\beta$-glycosidic linkages between glucose units in cellulose; $837 \mathrm{~cm}^{-1}$, $\mathrm{C}-\mathrm{H}$ stretching vibrations of aromatic ring, not observed in the SCB48-Na, thus confirming high lignin removal.

An analysis of the results of absorption bands/peaks, evaluated from the ATR-FTIR spectra of SCB48 and SCB48-Na (Figure 15), spares us from making repetitive comments on the corresponding values very close to those obtained for the ATR-FTIR spectra of SCB24 and those of two raw celluloses: SCB24-Na-I and SCB-Na-II (Figure 16). It is important to point out the peak at 1245 $\mathrm{cm}^{-1}$-it refers to stretching vibrations of hydroxyls of phenols and C-O-C in aryl alkyl ether, pertinent to lignin and hemicellulose-which practically disappears in the spectra of celluloses SCB24-Na-I and SCB24-Na-II, suggesting, therefore, that probably both have very low levels of lignin, and hemicellulose absence; the signal at $827 \mathrm{~cm}^{-1}$ refers to $\mathrm{C}-\mathrm{H}$ of stretching vibrations of aromatic ring. It only appeared in the SCB24 spectrum, and completely disappeared in the SCB24-Na-I and SCB24-Na-II spectra, again demonstrating a minimal lignin content in both celluloses. Another important aspect: the spectra of both celluloses are almost identical.

The values of the absorption bands/peaks obtained in the ATR-FTIR spectra of the bagasses (SCB48 and SCB24), as well as those of the raw celluloses extracted from them (Figure 15 and Figure 16), are in accordance with the results from lignocellulosic materials tested and reported in the literature [22] [35] [50] [51] [52].

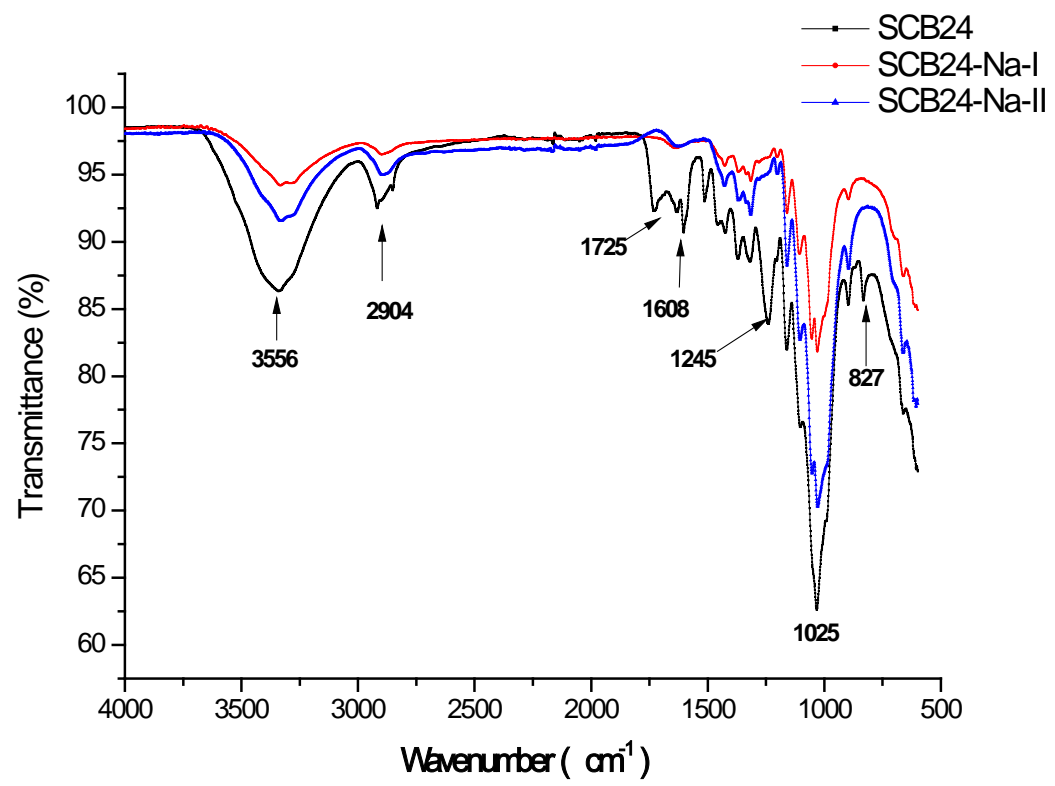

Figure 16. ATR-FTIR spectra of in natura sugarcane bagasse (SCB24) and celluloses (SCB24-Na-I and SCB24-Na-II) extracted from this. 


\subsubsection{Thermal Analysis (TA): Differential Scanning Calorimetry (DSC) and Thermogravimetric Analysis (TGA) \\ Sugarcane Bagasse (SCB24 and SCB48)}

The endothermic peaks recorded from ambient temperature to $116^{\circ} \mathrm{C}$ and $156^{\circ} \mathrm{C}$ refer to the elimination of water retained in the bagasses SCB 48 and SCB24-Figure 17(a) and Figure 17(b), respectively-linked to lignocellulosic components, chiefly to cellulose. Since the bagasse is formed by a complex mixture of components, the interpretation of DSC curves is not an easy task. The DSC measurements show, for example, that, even warming the sample of a pulp up to $170^{\circ} \mathrm{C}$, one cannot obtain it absolutely dry [51]. Two more important events were observed: an endothermic one in the range of $290^{\circ} \mathrm{C}-355^{\circ} \mathrm{C}$ due to the decomposition of cellulose and an exothermic one around $375^{\circ} \mathrm{C}$, possibly originated from the crystallization of cellulose.

Concerning the thermogravimetric analysis, Figure 18 shows the results of both SCBs.

The profiles of the TG/DTG curves-Figure 18(a) and Figure 18(b)] of the nonchemically treated bagasse are very similar to those published by Mandal and Chakrabarty (2011) [22]. The initial endothermy in the first stage of mass loss, which occurs in all two cases-Figure 18(a) and Figure 18(b)-at a temperature much lower than $110^{\circ} \mathrm{C}$ up to ca. $120^{\circ} \mathrm{C}$, means the loss of moisture due to the evaporation of free water and that of low-molecular-weight compounds as well as elimination of water from intermolecular hydrogen bonds in biomasses. In the second and third stages of mass loss, it occurs between $214^{\circ} \mathrm{C}$ and $375^{\circ} \mathrm{C}$, stressing a peak of an exothermic degradation at ca. $290^{\circ} \mathrm{C}$, possibly referring to the degradation of hemicelluloses $-220^{\circ} \mathrm{C}-315^{\circ} \mathrm{C}$, according to Yang et al. (2007) [52]; 304 ${ }^{\circ} \mathrm{C}$, Santos et al. (2011) [53] for both bagasses. Following, two exothermic degradation peaks at $329^{\circ} \mathrm{C}$ and $339^{\circ} \mathrm{C}$ for SCB48 and SCB24, respectively. Possibly it is due to cellulose degradation (TG up to $400^{\circ} \mathrm{C}$ ). In the fourth stage, above $375^{\circ} \mathrm{C}$, any peak arising may refer to lignin degradation, which is quite complex, also involving more stages at temperatures below $375^{\circ} \mathrm{C}$ [54]. All these peaks were revealed by the first derivative of TG. The differences are minimal between the profiles of the curves, indicating that they may probably originate from differences in sample quantities and not uniformity of the particle size/fibers of the biomass, in addition to impurities inherent to them.

About the the DSC of both celluloses, Figure 19 shows their profiles.

Two endothermic events were recorded in both celluloses, one with peaks at $142^{\circ} \mathrm{C}$ and $160^{\circ} \mathrm{C}$, caused by evaporation of the water from room temperature to $160^{\circ} \mathrm{C}$ or to enthalpy of dehydration, already explained from the results in Figure 17. The second endothermic peaks at $350^{\circ} \mathrm{C}$ and $352^{\circ} \mathrm{C}$ refer to decomposition of the cellulose. An exothermic event with peaks at $369^{\circ} \mathrm{C}$ and $374^{\circ} \mathrm{C}$, possibly originated from the crystallization or enthalpy of cellulose crystallization [55]. Such peaks at the respective temperatures herein mentioned are depicted in Figure 19(a) and Figure 19(b).

From the tests of thermogravimetric analysis, the TG/DTG curves (Figure 20) 
show that both celluloses must differ very little each other structurally.

The results of TG/DTG were close to those described by Mandal and Chakrabarty (2011) [22] and Liu et al. (2006) [50] on tests of celluloses from sugarcane bagasse, noting that the decomposition of cellulose occurs in two exothermic stages in a range of $320^{\circ} \mathrm{C}-375^{\circ} \mathrm{C}$. At $341^{\circ} \mathrm{C}$, mass losses were $95 \%$ for SCB24-Na-I and $87 \%$ for BCA-Na-II (curve profiles in Figure 20).

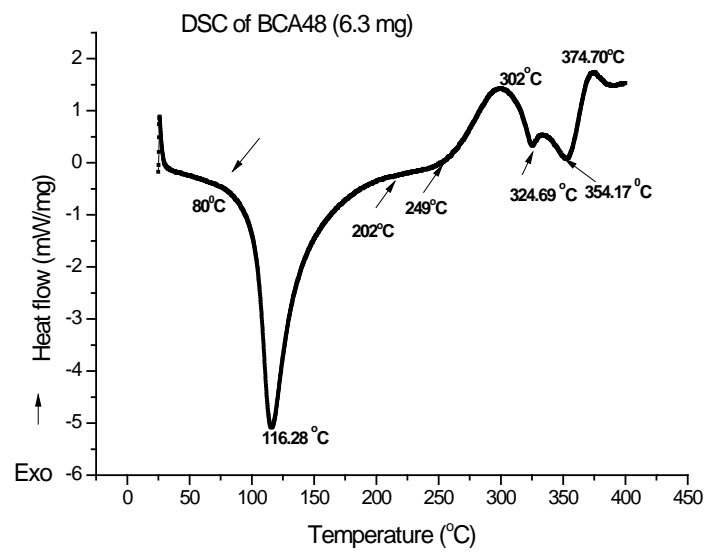

(a)

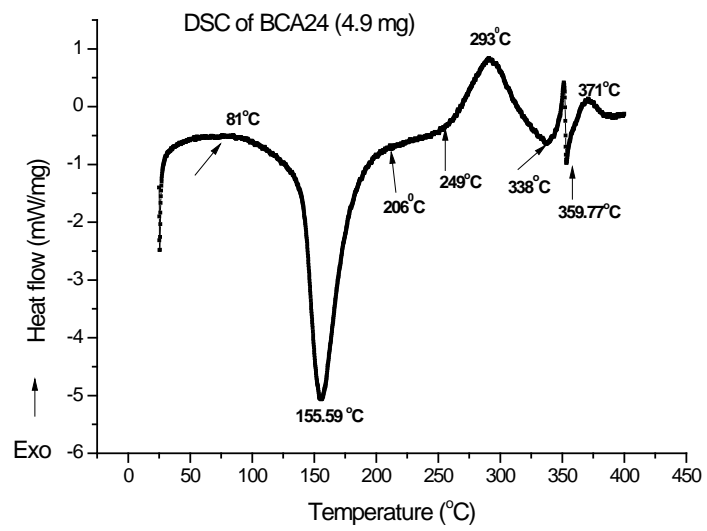

(b)

Figure 17. DSC curves of sugarcane bagasses: (a) SCB24 and (b) SCB48.

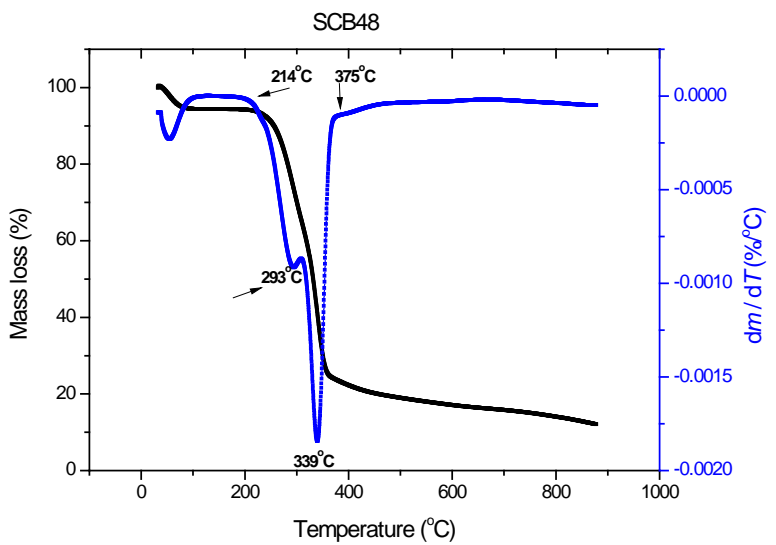

(a) 


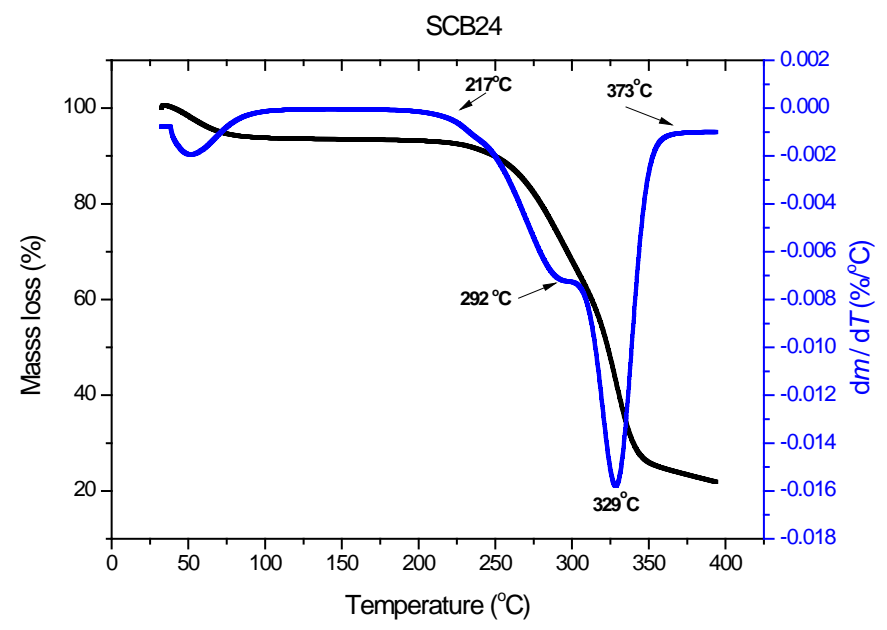

(b)

Figure 18. Mass losses and their first derivatives in function of the temperature for the crude bagasses SCB48 (a) and SCB24 (b).

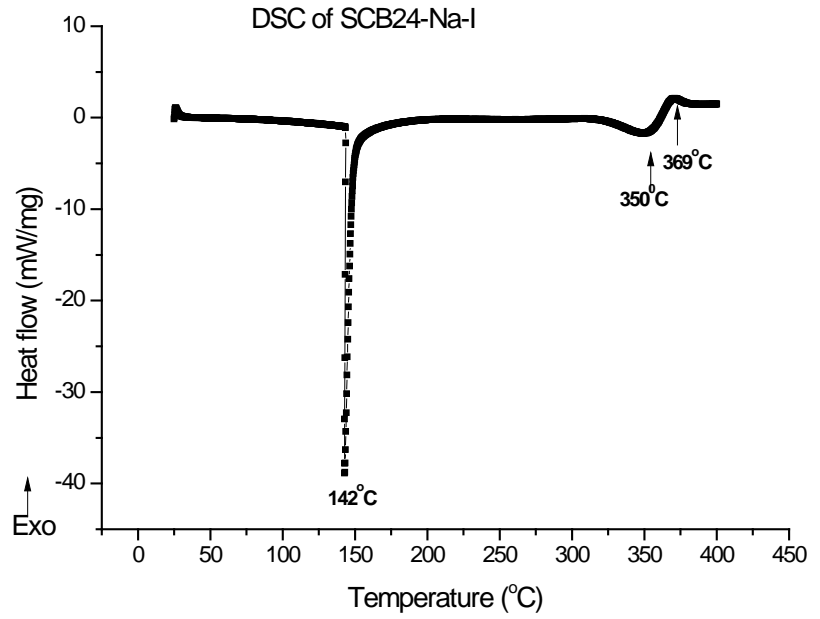

(a)

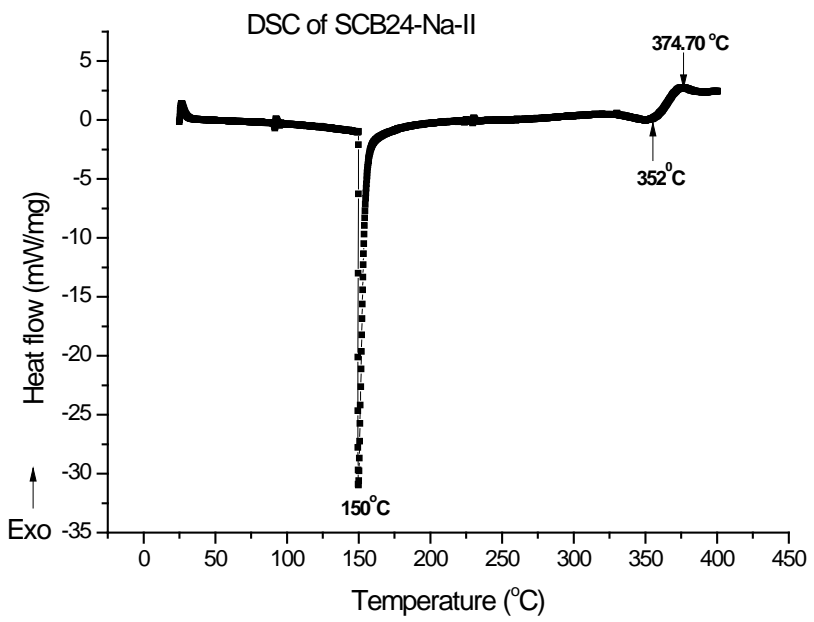

(b)

Figure 19. DSC curves of celluloses (a) SCB24-Na-I and (b) SCB24-Na-II. 


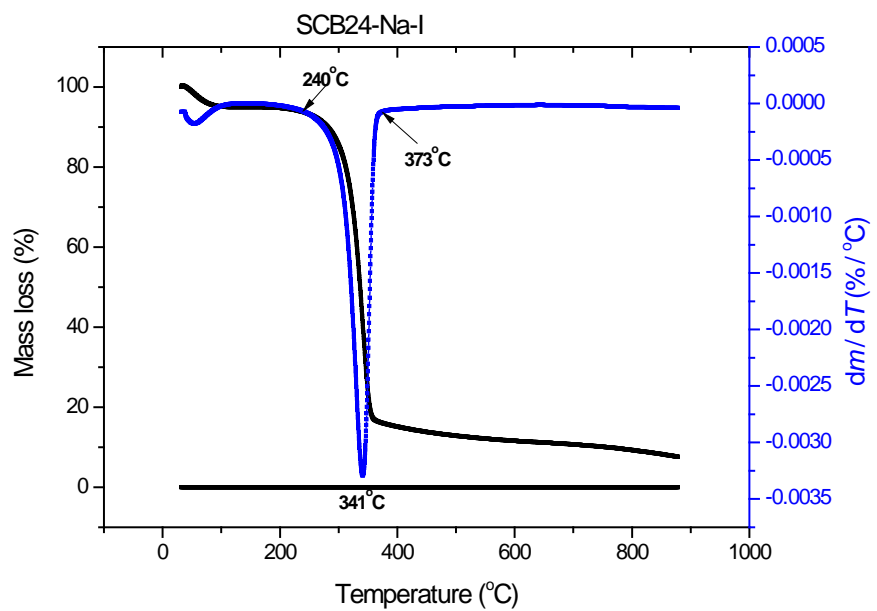

(a)

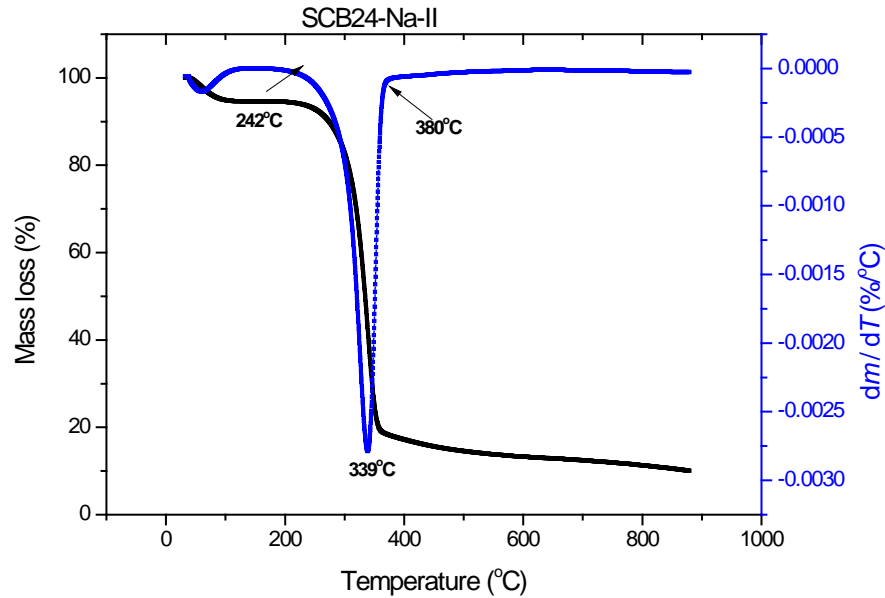

(b)

Figure 20. TG/DTG curves of celluloses extracted from sugarcane bagasse: (a) SCB24-Na-I and (b) SCB24-Na-II.

\subsubsection{X-Ray Diffractometry (XRD) of the Sugarcane Bagasses and Celluloses Extracted Therefrom}

The results from the X-ray diffractometry of SCB48 and WP24, as well as those of the celluloses extracted (SCB-Na-I and SCB-Na-II) from SCB24, were obtained by using Segal et al. (1959) method [32], developed to estimate the index of crystallinity (CI) of native cellulose in relation to reflection at $2 \theta=18$, based on Equation (3):

$$
\mathrm{CI}=\left(\frac{I_{002}-I_{a m}}{I_{002}}\right) \times 100
$$

where $I_{002}$ or $I_{\text {total }}$ represents the maximum intensity at $2 \theta=23^{\circ}$, the cellulose crystalline region, and $I_{\mathrm{am}}$ at $2 \theta=18^{\circ}$, the intensity of the cellulose amorphous region. Some essential measurement data are in Table 7 and Table 8, and Figure 21 and Figure 22 exhibit their respective X-ray diffractograms of the samples tested.

Sgarcane Bagasse (SCB48) and Wood Powder (WP24) 
Their profiles (Figure 21) related to the presence of cellulose in both biomasses are very similar to those published in the literature [16] [56] [57]. The wood powder (WP24) was tested in this experiment in order to know a little more of its structure, even having been discarded in the continuity of pulp extraction for reasons already explained in the subitem 3.1.2. The degrees of crystallinity, estimated based on Equation (3), for the native celluloses of SCB48 and WP24 were ca. $56 \%$ and ca. $61 \%$, respectively (inferred from Table 7 and Figure 21 ).

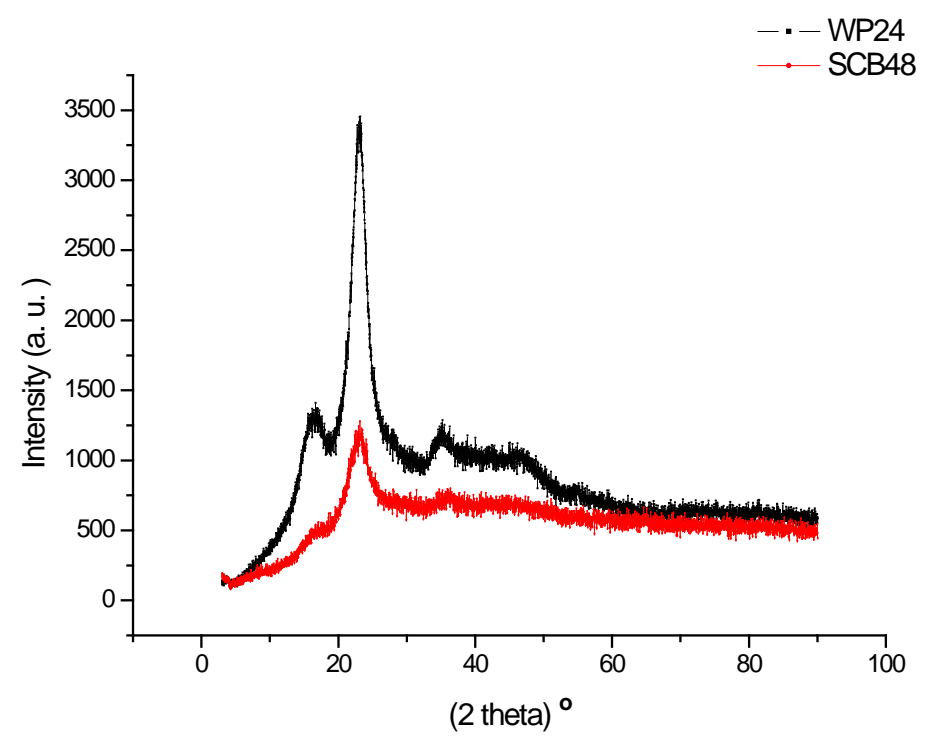

Figure 21. X-ray diffractograms of bagasse SCB48 and wood powder WP24.

Table 7. Results of X-ray Diffractometry of Sugarcane Bagasse (SCB48) and Wood Powder (WP24).

\begin{tabular}{cccccc}
\hline \multicolumn{7}{c}{ SCB48 } & & \\
\hline Peak n ${ }^{\circ}$ & 2 theta $\left(^{\circ}\right)$ & FWHM & d-value & Intensity (cps) & I/ I \\
\hline 1 & 16.080 & $* * * *$ & 5.5072 & 505 & 44 \\
2 & 23.180 & 2.706 & 3.8339 & 1158 & 100 \\
3 & 36.200 & 0.894 & 2.4793 & 693 & 60 \\
4 & 41.960 & 0.918 & 2.1513 & 665 & 58 \\
5 & 86.260 & 0.824 & 1.1267 & 505 & 44 \\
\hline Peak n & 2 theta $\left(^{\circ}\right)$ & FWHM & d-value & Intensity (cps) & I/I \\
\hline 1 & 16.820 & 3.153 & 5.2665 & 1297 & 40 \\
2 & 23.080 & 1.953 & 3.8503 & 3308 & 100 \\
3 & 34.960 & 1.412 & 2.5643 & 1143 & 35 \\
4 & 46.500 & $* * * * *$ & 1.9513 & 1063 & 33 \\
\hline
\end{tabular}

FWHM = full-width at half-maximum; d-value is the measurement of interplanar spacing in $\AA$ ( $1 \AA=0.1$ $\mathrm{nm}$ ). I/ $I_{\mathrm{o}}$ is the ratio of intensities where $I$ is the intensity (counts per second/cps) of the peak and $I_{\mathrm{o}}$ is the strongest peak intensity. 
Table 8. Results of X-ray diffractometry of celluloses extracted from bagasse SCB24.

\begin{tabular}{cccccc}
\hline \multicolumn{7}{c}{ Cellulose SCB24-Na-I } \\
\hline Peak n ${ }^{\circ}$ & 2 theta $\left(^{\circ}\right)$ & FWHM & d-value & Intensity (cps) & I/ $I_{\mathrm{o}}$ \\
\hline 1 & 15.800 & 0.259 & 5.6041 & 1568 & 32 \\
2 & 22.580 & 1.459 & 3.9344 & 5028 & 100 \\
3 & 34.720 & 0.282 & 2.5815 & 1280 & 26 \\
\hline \multicolumn{7}{c}{ Cellulose SCB24-Na-II } \\
\hline Peak n & 2 theta $\left(^{\circ}\right)$ & FWHM & d-value & Intensity (cps) & I/ $I_{\mathrm{o}}$ \\
\hline 1 & 16.020 & 0.282 & 5.5276 & 1452 & 33 \\
3 & 22.380 & 1.506 & 3.9691 & 4478 & 100 \\
\hline
\end{tabular}

FWHM = full-width at half-maximum); d-value is the measurement of interplanar spacing in $\AA$ ( $1 \AA=0.1$ $\mathrm{nm}$ ). $I / I_{\mathrm{o}}$ is the ratio of intensities where $I$ is the intensity (counts per second/cps) of the peak and $I_{\mathrm{o}}$ is the strongest peak intensity.

\section{Celluloses Extracted from Sugarcane Bagasse (SCB24)}

The profiles of the X-ray diffractograms (Figure 22) also are very alike to those obtained by Lengowski et al. (2013) [58] after alkaline treatments of dry paper sheet of Kraft cellulose from Eucalyptus spp. bleached industrially, but with formulations and conditions of temperatures and processing times very different from those applied in our work. Peaks at the regions of $2 \theta=18$ and $2 \theta$ $=23$ refer to the amorphous and crystalline regions of cellulose, respectively. Such peaks of $I_{\mathrm{am}}$ and $I_{\text {total }}$ considered in the CI calculations may vary around $16^{\circ}$ and $22^{\circ}$, respectively, in several publications [16] [56] [57]. The degrees of crystallinity, estimated based on Equation (3) for the celluloses extracted from sugarcane bagasse-BCA24-Na-I and BCA24-Na-II-were ca. $69 \%$ and ca. $68 \%$, respectively (inferred from Table 8 and Figure 22). The profiles of both celluloses are very resembling each other.

\subsubsection{Scanning Electron Microscopy (SEM) of the Sugarcane Bagasses and Celluloses Extracted Therefrom}

\section{Sugarcane Bagasse (SCB24)}

The morphologies and textures of SCB48 and SCB24 bagasse (Figure 23) show very little difference each other. An observation on the SEM images reinforces what was described in the work of Oliveira et al. (2018) [59]: "The materials have different shapes, sizes and textures, implying sizes of surface areas of the particles also different", expression translated from Portuguese into English by A. J. C. Brant.

Celluloses Extracted from the Sugarcane Bagasse: SCB-Na-I and SCB-Na-II

Figure 24 shows the surface images of both celluloses in the form of interlaced, loose fibers and compact mass at a magnification of 150× (A: SCB24-Na-I and B: SCB24-Na-II) and at magnifications of $800 \times$ and 1000× (A1: SCB24-Na-I and B1: SCB24-Na-II), respectively. They are morphologically very similar to each other and quite distinct from the micrographs of the SCB48 and SCB24 ba- 
gasse shown in Figure 23. By the fact that the samples were not sputtering-treated previously (using, for example, gold/palladium alloy, others), both bagasses and both celluloses may have generated micrographs with details a little limited. However, they were satisfactory and comparable to those presented by several authors in the literature dealing with sugarcane bagasse pulp and from other plant sources [60] [61] [62] [63].

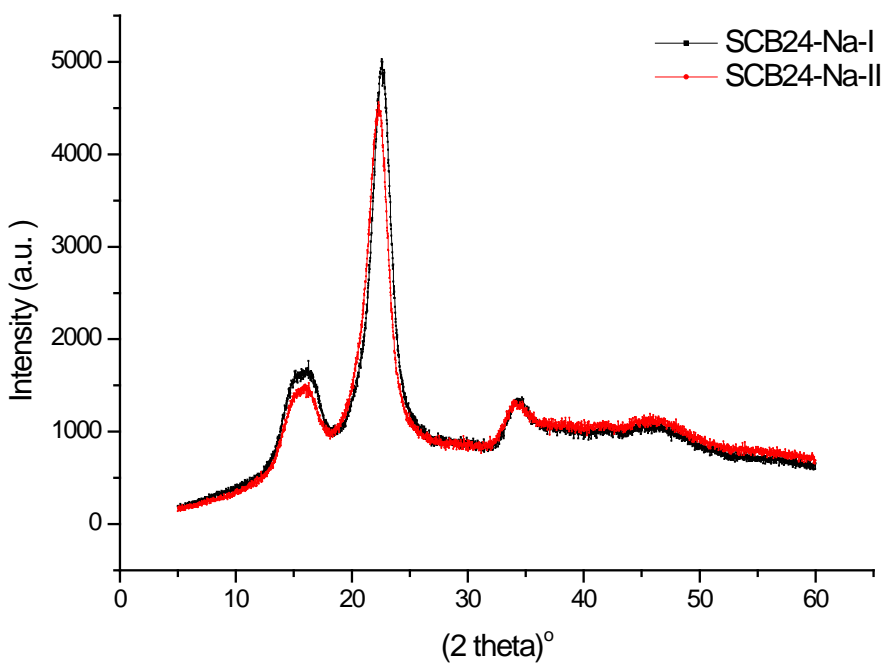

Figure 22. X-ray diffractograms of celluloses SCB24-Na-I and SCB24-Na-II.

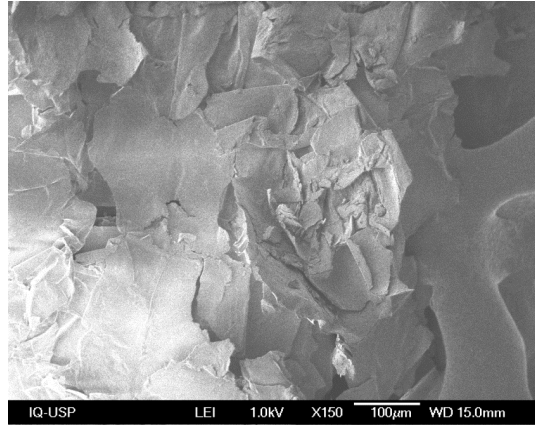

(a) $\mathrm{SCB} 48$

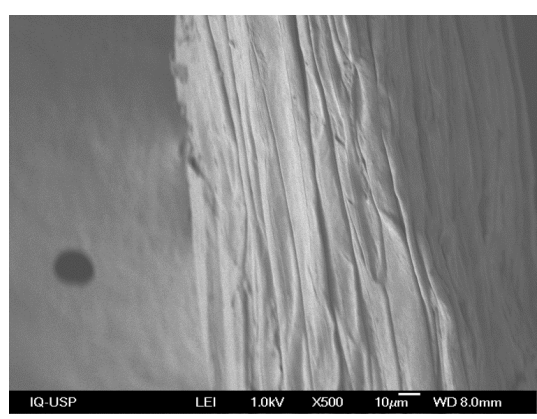

(a1) SCB48

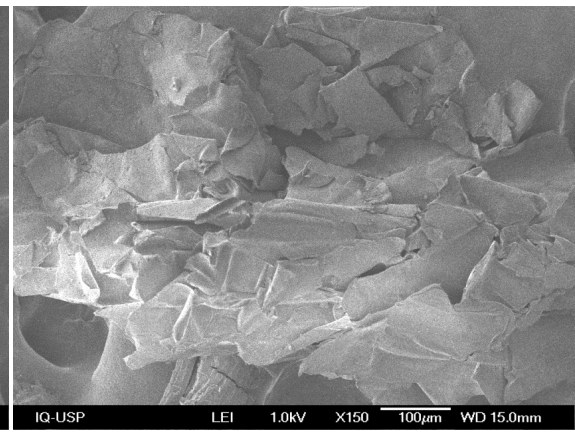

(b) SCB24

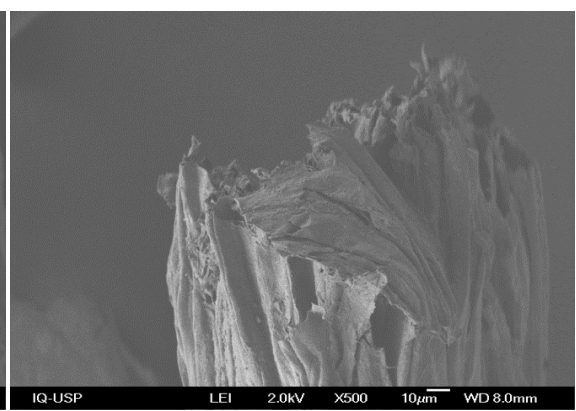

(b1) SCB24

Figure 23. Surface micrographs obtained by SEM of the sugarcane bagasses retained on 48 mesh and 24 mesh metal sieves, SCB48 and SCB24, respectively. Magnifications of $150 \times$ for (a) and (b) and $500 \times$ for (a1) and (b1), from a SEM JEOL Neoscope JCM-5000 equipment. 


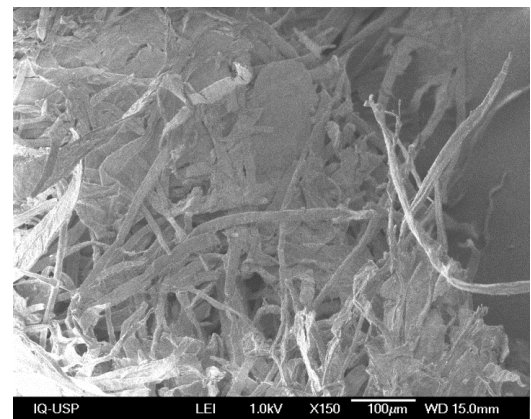

(a) SCB24-Na-I

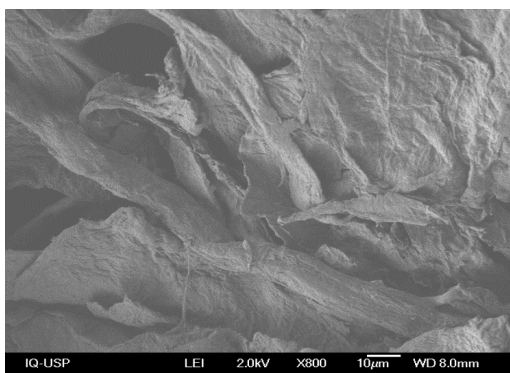

(a1) SCB24-Na-I

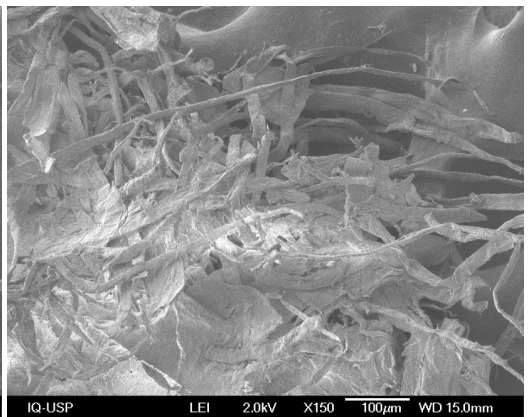

(b) SCB24-Na-II

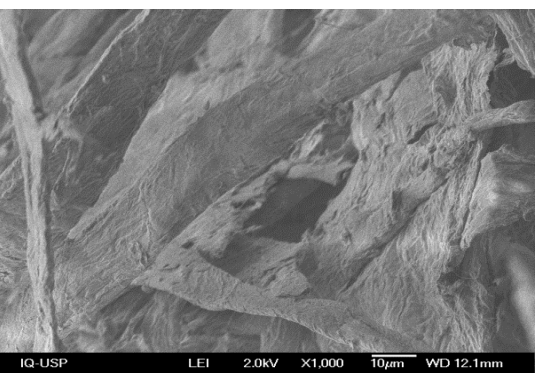

(b1) SCB24-Na-II

Figure 24. Micrographical surface images of celluloses extracted from sugarcane bagasse (BCA24-Na-I and BCA24-Na-II), obtained by SEM. Magnifications of $150 \times, 800 \times$ and $1000 \times$, from a SEM FESEM JEOL JSM-7401F.

\subsection{Part B: Obtaining of Cellulose Nanoparticles, Their Characterization and Application as Coating on Biodegradable Recipients}

Once neutrality was reached, after numerous washes with distilled water and centrifugations, a curious phenomenon was observed visually (with the naked eye) between samples of the SCBC1 and SCBC2 suspensions arranged separately in two Falcon tubes (Figure 25). After a slight manual shaking of these tubes, most of all the particles of the SCBC suspensions quickly settled-few particles remained dispersed in the suspensions $\mathrm{SCBC} 1$ and $\mathrm{SCBC} 2$ as supernatants. This phenomenon was probably due to a lowering of the colloidal stability of the particles and nanoparticles of cellulose in the dilute suspensions (supernatants) after shaking, tending to form larger agglomerates, which promptly precipitate.

\subsubsection{Transmission Electron Microscopy (TEM) of Cellulose Nanoparticles' Suspensions}

The images of the SCBC1 and SCBC2 suspensions obtained by TEM are shown in Figure 26 and Figure 27.

\subsubsection{Yields (R) of Cellulose Nanoparticles' Suspensions}

The yield of the SCBC1 and SCBC2 suspensions, based on $2.0 \mathrm{~g}$ of cellulose bagasse, calculated after their lyophilization, corresponded, respectively, to $9.6 \%$ and $12.0 \%$, showing that the use of the different types of sugarcane bagasse cellulose (with and without $\mathrm{KOH}$ treatment) practically did not influence the yield of their nanoparticles, that is, a difference of only $2.4 \%$ between them. 


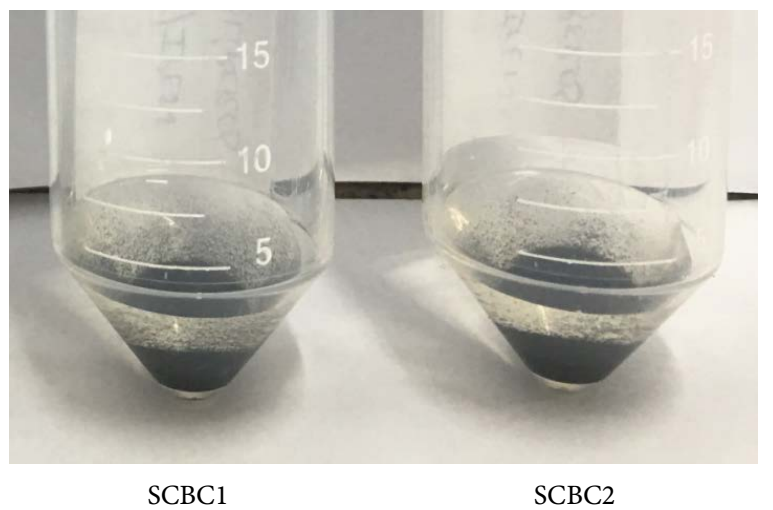

Figure 25. Sedimentation of the particles in SCBC suspensions, resulting from $60 \mathrm{~min}$ of different sugarcane bagasse celluloses hydrolysis ( $\mathrm{CBC} 1$ and $\mathrm{CBC} 2$ ), soon after slight manual agitation of the two Falcon tubes. SCBC = suspension after hydrolysis of $2.0 \mathrm{~g}$ of each sugarcane bagasse cellulose.
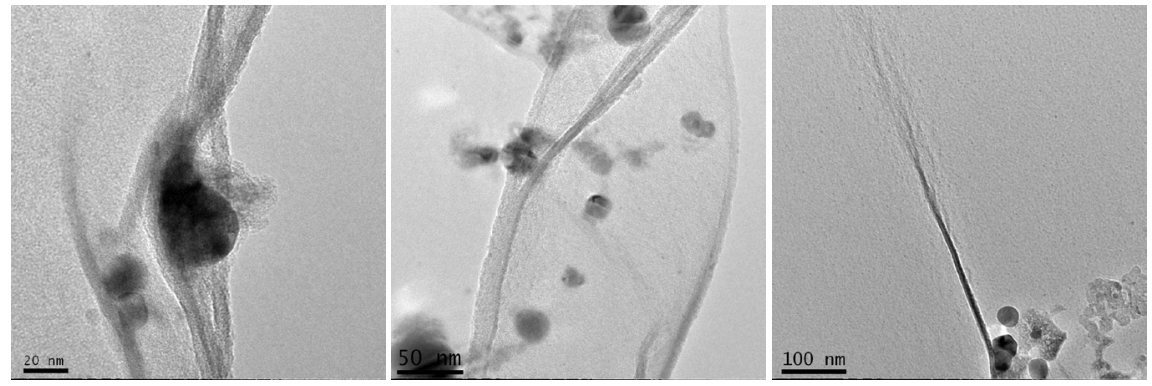

Figure 26. Transmission electron microscopy of the SCBC1 suspension (obtained for the type 1 sugarcane bagasse cellulose, which underwent acid hydrolysis for $60 \mathrm{~min}$ ) at scales of 20,50 and $100 \mathrm{~nm}$. SCBC = suspension after hydrolysis of $2.0 \mathrm{~g}$ sugarcane bagasse cellulose.
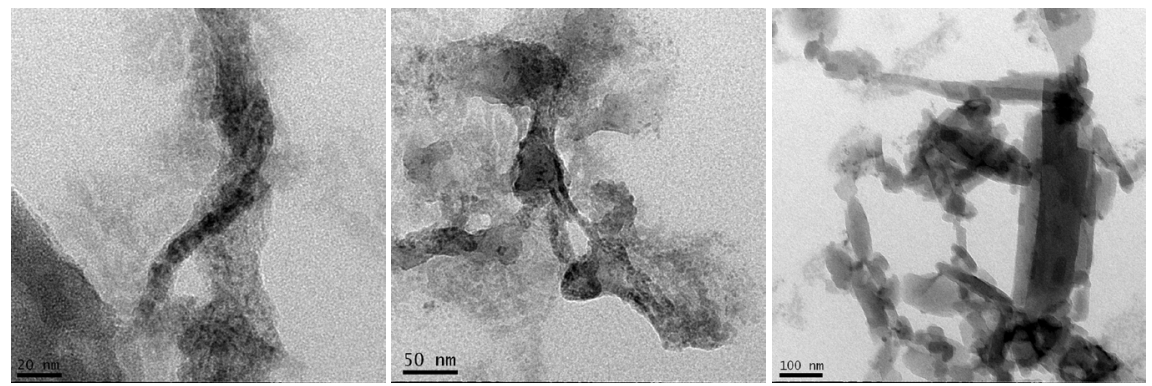

Figure 27. Transmission electron microscopy of the SCBC2 suspension (obtained for the type 2 sugarcane bagasse cellulose, which underwent acid hydrolysis for $60 \mathrm{~min}$ ) at scales of 20,50 and $100 \mathrm{~nm}$. SCBC = suspension after hydrolysis of $2.0 \mathrm{~g}$ sugarcane bagasse cellulose.

In turn, the yield of the SCBC1A and SCBC2A suspensions, based on $7.0 \mathrm{~g}$ of cellulose bagasse, calculated after their lyophilization, corresponded, respectively, to $12.2 \%$ and $14.5 \%$, indicating once again that the use of the different types of sugarcane bagasse cellulose (with and without $\mathrm{KOH}$ treatment) practically did not influence the yield of their nanoparticles, with a difference of only $2.3 \%$ between them. This value is very close to that observed between suspensions SCBC1 
and SCBC2 (2.4\%) initially described. When comparing these two yields with those obtained from $2.0 \mathrm{~g}$ of both $\mathrm{CBCs}$ (SCBC1: 9.6\% and SCBC2: 12.0\%), it can be said that there was no significant yield increase by using $7.0 \mathrm{~g}$ of each $\mathrm{CBC}$, but maintaining the same solid/liquid ratio.

\subsubsection{Scanning Electron Microscopy (SEM) of Cellulose Nanoparticles}

The images of the fragments (powders) resulting from the lyophilization of the SCBC1 and SCBC2 suspensions, obtained by SEM, are shown in Figure 28 and Figure 29.

TEM and SEM analyses of the different cellulose particles from $7.0 \mathrm{~g}$ samples, as well as their suspensions in distilled water obtained after neutrality of SCBC1A and SCBC2A, were not performed once their nano- and microstructural characterizations have already been shown previously (subitems 3.2.1 and 3.2.3 of this work), when the NPCs (powder and suspensions) were produced from $2.0 \mathrm{~g}$ of the same CBCs studied in the project (Figures 26-29).

\subsubsection{Brush Application of Cellulose Nanoparticles from Sugarcane Bagasse on Biodegradable Recipients}

The thin layer of the different film-forming suspensions (gels) brushed on the biodegradable recipients selected for tests, after drying in the oven, provided some brightness in their internal parts, when compared to the recipients uncoated-these named by "SEM F". In addition, the application of the F-CBC1 and F-CBC2 gels caused the cellulose particles to be clearly visible in the inner of the recipients, evidenced by small purplish spots (and in greater quantity when utilizing CBC2), as well as in the films formed in the Petri dishes. Figures 30-32 show these details in some of the recipients and films, respectively.

Figure 33 shows some of the films formed from $3.0 \mathrm{~g}$ and $4.0 \mathrm{~g}$ of the film-forming suspensions (gels), removed from their Petri dishes.

In the $\mathrm{F}-\mathrm{CBC} 1$ and $\mathrm{F}-\mathrm{CBC} 2$ films of Figure 32 and Figure 33, it can be seen that those containing $4.0 \mathrm{~g}$ of their respective film-forming suspensions (gels), the NPCs became more evident, in greater quantity and more concentrated in the center of the Petri dishes (Figure 32) comparing to the films formed with 3.0
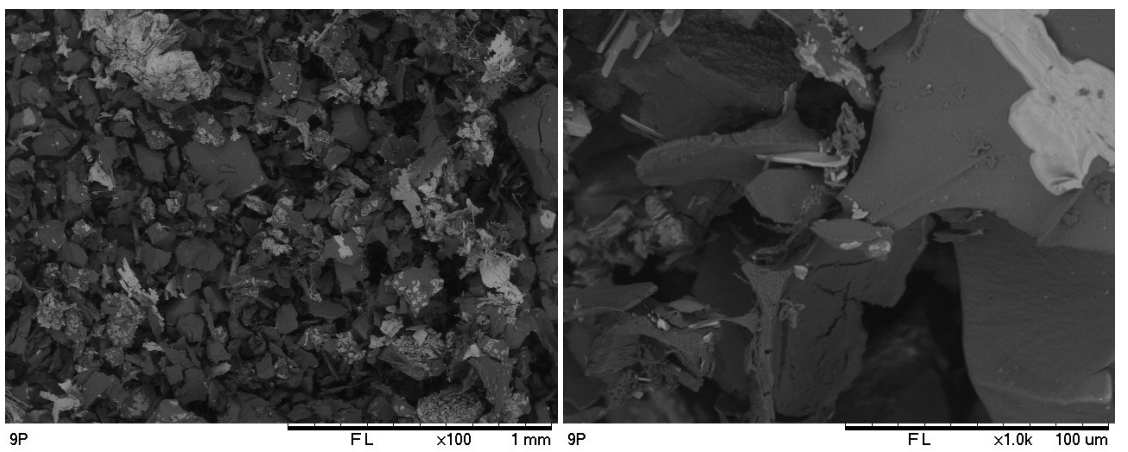

Figure 28. Scanning electron microscopies of the fragments resulting from the lyophilization of the SCBC1 suspension (obtained after $60 \mathrm{~min}$ of the type 1 sugarcane bagasse cellulose underwent acid hydrolysis), with increases of 100 and 1000 times. SCBC $=$ suspension after hydrolysis of $2.0 \mathrm{~g}$ sugarcane bagasse cellulose. 


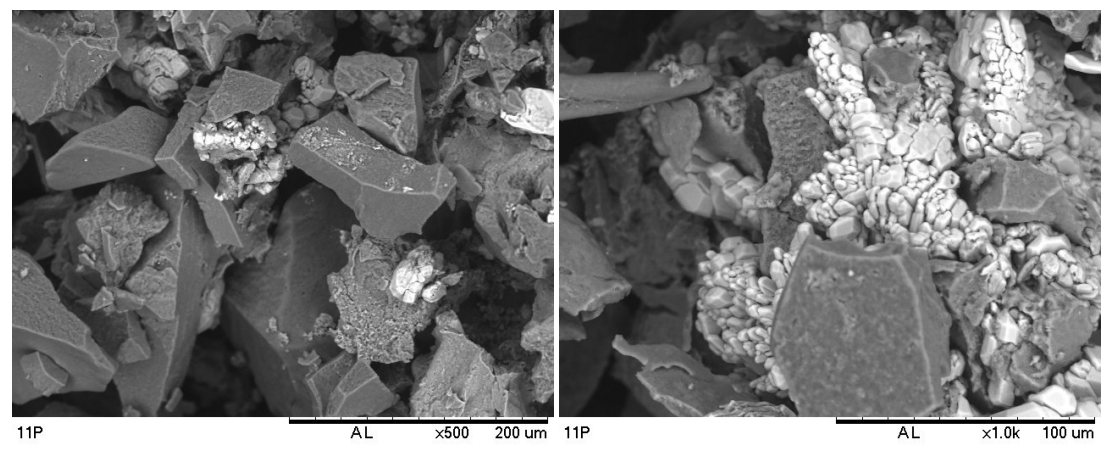

Figure 29. Scanning electron microscopies of the fragments resulting from the lyophilization of the SCBC2 suspension (obtained after 60 min of the type 2 sugarcane bagasse cellulose underwent acid hydrolysis), with increases of 500 and 1000 times. SCBC $=$ suspension after hydrolysis of $2.0 \mathrm{~g}$ sugarcane bagasse cellulose.

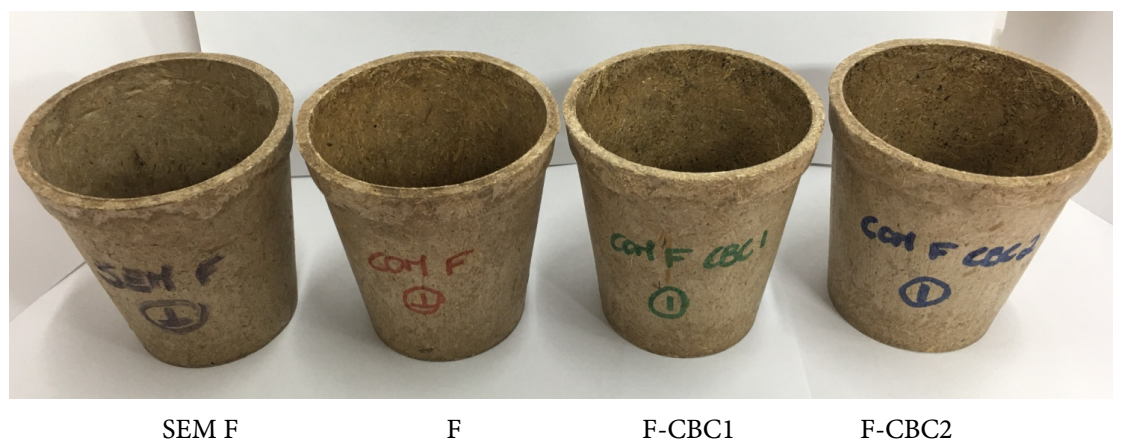

Figure 30. Biodegradable recipients' types selected for tests.

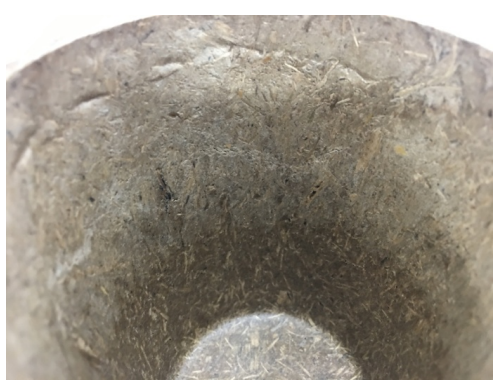

SEM-F

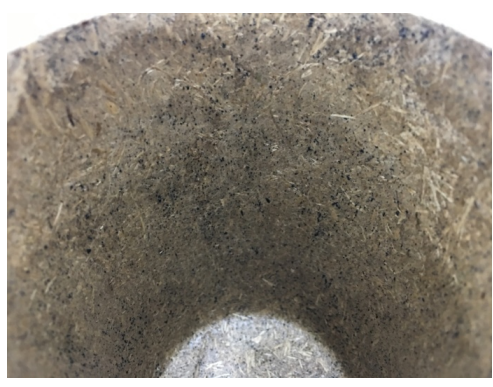

F-CBC1

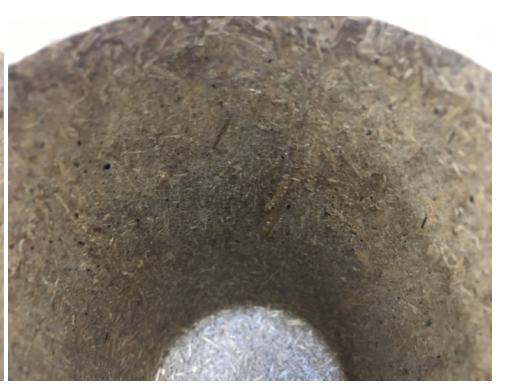

F

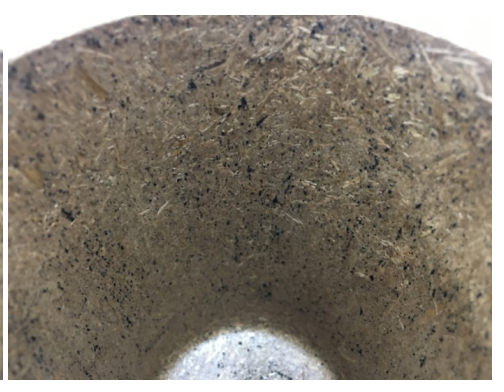

F-CBC2

Figure 31. Internal part detail of some of the uncoated biodegradable recipients and thin layer of the different film-forming suspensions (gels). RECIPIENTS: SEM F = without film; F = film without NPCs; F-CBC1 = film with CBC1 NPCs; F-CBC2 = film with CBC2 NPCs. 


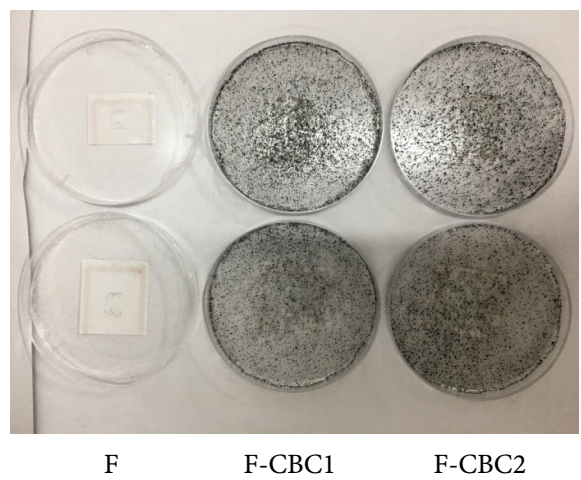

Figure 32. Details of some of the films without and with CBC1 and CBC2 NPCs formed in the Petri dishes, after oven drying of $3.0 \mathrm{~g}$ (bottom dishes) and $4.0 \mathrm{~g}$ (upper dishes) of each film-forming suspension (gel). $\mathrm{F}=$ film without NPCs; F-CBC1 = film with $\mathrm{CBC} 1$ NPCs; F-CBC2 = film with CBC2 NPCs.

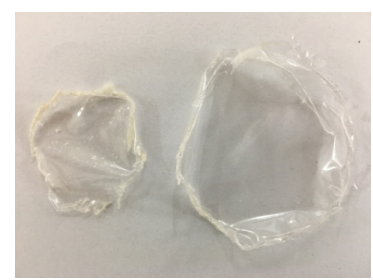

F

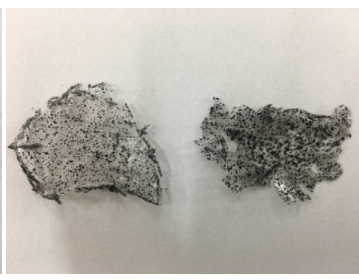

F-CBC1

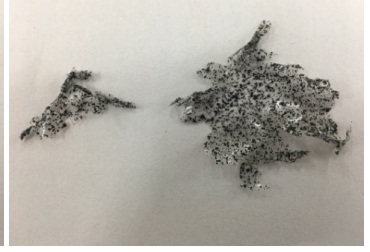

F-CBC2

Figure 33. Films produced from $3.0 \mathrm{~g}$ (left) and $4.0 \mathrm{~g}$ (right) of each film-forming suspension (gel) studied after detachment of their respective Petri dishes. $\mathrm{F}=$ film without NPCs; F-CBC1 = film with CBC1 NPCs; F-CBC2 = film with CBC2 NPCs.

g suspension. The visual appearance of the films without NPCs (F) did not differ for both employed quantities of film-forming suspensions, and they are smooth and transparent. However, the incorporation of the NPCs showed films (F-CBC1 and $\mathrm{F}-\mathrm{CBC} 2$ ) with a certain transparency, despite the numerous small purple spots on their surfaces, characteristic of the $\mathrm{CBC}$ particles of this project. From Figure 33 it can be seen that the detachment of the films without NPCs (F) was better and easier than those with NPCs (F-CBC1 and F-CBC2), a fact already expected due to the roughness of the films conferred by the cellulose particles (not solubilized), making difficult the complete removal of their films. Taking into account all 12 samples of each type of film formed (it means the 36 samples of this experiment), it can be said that, in general, the films obtained with $4.0 \mathrm{~g}$ of their respective suspensions were more and better easily detached from Petri dishes than those formed with $3.0 \mathrm{~g}$ of film-forming suspension. Table 10 shows the average thickness (in $\mathrm{mm}$ ) of each film formed from 3.0 and $4.0 \mathrm{~g}$ of their respective film-forming suspensions (gels), which were measured using a Digimess electronic micrometer, from 0.001 to $25 \mathrm{~mm}$ accuracy.

The incorporation of sugarcane bagasse NPCs into film-forming suspensions increased the thickness of the formed films, as expected (due to the presence of both nonsolubilized cellulose particles), especially when untreated sugarcane bagasse (CBC2) NPCs were added, as these become more concentrated and in 
greater quantity in the dried suspensions. Therefore, it can be said that the thinnest films were those produced by suspension without NPCs (F), while thicker films were formed by suspensions containing NPCs (F-CBC1 and F-CBC2), being those produced with untreated sugarcane bagasse NPCs (F-CBC2) the thickest ones. It is still noted in Table 9 that as higher the amount of suspension, obviously, higher the film thickness.

The recipients internally coated by a thin and dried layer of the three gel types, after also remaining purposely 48 hours in the fume hood of the Polymers Laboratory of the CQMA/IPEN (for the same reason mentioned above), at room temperature and relative humidity, could not have their films detached from their walls, and, consequently, it was not possible to measure their thicknesses. This impossibility most probably occurred due to the very small amount of film-forming suspensions brushed on the inner part of the recipients and perhaps also due to the adhesion of these very thin layers of the different gels to the porous walls of the recipients, thus making it difficult to form films and their consequent detachments. Despite the nonformation of "palpable" films, and in order to at least quantify the different film-forming suspensions (gels) that were brushed internally on each recipient, it was decided to weigh such recipients after drying - since they had already been weighed prior to the application of their coatings-using a digital analytical balance, and thus calculating the average amounts of the different gels in them. Table 10 shows the average amounts (in g) of the different film-forming suspensions (gels) brushed on the recipients. It is worth noting that the values shown in the referred table represent approximated average quantities since such recipients possibly absorbed moisture after being removed from the oven and remaining in the laboratory fume hood for 48 hours without controlled temperature and relative humidity.

Table 9. Average thickness of films produced from 3.0 and $4.0 \mathrm{~g}$ of each studied film-Forming suspension (Gel), after detachment of their respective petri dishes.

\begin{tabular}{ccc}
\hline & \multicolumn{2}{c}{ Thickness \pm Error (mm) } \\
& Quantity of film-forming suspension (gel) \\
\hline Recipients* & $3.0 \mathrm{~g}$ & $\mathbf{4 . 0} \mathrm{g}$ \\
\hline F & $0.067 \pm 0.007$ & $0.115 \pm 0.019$ \\
F-CBC1 & $0.198 \pm 0.008$ & $0.229 \pm 0.012$ \\
F-CBC2 & $0.230 \pm 0.009$ & $0.267 \pm 0.005$ \\
\hline
\end{tabular}

${ }^{\star} \mathrm{F}=$ film without NPCs; F-CBC1 = film with CBC1 NPCs; F-CBC2 = film with CBC2 NPCs.

Table 10. Average (and approximated) quantities of the different film-forming suspensions (Gels) brushed on the inner part of the recipients.

\begin{tabular}{cc}
\hline Film-forming suspensions (gels)* & Quantity \pm Error $(\mathrm{g})$ \\
\hline F & $0.308 \pm 0.045$ \\
F-CBC1 & $0.372 \pm 0.028$ \\
F-CBC2 & $0.421 \pm 0.037$ \\
\hline
\end{tabular}

${ }^{*} \mathrm{~F}=$ gel without NPCs; F-CBC1 = gel with CBC1 NPCs; F-CBC2 = gel with CBC2 NPCs. 
It can be seen from Table 10 that actually a very thin layer of each suspension (gel) was brushed on the inner part of the recipients, all of them corresponding to less than half a gram; there was no significant difference among them. As expected, the highest amounts were observed in the NPCs-coated recipients, especially when incorporating the untreated sugarcane bagasse cellulose (CBC2) particles. The difference of applied quantity in the recipients between that of gel without NPCs (F) and those of the gels with the sugarcane bagasse NPCs (F-CBC1 and F-CBC2) was approximately $0.1 \mathrm{~g}$.

In order to verify the influence on the physical and water barrier properties of the recipients after coated with sugarcane bagasse NPCs, the pots were submitted to the tests of: 1) water absorption; 2) development of crotalaria plantation in them, and 3) integrity of the recipients with and without coatings (gels). Moisture absorption by recipients with and without coatings (gels) was also studied over 14 days-reduced and limited time due to the deadline for submission this work.

\subsubsection{Water Absorption by Biodegradable Recipients with and without Sugarcane Bagasse NPCs}

The results of water absorption by biodegradable recipients with and without sugarcane bagasse NPCs are presented in Table 11 and expressed in water absorption content (\%).

The different coatings applied inside of the recipients significantly contributed to the reduction of water absorption. It can be said that, in general, the coatings reduced in almost half the water absorption by the recipients (when compared to the SEM F recipients), being those coated with film-forming suspensions containing NPCs (F-CBC1 and F-CBC2) the ones which less absorbed water, especially when using the $\mathrm{CBC}$ particles without residue treatment (CBC2).

\subsubsection{Moisture Absorption by Biodegradable Recipients with and without Sugarcane Bagasse NPCs}

Figure 34 presents the results of moisture absorption by the different recipients, along the days, without controlled temperature and relative humidity, expressed in moisture content (\%).

Table 11. Water absorption by recipients without film/gel and by those internally coated with different film-Forming suspensions (Gels).

\begin{tabular}{cc}
\hline Recipients $^{*}$ & Water absorption content $(\%) \pm$ Error \\
\hline SEM F & $11.2 \pm 1.4$ \\
F & $6.2 \pm 1.1$ \\
F-CBC1 & $5.7 \pm 0.3$ \\
F-CBC2 & $5.3 \pm 0.2$ \\
\hline
\end{tabular}

*SEM F = without film; F = film without NPCs; F-CBC1 = film with $\mathrm{CBC} 1 \mathrm{NPCs} ; \mathrm{F}-\mathrm{CBC} 2=$ film with CBC2 NPCs. 


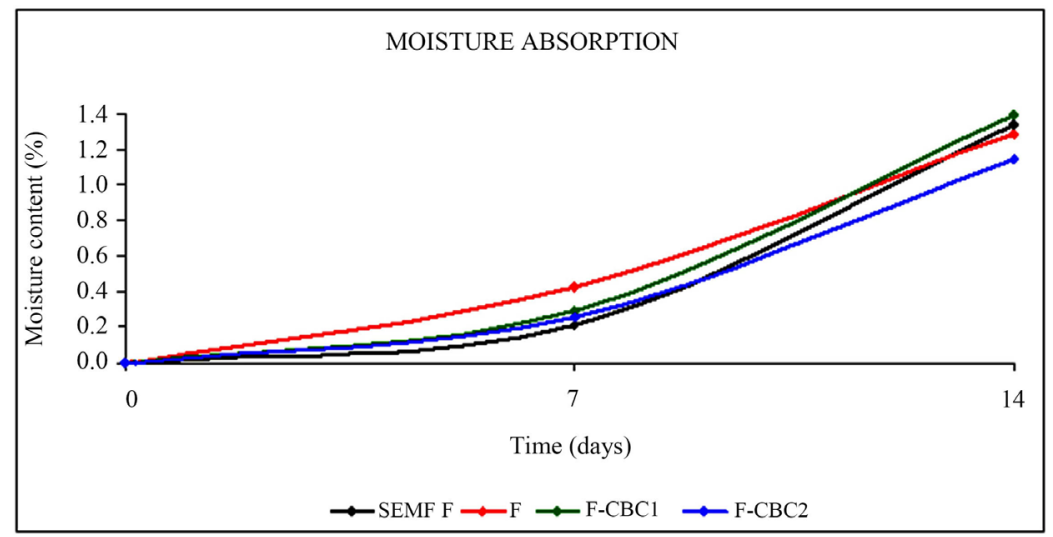

Figure 34. Trendlines of moisture absorption by recipients without film/gel and those internally coated with the different film-forming suspensions (gels), for 14 days, without controlled temperature and relative humidity. RECIPIENTS: SEM F = without film; F = film without NPCs; F-CBC1 = film with CBC1 NPCs; F-CBC2 = film with CBC2 NPCs.

The increase in moisture absorption by uncoated recipients (SEM F) as well as by all those internally coated through the different film-forming suspensions (F, $\mathrm{F}-\mathrm{CBC} 1$ and $\mathrm{F}-\mathrm{CBC} 2$ ) during the 14 days of the test, shown in Figure 34, certainly occurred due to the differences in temperature and relative humidity observed during the days of this experiment analysis. When recipients were weighed on $11 / 12 / 2018$, it means, on the seventh day of the test, the temperature and relative humidity in the fume hood of CQMA/IPEN Polymers Laboratory registered, respectively, $25^{\circ} \mathrm{C}$ and $76 \%$, while seven days later, on the fourteenth day of the test $(11 / 19 / 2018)$ the climatic conditions were different: $21^{\circ} \mathrm{C}$ of temperature and $88 \%$ of relative humidity. The difference in moisture absorption between the studied recipients was very small, both on the seventh day of analysis and on the fourteenth day, with no relation between them. Seven days after the beginning of this experiment, for example, the recipient without film/gel was the one that less absorbed moisture (SEM F $=0.2 \% \pm 0.1 \%$ ) and the recipient coated by film-forming suspension without NPCs the ones that most absorbed moisture $(\mathrm{F}=0.4 \% \pm 0.2 \%)$, corresponding to a difference between them of only $0.2 \%$; while fourteen days later, the recipient that less absorbed moisture was that one coated with gel of NPCs with untreated sugarcane bagasse residue $(\mathrm{F}-\mathrm{CBC} 2=$ $1.1 \% \pm 0.1 \%)$ and the one which absorbed more humidity was the recipient $\mathrm{F}-\mathrm{CBC} 1=1.4 \% \pm 0.1 \%$, corresponding to a difference between them of only $0.3 \%$. The moisture contents of the coated recipients with gels of both sugarcane bagasse NPCs (F-CBC1 and F-CBC2) on the seventh day of analysis were the same: $0.3 \% \pm 0.1 \%$. On the fourteenth day of the experiment, the moisture absorption by the recipients without film/gel (SEM F) and those coated with gel without NPCs (F) were also the same: $1.3 \% \pm 0.1 \%$. In short, starch films plasticized with glycerin are quite hydrophilic, and it makes difficult to achieve their precise moisture absorption data in air-conditioned rooms without a rigorous climatic control. Nevertheless, the incorporation of the nanocellulose particles into the films burushed on the recipients/pots diminished the moisture absorp- 
tion of these.

\subsubsection{Crotalaria Plantation in Biodegradable Recipients with and without Sugarcane Bagasse NPCs}

Crotalaria juncea is an annual spring-summer legume, growing very fast and vigorous, and its species produces the highest amount of biomass in the shortest time and, consequently, supplies nitrogen in greater quantity [64]. Crotalaria has its origins in India and Tropical Asia, and, interestingly, it helps to combat the mosquito that transmits dengue fever. Its beautiful yellow flowers attract the dragonflies, which need clean water to place their larvae. These larvae devour those of the Aedes aegypti mosquito and, after adults, the dragonflies also feed on the larvae of dengue main vector in Brazil [65].

Some of the crotalaria seeds of this study germinated in only three days of sowing, and on the fourth day of planting all recipients (without exception) already contained at least one of their sprouts (remembering that four seeds were planted in each vessel), as shown in Figure 35.

Figure 36 and Figure 37 show the plants' development (still without flowers) and the integrity of the uncoated recipients and those coated with and without the sugarcane bagasse NPCs, seven and fourteen days after the beginning of planting.

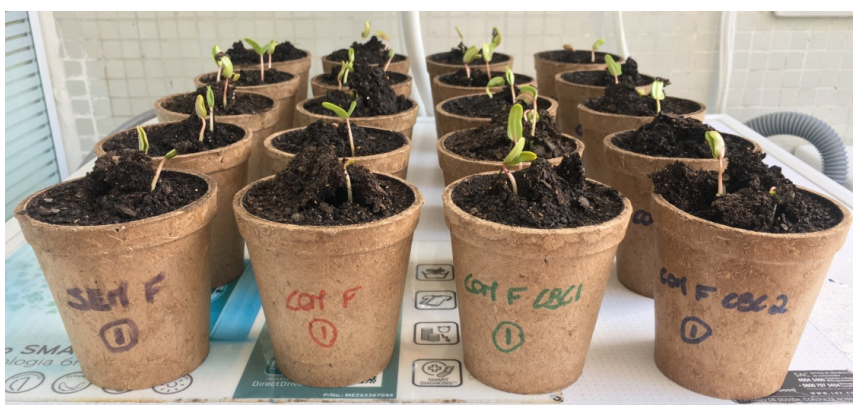

Figure 35. Crotalaria germination in all recipients of the experiment, after just four days of sowing. RECIPIENTS: SEM F = without film; $\mathrm{F}=$ film without NPCs; $\mathrm{F}-\mathrm{CBC} 1=$ film with $\mathrm{CBC} 1 \mathrm{NPCs} ; \mathrm{F}-\mathrm{CBC} 2=$ film with $\mathrm{CBC} 2 \mathrm{NPCs}$.

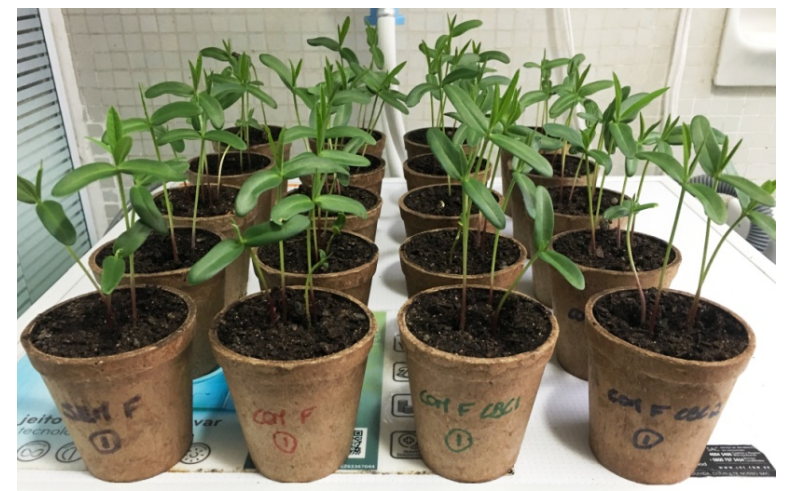

Figure 36. Crotalaria development and integrity of the different recipients in tests, after seven days of sowing. RECIPIENTS: SEM F = without film; $\mathrm{F}=$ film without NPCs; F-CBC1 = film with CBC1 NPCs; F-CBC2 = film with CBC2 NPCs. 


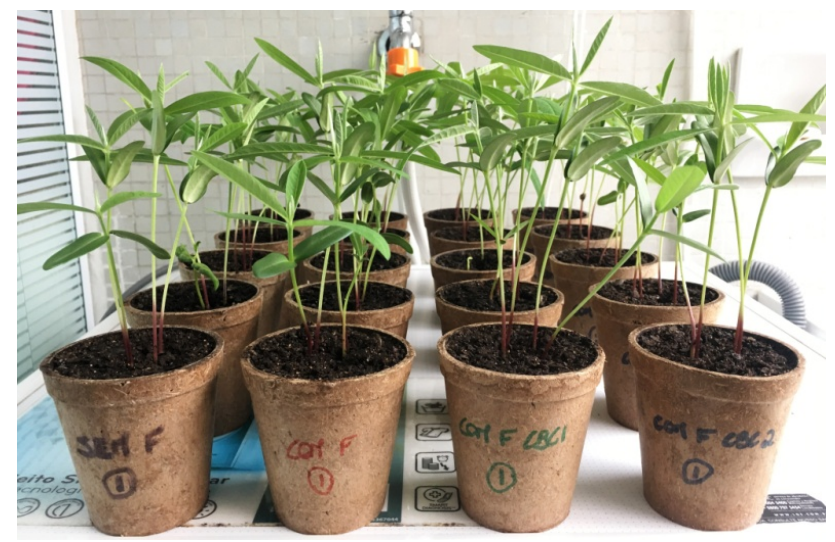

Figure 37. Crotalaria development and integrity of the different recipients in tests, after fourteen days of sowing. RECIPIENTS: SEM F = without film; $\mathrm{F}=$ film without NPCs; F-CBC1 = film with CBC1 NPCs; F-CBC2 = film with CBC2 NPCs.

More specific data and details on crotalaria seedlings and recipient physical integrity with and without sugarcane bagasse NPCs, during the fourteen days after sowing, are presented in the subsequent subitems of this report.

Plants' Development in Recipients with and without Sugarcane Bagasse NPCs

Figure 38 and Figure 39 show the crotalaria development, respectively, in terms of their heights and number of leaves, in the uncoated recipients and those coated with and without the sugarcane bagasse NPCs, during the first 14 days of planting.

During the 14 days of planting, the plants grown in the recipients coated with treated sugarcane bagasse NPCs (F-CBC1) were the ones that grew the mostcorresponding to the average heights of 9.1 and $13.9 \mathrm{~cm}$ on the 7th and 14th days of sowing, respectively-when compared to the other seedlings in the different recipients. On the other hand, the ones that grew the least during the same period were those sprouted in the recipients coated with untreated sugarcane bagasse NPCs (F-CBC2), corresponding to the average heights of 7.7 and $11.9 \mathrm{~cm}$ on the 7th and 14th days of sowing, respectively. The plants developed in the recipients without film (SEM F) and those in gel coated without NPCs (F) had, respectively, average heights of: 8.5 and $7.9 \mathrm{~cm}$ on the seventh day; and 12.3 and $12.4 \mathrm{~cm}$ on the fourteenth day. From the mentioned values, it can be said that between one day and another of analyses (on 7th and 14th days), the plants grew $3.8 \mathrm{~cm}$ in the uncoated recipients (SEM F); $4.5 \mathrm{~cm}$ in those coated without NPCs (F); $4.8 \mathrm{~cm}$ in the recipients with treated sugarcane bagasse NPCs (F-CBC1); and $4.2 \mathrm{~cm}$ in those with untreated sugarcane bagasse NPCs (F-CBC2). Therefore, although the height difference between the plants grown in the studied recipients be very small (practically about $1.0 \mathrm{~cm}$ ), it is concluded that crotalaria seedlings have grown more in the gel-coated recipients with $\mathrm{KOH}$-treated sugarcane bagasse NPCs (F-CBC1).

The average number of leaves of crotalaria was the same in the different reci- 
pients in tests, during the two days of analysis. Hence, Figure 39 shows only one curve in the graph, where in fact the curves are superimposed one another. The plants developed in both uncoated and coated with and without sugarcane bagasse NPCs presented 4 leaves on the seventh day and 6 leaves (two more) on the $14^{\text {th }}$ day after sowing; so there is no difference in the number of leaves between the recipients with and without coating of film-forming suspensions (with and without NPCs).

Integrity of the Recipients with and without Sugarcane Bagasse NPCs along the Plant Development

As a reminder, the pots were qualitatively evaluated by assigning them numerical values from 3 to 0 , where: 3 = good (integers, without any modification); $2=$ softened and/or cracked; $1=$ very softened and/or very cracked; and $0=$ broken/dismantled. Figures 40-42 show the integrity of the edges, walls and bottoms, respectively, of the different recipients during the first 14 days of planting.

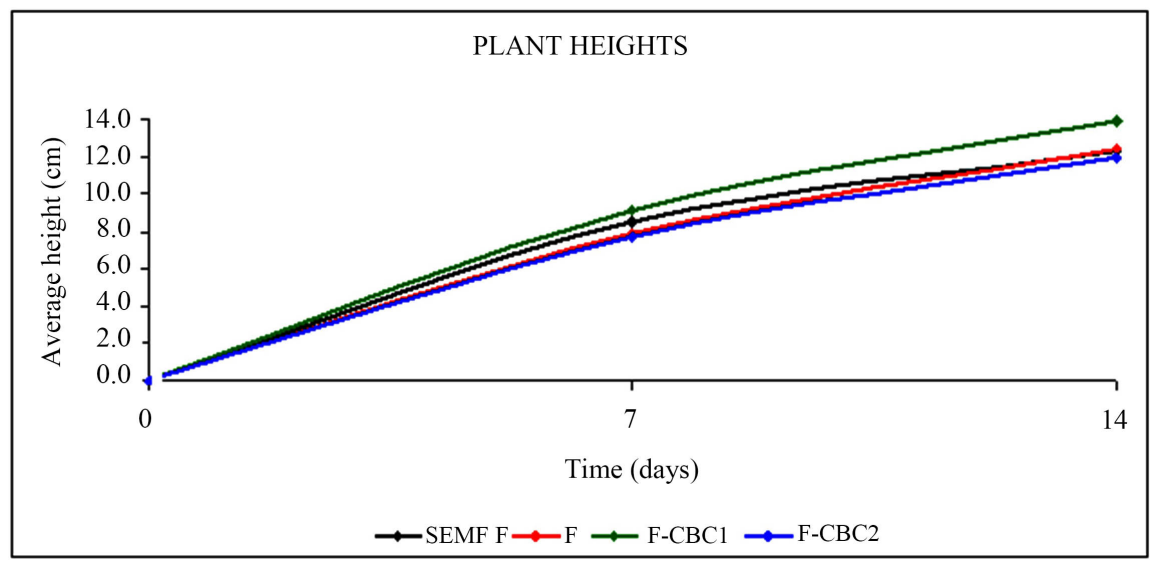

Figure 38. Trendlines of average height of the crotalaria developed in the different recipients in tests, after 14 days of sowing. RECIPIENTS: SEM $F=$ without film; $F=$ film without NPCs; F-CBC1 = film with CBC1 NPCs; F-CBC2 = film with CBC2 NPCs.

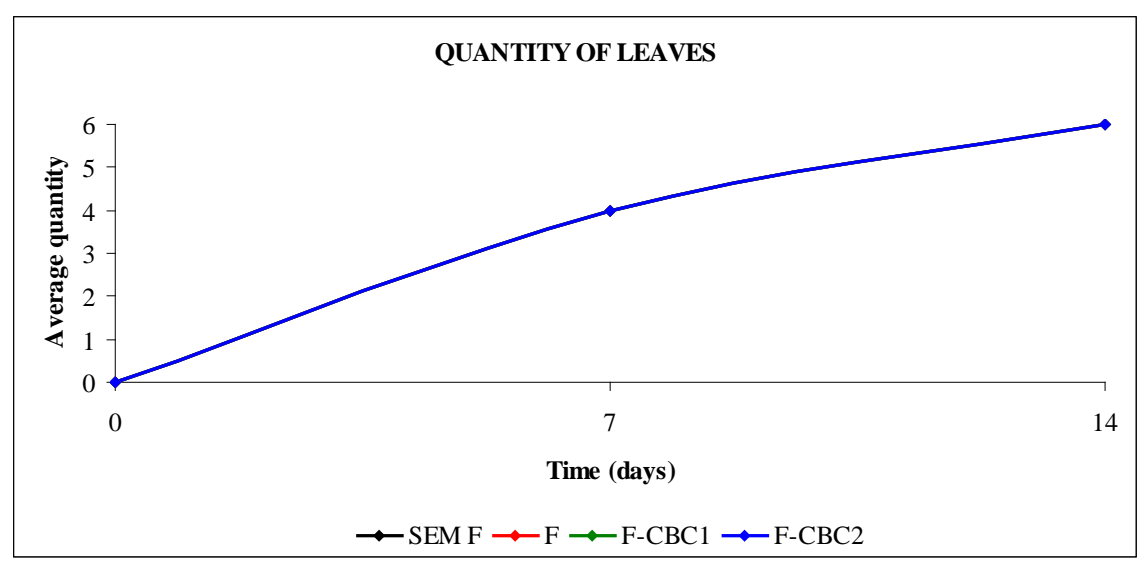

Figure 39. Trendline of average quantity of leaves of the crotalaria developed in the different recipientsin tests, after 14 days of sowing. RECIPIENTS: SEM F = without film; F = film without NPCs; F-CBC1 = film with CBC1 NPCs; F-CBC2 = film with $\mathrm{CBC} 2$ NPCs. 


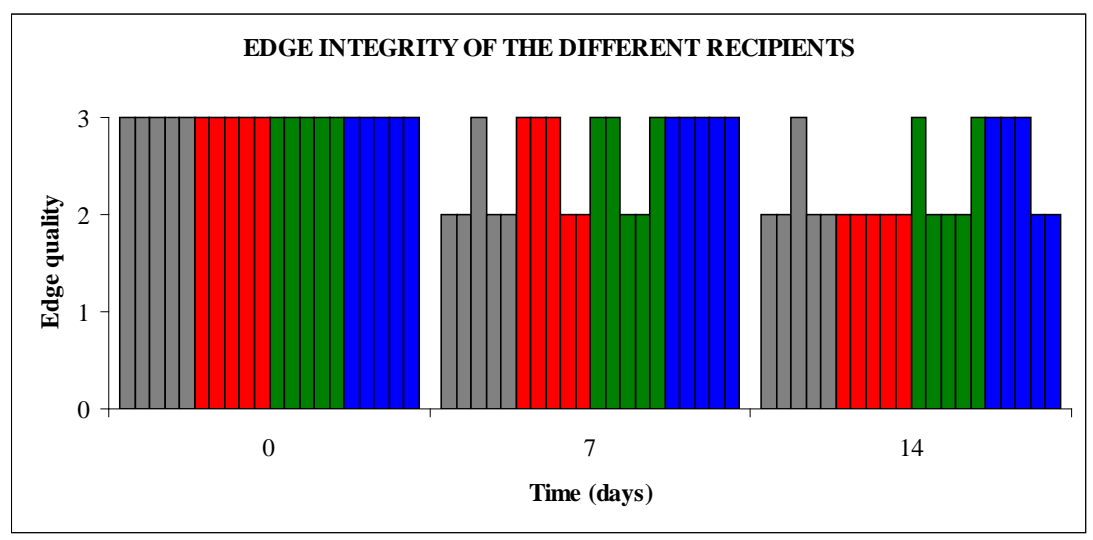

Figure 40. Edge integrity of the different recipients during the 14 days of crotalaria planting. Color bars: GRAY $=$ SEM F recipients (without film); RED $=$ F recipients (with film without NPCs); GREEN = F-CBC1 recipients (with CBC1 NPCs film); BLUE $=$ F-CBC2 recipients (with CBC2 NPCs film).

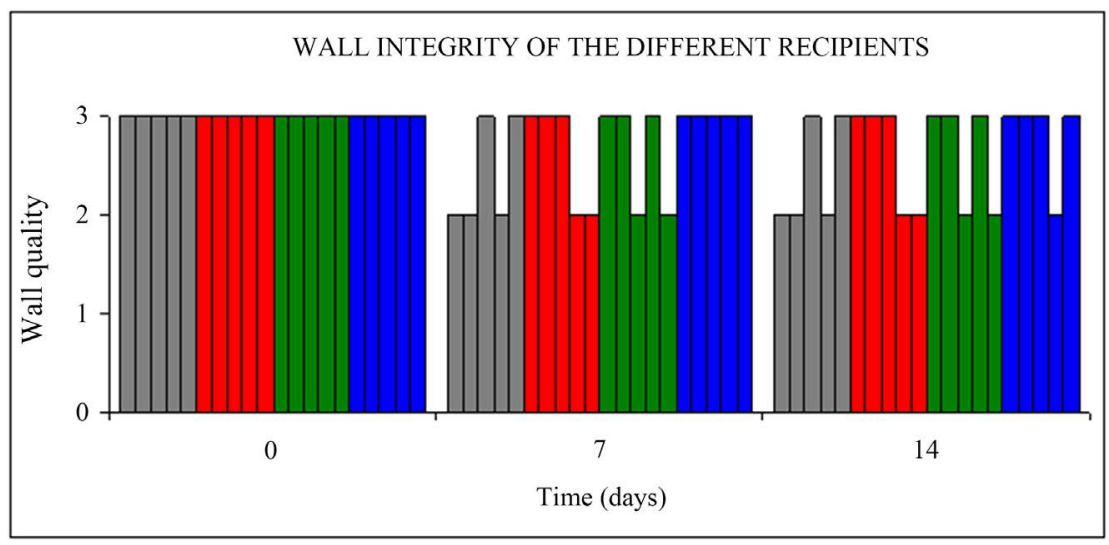

Figure 41. Wall integrity of the different recipients during the 14 days of crotalaria planting. Color bars: GRAY $=$ SEM F recipients (without film); RED $=$ F recipients (with film without NPCs); GREEN = F-CBC1 recipients (with CBC1 NPCs film); BLUE $=$ F-CBC2 recipients (with CBC2 NPCs film).

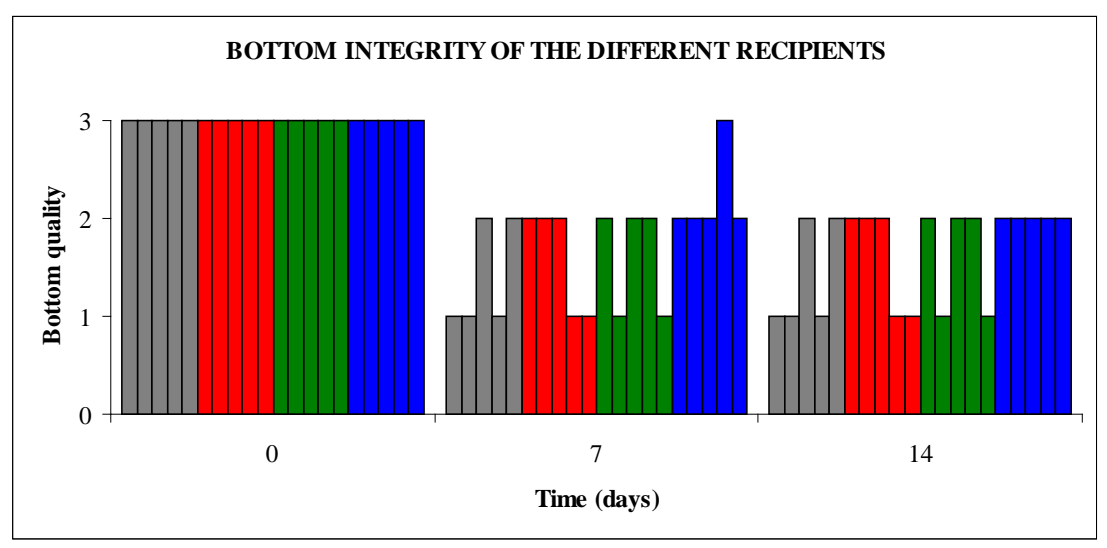

Figure 42. Bottom integrity of the different recipients during the 14 days of crotalaria planting. Color bars: GRAY $=$ SEM F recipients (without film); RED $=$ F recipients (with film without NPCs); GREEN = F-CBC1 recipients (with CBC1 NPCs film); BLUE $=$ F-CBC2 recipients (with CBC2 NPCs film). 


\section{Integrity of the Edges}

Figure 40 displays the profile of quality of the edges.

Seven days after sowing, with the exception of the recipients coated with untreated sugarcane bagasse NPCs (F-CBC2 = blue bars), at least two of five recipients of each type in tests had their edges softened to level 2. On the seventh day, the edges of the five recipients coated with untreated sugarcane bagasse NPCs $(\mathrm{F}-\mathrm{CBC} 2$ = blue bars) remained intact, with no modification, whereas practically all recipients without coating $(4$ of the 5 SEM $\mathrm{F}$ recipients = gray bars) had their edges softened to level 2. On the same day, three of the five recipients coated with no NPCs ( $\mathrm{F}=$ red bars) and the same amount of those coated with treated sugarcane bagasse NPCs $(\mathrm{F}-\mathrm{CBC} 1$ = green bars) did not show any changes in their edges. Fourteen days after sowing, all the five recipients coated without NPCs ( $\mathrm{F}=$ red bars) had their edges softened to level 2-equal level of deformation was verified in: 4 recipients without film (SEM F = gray bars); 3 of the recipients coated with treated sugarcane bagasse NPCs $(\mathrm{F}-\mathrm{CBC} 1=$ green bars); and 2 of those coated with untreated sugarcane bagasse NPCs $(\mathrm{F}-\mathrm{CBC} 2=$ blue bars). Thus, in general terms, it can be said that, up to the present time, it means, in 14 days after crotalaria planting, the recipients which presented their most preserved edges were those coated with $\mathrm{KOH}$-untreated sugarcane bagasse NPCs (F-CBC2 = blue bars), followed by those coated with treated sugarcane bagasse NPCs (F-CBC1 = green bars). In this same period, the recipients coated without NPCs ( $\mathrm{F}=$ red bars) were the most damaged on their edges.

\section{Integrity of the Walls}

In relation to the walls' integrity of the recipients in the crotalaria plantation (Figure 41), it is verified that, seven days after sowing, the quantity of recipients with softened walls at level 2 was higher for those without coating (three of the five SEM F = gray bars), followed by recipients coated without NPCs and with treated sugarcane bagasse NPCs (two of five: $\mathrm{F}=$ red bars and $\mathrm{F}-\mathrm{CBC} 1=$ green bars). On the same day, the recipients coated with $\mathrm{KOH}$-untreated sugarcane bagasse NPCs (F-CBC2 = blue bars) did not show changes in their bodies. Seven days later, it means, on the 14th day of planting, the walls' conditions of practically all the previously analyzed recipients remained the same, except for one of the five recipients coated with untreated sugarcane bagasse NPCs $(\mathrm{F}-\mathrm{CBC} 2=$ bars blue), which had its body slightly softened (at level 2). Thus, in general terms, it can be said that up to now, it means, in 14 days of crotalaria planting, the recipients which presented their most preserved walls were those coated with $\mathrm{KOH}$-untreated sugarcane bagasse NPCs (F-CBC2 = blue bars), followed by those coated with $\mathrm{KOH}$-treated sugarcane bagasse NPCs (F-CBC1 = green bars), and in the same amount of the latter, by those coated without NPCs ( F = red bars). In this same period, the bodies of the recipients without film (SEM F = gray bars) were the most damaged.

\section{Integrity of the Bottoms}

From Figure 42, it can be inferred that the bottoms were the recipient parts that most suffered changes in comparison to their other analyzed parts (edge 
and walls) in this experiment, in which practically all the recipients had their bottoms' quality fell to level 2 (soft), and even to level 1 (very soft), on the seventh day of the crotalaria plantation.

Seven days after sowing, only one of the five recipients coated with $\mathrm{KOH}$-untreated sugarcane bagasse NPCs $(\mathrm{F}-\mathrm{CBC} 2$ = blue bars) kept its bottom intact, without any modification; however, on the 14th day of planting, this same recipient had its bottom softened at level 2 (soft), and it was the only change observed between the two days of this test analysis by the way. On the 7th and 14th days of planting, the number of softened recipients at level 2 (soft) was: 2 of the uncoated recipients (SEM F = gray bars); 3 of those coated without NPCs $(F=$ red bars); and 3 of those coated with treated sugarcane bagasse NPCs (F-CBC1 $=$ green bars), and the rest of the five recipients of each studied group were qualified at level 1 (very soft). Thus, in general terms, it can be said that up to now-it means, in 14 days of crotalaria planting-the recipients which presented their most preserved bottoms were those coated with $\mathrm{KOH}$-untreated sugarcane bagasse NPCs $(\mathrm{F}-\mathrm{CBC} 2$ = blue bars), followed by those coated with $\mathrm{KOH}$-treated sugarcane bagasse NPCs (F-CBC1 = green bars) and, in equal quantity, the recipients coated without NPCs ( $\mathrm{F}=$ red bars). In this same period, the bottoms of the recipients without film (SEM F = gray bars) were the most damaged.

In summary, the starch coatings somehow improved the resistance of the edges, walls, and bottoms of the recipients (data shown in Figures 38-40, respectively), along with the plantation development for 14 days, however with somewhat better results for those containing NPCs.

\section{Conclusions}

The pulping and bleaching of sugarcane bagasse based on the alkaline process involved numerous chemical treatments to achieve celluloses with a reasonable whiteness. From a selfcritical vision of the results, they were classified as raw celluloses.

Successive vacuum filtrations and washings with distilled water may lead to reasonable decreases in cellulose yields.

$\mathrm{NaOH} / \mathrm{KOH}$ at concentrations above $4 \%(\mathrm{~m} / \mathrm{v})$, associated with temperatures of ca. $100^{\circ} \mathrm{C}$ and cooking times above $2 \mathrm{~h}$ under mechanical or magnetic stirring, appeared to play the most important role in the bagasse delignification.

The celluloses extracted from the sugarcane bagasse (SCB24-Na-I and SCB24Na-II with yields ca. $37 \%$ and ca. $41 \%$, respectively) presented characteristics very close to each other, based on the results from their characterizations. Both products were considered promising in terms of coloration (acceptable whiteness) and future technological applications.

The acid hydrolysis conditions applied to the celluloses extracted from the sugarcane bagasse, with and without $\mathrm{KOH}$ treatment of their filtration residues during the extraction processes, allowed us to obtain their NPCs, represented in the TEM images by a mixture of fibrils and spheres, thus evidencing the formation of nanocellulose particles in a needle form. 
The sugarcane bagasse NPCs incorporation, through thin layers of film-forming suspensions brushed inside of the biodegradable recipients, made the pots physically more resistant along with crotalaria growth-after their edges, walls and bottoms having been analyzed-not interfering in the good plant development (seedlings' heights and quantity of leaves). In addition, the sugarcane bagasse recipients coated with NPCs absorbed less water than those that were coated without nanoparticles, especially when compared to those without coating.

Although the sugarcane bagasse NPCs improved the physical and water barrier properties of the recipients, the time and water consumption during the washes and centrifugations of the suspensions (obtained after hydrolysis) until to achieve neutrality were exorbitant-mainly considering the very low amount of CBC used (7.0 g of each type)) and its very low yield.

The technique used for NPCs' production in this project for their later incorporation in the biodegradable recipients almost became impracticable in laboratory and probably, the same would occur at industrial levels, too, especially for a sustainable company. Thus, it still demands deeper studies in terms of the process time (very long) for obtaining the nanoparticles besides trying to increase their yields (low in this case) and lower the high cost of the whole process in general.

\section{Acknowledgements}

The researchers thank the laboratories of Environment and Chemistry Center (CQMA) of IPEN/USP for providing the centrifuge and freeze drier; the Applications and Lasers Center (CLA) and the Technology of Materials and Science Center (CCTM) of the IPEN/USP for the scanning and transmission electron microscopy images, respectively; the FINEP/FUNDEP for the awarded grants; the FAPESP (process \# 2017/09469-2) for financial support; and SIBRATECNANO for the opportunity of this project.

\section{Conflicts of Interest}

The authors declare no conflicts of interest regarding the publication of this paper.

\section{References}

[1] Maranhão, R. and Kating, V. (2011) Diário de Navegação-Pero Lopes e a Expedição de Martim Afonso de Sousa (1530-1532). Editora Terceiro Nome, São Paulo. https://www.amazon.com.br/Di\%C3\%A1rio-Navega\%C3\%A7\%C3\%A3o-Expedi\% C3\%A7\%C3\%A3o-Martim-1530-1532/dp/8578160746

[2] Sales, A. and Lima, S.A. (2010) Use of Brazilian Sugarcane Bagasse Ash in Concrete as Sand Replacement. Waste Menagement, 30, 1114-1122. https://doi.org/10.1016/j.wasman.2010.01.026

[3] Costa, P.R.O. and Duarte, F.S. (2010) A Utilização da Biomassa da Cana-de-Açúcar como Fonte de Energia Renovável Aplicada no Setor Sucroalcooleiro. RAF-Revista de Administração da Fatea, 3, 2-107. 
http://unifatea.com.br/seer3/index.php/RAF/article/view/651/690

[4] Fernandes, A.S. and Miguel, E.R. (2011) A Importância da Utilização do Bagaço de Cana-de-Açúcar na Geração de Energia em Termelétrica. III Encontro Científico e Simpósio de Educação Unisalesiano, Lins, 21 de Outubro de 2011, 1-11. http://www.unisalesiano.edu.br/simposio2011/publicado/artigo0034.pdf

[5] Teixeira, F.A. (2007) Bagaço de Cana-de-Açúcar na Alimentação de Bovinos (Sugarcane Pulp in the Feeding of Bovine). REDVET. Revista Electrónica de Veterinaria, 8, 1695-7504. http://www.veterinaria.org/revistas/redvet/n060607/060708.pdf

[6] Soares, M.S., Pires, A.J.V., Silva, L.G., Guimarães, J.O., Machado, T.C. and Frazão, O.S. (2015) Utilização do Bagaço de Cana-de-Açúcar na Alimentação de Ruminantes. Revista Eletrônica Nutritime, 12, 3837-3855. https://www.nutritime.com.br/arquivos_internos/artigos/ARTIGO287.pdf

[7] Aguiar, M.M., Ferreira, L.F.R. and Monteiro, R.T.R. (2010) Use of Vinasse and Sugarcane Bagasse for the Production of Enzymes by Lignocellulolytic Fungi. Brazilian Archives of Biolology and Technolology, 53, 1245-1254.

https://doi.org/10.1590/S1516-89132010000500030

[8] Magalhães, M.A., Matos, A.T., Denículi, W. and Tinoco, I.F.F. (2006) Composting of Sugarcane Trash Used as Filtering Material for Swine Wastewater. Revista Brasileira de Engenharia Agrícola e Ambiental, 10, 466-471. https://doi.org/10.1590/S1415-43662006000200030

[9] Barbieri, R.H.T. and Barcelos, I.S. (2009) Produção de Fertilizante Orgânico a Partir do Bagaço de Cana-de-Açúcar: Uma Alternativa para O Gerenciamento do Resíduo Oriundo de Indústrias Sucroalcooleiras. VIII Congresso Brasileiro de Engenharia Química em Iniciação Científica, Uberlândia, 27 a 30 de julho de 2009, 1-6.

http://docplayer.com.br/30020079-Bolsista-de-iniciacao-cientifica-bitec-iel-faacz-di scente-do-curso-de-engenharia-quimica.html

[10] Trani, P.E. and Berton, R.S. (2012) Preparo do Composto a Partir do Bagaço de Cana com Esterco Animal. Instituto Agronômico de Campinas (IAC), 1-5.

http://www.iac.sp.gov.br/imagem_informacoestecnologicas/76.pdf

[11] Bio \& Green Embalagens Biodegradáveis. https://portfoliolovers.com/2017/posts/biogreen-e-os-vasos-biodegradaveis/

[12] Pedeschi, R. (2009) Aproveitamento do Bagaço de Cana da Indústria Sucroaalcoleira na Produção de Painéis Aglomerados. Universidade Federal de Lavras, Lavras, Brazil, 49 p. http://repositorio.ufla.br/jspui/handle/1/2931

[13] Omotoso, M.A. and Owolabi, A.W. (2015) Pulp and Paper Evaluation of Solid Wastes from Agricultural Produce. International Journal of Chemistry, 7, 113-121. https://doi.org/10.5539/ijc.v7n2p113

[14] Lawal, S.A. and Ugheoke, B.I. (2010) Investigation of Alpha-Cellulose Content of Agro-Waste Products as Alternatives for Paper Production. AU Journal of Technology, 13, 258-260. https://www.researchgate.net/publication/267246438_

[15] Israel, A.U., Obot, I.B., Umoren, S.A., Mkpenie, V. and Asuquo, J.E. (2008) Production of Cellulosic Polymers from Agricultural Wastes. E-Journal of Chemistry, 5, 81-85. https://doi.org/10.1155/2008/436356

[16] Kumar, A., Negi, Y.S., Choudhary, V. and Bhardwaj, N.K. (2014) Characterization of Cellulose Nanocrystals Produced by Acid-Hydrolysis from Sugarcane Bagasse as Agro-Waste. Journal of Materials Physics and Chemistry, 2, 1-8.

[17] Dungani, R., Karina, M., Sulaeman, S.A., Hermawan, D. and Hadiyane, A. (2016) Agricultural Waste Fibers towards Sustainability and Advanced Utilization: A Review. Asian Journal of Plant Science, 15, 42-55. 
https://doi.org/10.3923/ajps.2016.42.55

[18] Xu, C., Arancon, R.A., Labidi, J. and Luque, R. (2014) Lignin Depolymerisation Strategies: Towards Valuable Chemicals and Fuels. Chemical Society Review, 43, 7485-7500. https://doi.org/10.1039/C4CS00235K

[19] Rocha, G.J.M. and Mulinari, D.R. (2011) Modificação das Fibras de Celulose Provenientes do Bagaço de Cana-de-Açúcar com Hidróxido de Alumínio. Cadernos Unifoa MeMat, 6, 1-8.

[20] Rezende, C.A., Lima, M.A., Maziero, P., Azevedo, E.R., Garcia, W. and Polikarpov, I. (2011) Chemical and Morphological Characterization of Sugarcane Bagasse Submitted to a Delignification Process for Enhanced Enzymatic Digestibility. Biotechnology for Biofuels, 4, 1-18. https://doi.org/10.1186/1754-6834-4-54

[21] Mulinari, D.R., Silva, G.L.J.P., Rodrigues, L.A. and Silva, M.L.C.P. (2007) Adsorção de Íons Fosfato nos Compósitos Celulose $/ \mathrm{ZrO}_{2} \cdot \mathrm{nH}_{2} \mathrm{O}$ Preparados pelos Métodos da Precipitação Convencional e em Solução Homogênea. Cerâmica, 53, 345-353. https://doi.org/10.1590/S0366-69132007000400003

[22] Mandal, A. and Chakrabarty, D. (2011) Isolation of Nanocellulose from Waste Sugarcane Bagasse (SCB) and Its Characterization. Carbohydrate Polymers, 86, 1291-1299. https://doi.org/10.1016/j.carbpol.2011.06.030

[23] Lee, J.M., Shi, J., Venditti, R.A. and Jameel, H. (2009) Autohydrolysis Pretreatment of Coastal Bermuda Grass for Increased Enzyme Hydrolysis. Bioresource Technolology, 100, 6434-6441. https://doi.org/10.1016/j.biortech.2008.12.068

[24] Cardona, C.A., Quintero, J.A. and Paz, I.C. (2010) Production of Bioethanol from Sugarcane Bagasse: Status and Perspectives. Bioresource Technology, 101, 4754-4766. https://doi.org/10.1016/j.biortech.2009.10.097

[25] Avira, P., Tomas-Pejeo, E., Ballesteros, M. and Negro, M.J. (2010) Pretreatment Technologies for an Efficient Bioethanol Production Process Based on Enzymatic Hydrolysis: A Review. Bioresource Technology, 101, 4851-4861.

https://doi.org/10.1016/j.biortech.2009.11.093

[26] Haafiz, M.K., Hassan, A., Zakaria, Z. and Inuwa, I.M. (2014) Isolation and Characterization of Cellulose Nanowhiskers from Oil Palm Biomass Microcrystalline Cellulose. Carbohydrate Polymers, 103, 119-125. https://doi.org/10.1016/j.carbpol.2013.11.055

[27] Pereira, A.L.S. (2010) Extração de Nanocelulose de Fibras Vegetais. Monografia. Departamento de Engenharia Química, Universidade Federal do Ceará, Fortaleza. (In Portuguese) http://www.eq.ufc.br/TFC/TFC_2010_Pereira.pdf

[28] Ioelovich, M. (2012) Optimal Conditions for Isolation of Nanocrystalline Cellulose Particles. Journal of Nanoscience and Nanotechnology, 2, 9-13. https://doi.org/10.5923/j.nn.20120202.03

[29] Barros, L.P.R.C. (2017) Obtenção de Nanocelulose por Hidrólise Ácida e Enzimática de Fibras de Algodão de Resíduo de Tecido Tingido com Corante Índigo. Tese de doutorado apresentada ao Programa de Pós-Graduação em Engenharia Mecânica do Centro de Tecnologia da Universidade Federal do Rio Grande do Norte, Natal. (In Portuguese)

https://repositorio.ufrn.br/jspui/bitstream/123456789/24141/1/LucianiPaolaRochaC ruz_TESE.pdf

[30] Rocha, G.J.M.R., Nascimento, V.M., Silva, F.M.N., Corso, D.L.S. and Gonçalves, A.R. (2014) Contributing to the Environmental Sustainability of the Second Generation Ethanol Production: Delignification of Sugarcane Bagasse with Sodium Hydroxide Recycling. Industrial Crops and Products, 59, 63-68. 
https://doi.org/10.1016/j.indcrop.2014.05.002

[31] Silvério, H.A., Neto, W.P.F., Dantas, N.O. and Pasquini, D. (2013) Extraction and Characterization of Cellulose Nanocrystals from Corncob for Application as Reinforcing Agent in Nanocomposites. Industrial Crops and Products, 44, 427-436. https://doi.org/10.1016/j.indcrop.2012.10.014

[32] Segal, L., Creely, J.J., Martin, A.E. and Conrad, C.M. (1959) An Empirical Method for Estimating the Degree of Crystallinity of Native Cellulose Using the X-Ray Diffractometer. Textile Research Journal, 29, 786-794. https://doi.org/10.1177/004051755902901003

[33] Pandey, A., Soccol, R.C., Nigam, P. and Soccol, V.T. (2000) Biotechnological Potential of Agro-Industrial Residues. I: Sugarcane Bagasse. Bioresource Technology, 74, 69-80. https://doi.org/10.1016/S0960-8524(99)00142-X

[34] Martín, C., Klinke, H.B. and Thomsen, A.B. (2007) Wet Oxidation as A Pretreatment Method for Enhancing the Enzymatic Convertibility of Sugarcane Bagasse. Enzyme and Microbial Technology, 40. 426-432. https://doi.org/10.1016/j.enzmictec.2006.07.015

[35] Sun, J.X., Sun, X.F., Zhao, H. and Sun, R.C. (2004) Isolation and Characterization of Cellulose from Sugarcane Bagasse. Polymer Degradation and Stability, 84, 331-339. https://doi.org/10.1016/j.polymdegradstab.2004.02.008

[36] Neves, P.V. (2014) Caracterização do Extrato Etanólico do Bagaço de Cana-de-Açúcar e Determinação da Sua Influência sobre O Processo de Produção de Etanol Celulósico. Master's Dissertation, the Federal University of Paraná, Brazil. (In Portuguese) http://hdl.handle.net/1884/37984

[37] Canilha, L., Carvalho, W., Rocha, G.J.M., Almeida e Silva, J.B. and Giulietti, M. (2007) Caracterização do Bagaço de Cana-de-Açúcar in Natura, Extraído com Etanol ou Ciclo-Hexano/Etanol. Natal. http://www.abq.org.br/cbq/2007/trabalhos/11/11-570-713.htm

[38] Hoareau, W., Oliveira, F.B., Grelier, S., Siegmund, B., Frollini, E. and Castellan, A. (2006) Fiberboards Based on Sugarcane Bagasse Lignin and Fibers. Macromolecular Materials and Engineering, 291, 829-839. https://doi.org/10.1002/mame.200600004

[39] Rowell, R.M., Sanadi, A.R., Caulfiel, D.F. and Jacobson, R.E. (1997) Utilization of Natural Fibers in Plastic Composites: Problems and Opportunities. Universidade de São Paulo Press, São Paulo, Brazil, 23-52. https://www.fpl.fs.fed.us/documnts/pdf1997/rowel97d.pdf

[40] Ali, M., Byrd, M. and Jameel, H. (2002) Chemimechanical Pulping of Cotton Stalks. 2002 TAPPI Pulping Conference, 1-18. http://ww.paperonweb.com/Articles/cottonchemimcechanical.pdf

[41] Shaikh, H.M., Pandare, K.V., Nair, G. and Varma, A.J. (2009) Utilization of Sugarcane Bagasse Cellulose for Producing Cellulose Acetates: Novel Use of Residual Hemicellulose as Plasticizer. Carbohydrate Polymers, 76, 23-29. https://doi.org/10.1016/j.carbpol.2008.09.014

[42] Hubbell, A. and Ragauskas, A.J. (2010) Effect of Acid-Chlorite Delignification on Cellulose Degree of Polymerization. Bioresource Technology, 101, 7410-7415. https://doi.org/10.1016/j.biortech.2010.04.029

[43] Fahmy, Y., Fahmy, T.Y.A., Mobarak, F., El-Sakhawy, M. and Fadl, M.H. (2017) Agricultural Residues (Wastes) for Manufacture of Paper, Board, and Miscellaneous Products: Background Overview and Future Prospects. International Journal of Chem Tech Research, 10, 424-448. https://ssrn.com/abstract=3026418 
[44] Karp, S.G., Woiciechowski, A.L., Soccol, V.T. and Soccol, C.R. (2013) Pretreatment Strategies for Delignification of Sugarcane Bagasse: A Review. Brazilian Archives of Biology and Technology, 56, 679-689. https://doi.org/10.1590/S1516-89132013000400019

[45] Paula, L.E.R., Trugilho, P.F., Napoli, A. and Bianchi, M.L. (2011) Characterization of Residues from Plant Biomass for Use in Energy Generation. Cerne, 17, 237-246. https://doi.org/10.1590/S0104-77602011000200012

[46] Ferreira, B.C.S., Teodoro, F.S., Mageste, A.B., Gil, L.F., Freitas, R.P. and Gurgel, L.V.A. (2015) Application of a New Carboxylate-Functionalized Sugarcane Bagasse for Adsorptive Removal of Crystal Violet from Aqueous Solution: Kinetic, Equilibrium and Thermodynamic Studies. Industrial Crops and Products, 65, 521-534. https://doi.org/10.1016/j.indcrop.2014.10.020

[47] Barsbay, M., Kodama, Y. and Güven, O. (2014) Functionalization of Cellulose with Epoxy Groups via $\gamma$-Initiated RAFT-Mediated Grafting of Glycidyl Methacrylate. Cellulose, 21, 4067-4079. https://doi.org/10.1007/s10570-014-0416-y

[48] Ferreira, F.J.L. (2018) Funcionalização da Celulose com Aminosilano e Aplicação na Adsorção de Corante Aniônico. Master's Dissertation, the Federal University Piauí-UFPI, Brazil. http://repositorio.ufpi.br/xmlui/handle/123456789/1331

[49] de Assumpção, S.M.N., Pontes, L.A.M., de Carvalho, L.S., Campos, L.M.A., de Andrade, J.C.F. and Silva, E.G. (2016) Pré-Tratamento Combinado $\mathrm{H}_{2} \mathrm{SO}_{4} / \mathrm{H}_{2} \mathrm{O}_{2} / \mathrm{NaOH}$ para Obtenção das Frações Lignocelulósicas do Bagaço da Cana-de-Açúcar. Revista Virtual de Química, 8, 803-822.

[50] Sun, J.X., Sun, X.F., Zhao, H. and Sun, R.C. (2004) Isolation and Characterization of Cellulose from Sugarcane Bagasse. Polymer Degradation and Stability, 84, 331-339. https://doi.org/10.1016/j.polymdegradstab.2004.02.008

[51] Szcześniak, L., Rachocki, A. and Tritt-Goc, J. (2008) Glass Transition Temperature and Thermal Decomposition of Cellulose Powder. Cellulose, 15, 445-451. https://doi.org/10.1007/s10570-007-9192-2

[52] Yang, H., Yan, R., Chen, H., Lee, D.H. and Zheng, C. (2007) Characteristics of Hemicellulose, Cellulose and Lignin Pyrolysis. Fuel, 86, 1781-1788.

https://doi.org/10.1016/j.fuel.2006.12.013

[53] Santos, M.L., Lima, O.J., Nassar, E.J., Ciuffi, K.J. and Calefi, P.S. (2011) Estudo das Condições de Estocagem do Bagaço de Cana-de-Açúcar por Análise Térmica. Química Nova, 34, 507-511. https://doi.org/10.1590/S0100-40422011000300024

[54] Vasile, C., Popescu, C.-M., Popescu, M.-C., Brebu, M. and Willfor, S. (2011) Thermal Behaviour/Treatment of Some Vegetable Residues. IV. Thermal Decomposition of Eucalyptus Wood-Cellulose. Cellulose Chemical Technology, 45, 29-42. http://www.cellulosechemtechnol.ro/pdf/CCT1-2(2011)/p.29-42.pdf

[55] Mulinari, D.R., Voorwald, H.J.C., CIoffi, M.O. and Silva, M.L.C.P. (2009) Preparation and Properties of HDPE/Sugarcane Bagasse Cellulose Composites Obtained for Thermokinetic Mixer. Carbohydrate Polymers, 75, 317-321. https://doi.org/10.1016/j.carbpol.2008.07.028

[56] Li, Q. and Renneckar, S. (2011) Supramolecular Structure Characterization of Molecularly Thin Cellulose I Nanoparticles. Biomacromolecules, 12, 650-659. https://doi.org/10.1021/bm101315y

[57] Phinichka, N. and Kaenthong, S. (2018) Regenerated Cellulose from High Alpha Cellulose Pulp of Steam-Exploded Sugarcane Bagasse. Journal of Materials Research and Technology, 7, 55-65. https://doi.org/10.1016/j.jmrt.2017.04.003 
[58] Lengowski, E.C., Muniz, G.I.B., Nisgoski, S. and Magalhães, E.W.L. (2013) Avaliação de Métodos de Obtenção de Celulose com Diferentes Graus de Cristalinidade. Scientia Forestalis Journal, 41, 185-194.

https://ainfo.cnptia.embrapa.br/digital/bitstream/item/87065/1/Wash-avaliacao-demetodos-de-obtencao-de-celulose-com-diferentes-graus-de-cristalinidade.pdf

[59] Oliveira, R.S., Borges, M.F., Vieira, A.T., Alves, M., Ribeiro, E.A.M., Henrique, F.A.B., Portela, F.M., Pereira, N.R., Assunção, R.M.N. and Ruggiero, R. (2018) Adsorção de Contaminantes do Biodiesel por Fibras de Bagaço Modificadas na Superfície. Química Nova, 41, 121-128.

https://doi.org/10.21577/0100-4042.20170164

[60] Sutherland, J.W. (1998) Reviews: Novel and Established Applications of Microbial Polysaccharides. Trends in Biotechnology, 16, 41-46.

https://doi.org/10.1016/S0167-7799(97)01139-6

[61] Luz, M., Gonçalves, A.R. and Del'Arco, A.P. (2006) Microestrutura e Propriedades Mecânicas de Compósitos de Polipropileno Reforçado com Celulose de Bagaço e Palha de Cana. Revista Matéria, 11, 101-110. https://doi.org/10.1590/S1517-70762006000200004

[62] Cassales, A.R., Morais, J.P.S., Rosa, M.F., Alexandre, L.C., Norões, A.K.M. and Mota, M.C.G. (2011) Caracterização Morfológica por MEV de Fibras de Línter de Algodão. $20118^{\circ}$ Congresso Brasileiro de Algodão \& Cotton Expo, São Paulo, 1872-1876. http://www.alice.cnptia.embrapa.br/alice/handle/doc/908964

[63] Almeida, J.S., Nascimento, D.M, Dias, A.F., Figueirêdo, M.C.B., Morais, J.P.S. and Rosa, M.F. (2014) Desenvolvimento Tecnológico de Produtos e Processos para o Aproveitamento da Fibra do Coco. $54^{\circ}$ Congresso Brasileiro de Química (CBQ), Natal, 03 a 07 Novembro 2014. http://www.abq.org.br/cbq/2014/trabalhos/8/6127-18092.html

[64] Piraí Sementes (2018). http://www.semagro.ms.gov.br/saiba-qual-crotalaria-escolher-para-rotacao-de-cult uras-e-adubacao-verde/

[65] Plantei (2018). https://blog.plantei.com.br/uso-da-planta-crotalaria-no-combate-a-dengue/ 